INSTITUTO DE PESQUISAS ENERGÉTICAS E NUCLEARES AUTARQUIA ASSOCIADA À UNIVERSIDADE DE SÃO PAULO

\title{
Estudo de um Sistema de Coincidências $4 \pi \beta-\gamma$ para a Medida Absoluta de Atividade de Radionuclídeos Empregando Cintiladores Plásticos
}

HÉLIO PIUVEZAM FILHO

Dissertação apresentada como parte dos requisitos para obtenção do grau de Mestre em Ciências na Área de Tecnologia Nuclear - Aplicações Orientador: Dr. Mauro da Silva Dias 
À minha querida esposa Rosana

Aos meus filhos Daniel, Raquel e Esther 


\section{AGRADECIMENTOS}

Ao Dr. Mauro da Silva Dias, orientador deste trabalho, pelas sugestões, apoio, paciência e dedicação durante o desenvolvimento desta dissertação.

À Dra. Marina Fallone Koskinas, pelas sugestões e discussões, apoio e incentivo durante todo o desenvolvimento deste trabalho.

Aos colegas, Dr. Mauro N. Takeda, Eliezer Antônio da Silva pelas preciosas informações, sugestões, apoio, incentivo e amizade.

Ao Dr. Rajendra N. Saxena, gerente do Centro do Reator de Pesquisas (CRPq), pela oportunidade oferecida para realização deste trabalho.

Especialmente ao amigo Sidnei Gomes, que sempre me incentivou, apoiou e, principalmente, colaborou com sugestões preciosas na área de informática.

Aos colegas Dra. Denise Simões Moreira, Dr. Frederico Antonio Genezini, Dr. José Agostinho Gonçalves de Medeiros, Dra. Sônia Pompeo, MSc. Franco Brancaccio, MSc. Claudia Regina Ponte-Ponge Ferreira, MSc. Ione M. Yamazaki, MSc. Cláudio Domienikan, MSc. Laura Cristina de Oliveira, Fábio de Toledo, Carlos Augusto Pires, Caio Marcio de Paula Iost, Rui Nishizawa, e pelo apoio, incentivo e amizade.

Ao Colégio Magister, na pessoa de Kátia Senise Martinho Rabelo e na pessoa de Patrícia da Silva Michelini Muniz pela paciência e apoio.

Ao Instituto de Pesquisas Energéticas e Nucleares, na pessoa do Superintendente Dr. Cláudio Rodrigues, pela possibilidade oferecida para o desenvovimento deste trabalho. Ao pessoal da Comissão de Pós-Graduação do IPEN pelo apoio oferecido.

À minha querida esposa Rosana, que me apoiou e incentivou nos momentos mais difíceis, pela compreensão, e pelo amor a mim dispensado.

Aos meus queridos filhos Daniel, Raquel e Esther que são minhas fontes de inspiração, alegria, incentivo e entusiasmo. 
Aos meus pais que sempre apoiaram e incentivaram os meus estudos.

A Deus, por ter-me inserido em de sua grande Obra.

A todos que direta ou indiretamente colaboraram na execução e realização deste trabalho. 
"Nós não podemos entender onde estamos indo sem um entendimento de onde estivemos."

(Douglass C. North, 1920 -) 


\title{
Estudo de um Sistema de Coincidências $4 \pi \beta-\gamma$ para a Medida Absoluta de Atividade de Radionuclídeos Empregando Cintiladores Plásticos
}

\author{
Hélio Piuvezam Filho
}

\begin{abstract}
Resumo
O presente trabalho teve como objetivo o estudo de um sistema de coincidências $4 \pi(\mathrm{PS}) \beta-\gamma$, para a medida absoluta de atividade, empregando cintiladores plásticos, em geometria $4 \pi$. Além de experimentos no sistema de coincidências, foram feitas também simulações utilizando o Método de Monte Carlo, por meio dos programas PENELOPE e ESQUEMA. Estas simulações tiveram como objetivo estabelecer a curva de extrapolação do método de coincidência $4 \pi \beta-\gamma$ e comparar com os dados experimentais. Uma nova geometria foi proposta para o sistema de coincidências, onde foi acrescentada uma segunda fotomultiplicadora ao sistema anterior. Este procedimento objetivou melhorar a coleção de luz do cintilador plástico, uma vez que este sistema apresentava limitações na energia mínima detectada, em razão da presença de ruído eletrônico e baixo ganho. Os resultados mostram que houve uma melhoria na relação sinal-ruído, com redução na energia mínima detectável. Além disso, observou-se um aumento na eficiência de detecção. Com estas modificações, tornou-se viável a padronização de radionuclídeos que emitem elétrons ou raios-X de baixa energia, ampliando o número de radionuclídeos padronizáveis com este tipo de sistema.
\end{abstract}




\title{
Study of a $4 \pi(\mathrm{PS}) \beta-\gamma$ Coincidence System for Absolute Radionuclide Activity Measurement Using Plastic Scintillators
}

\author{
Hélio Piuvezam Filho
}

\begin{abstract}
The present work was intended to study a coincidence system $4 \pi(\mathrm{PS}) \beta-\gamma$ for absolute activity measurement using plastic scintillators in $4 \pi$ geometry. Along with experiments on the coincidence system, simulations were also performed applying the Monte Carlo Method, by means of codes PENELOPE and ESQUEMA. These simulations were performed in order to calculate the extrapolation curve of the coincidence system $4 \pi(\mathrm{PS}) \beta-\gamma$ and compare it to experimental data. A new geometry was proposed to the coincidence system adding up a second photomultiplier tube to the previous system for improving light collection from the plastic scintillator, as this system presented limitations in the minimum detected energy due to the presence of electronic noise and low gain. The results show that an improvement in the signal-to-noise ratio was obtained, as well as in the minimum detected energy. Moreover, there was an increase in the detection efficiency. With these modifications, it is now possible to calibrate radionuclides which emit low energy electrons or X-rays, increasing the number of radionuclides that can be standardized with this type of system.
\end{abstract}




\section{SUMÁRIO}

\section{Página}

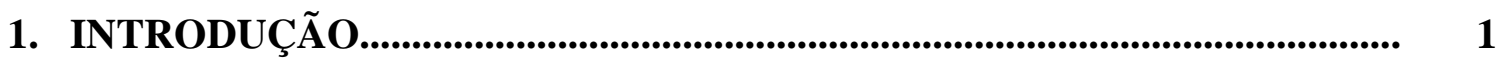

1.1. Revisão da Literatura.................................................................................... 1

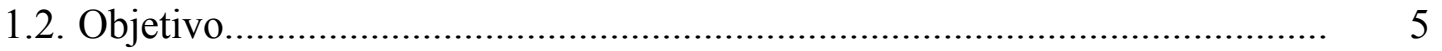

2. FUNDAMENTOS TEÓRICOS................................................................... 6

2.1. Transições Atômicas.................................................................................... 6

2.1.1. Emissões de Raios-X..................................................................... 6

2.1.2. Emissão de Elétrons Auger............................................................ 6

2.2. Transições Nucleares................................................................................... 7

2.2.1. Desintegração Alfa............................................................................ 7

2.2.2. Desintegração Beta............................................................................. 7

2.2.3. Captura Eletrônica.......................................................................... 8

2.2.4. Transições Gama............................................................................. 9

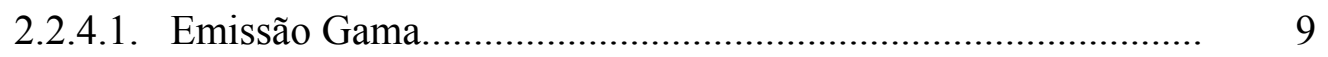

2.2.4.2. Conversão Interna.................................................................. 9

2.3. Interação da Radiação com a Matéria......................................................... $\quad 10$

2.3.1. Partículas Carregadas........................................................................... 10

2.3.2. Radiações Gama e X.............................................................................. 11

2.4. Detectores de Cintilação............................................................................. 13

2.4.1. Processo de deteç̧ão da radiação........................................................ 13

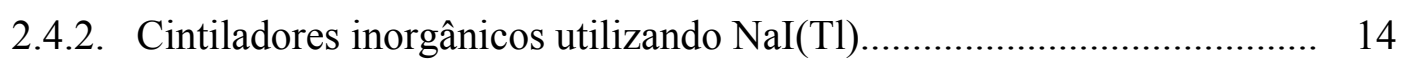

2.4.3. Cintiladores orgânicos utilizando plásticos........................................ 15

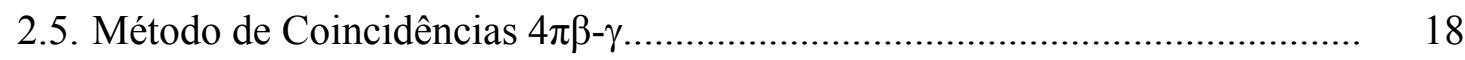

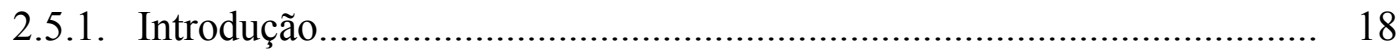

2.5.2. Equações do Método de Coincidências................................................. 19

2.5.3. Técnica da Extrapolação Linear....................................................... 21

2.6. Método de Monte Carlo............................................................................... 22

2.6.1. Transporte da Radiação pelo Método de Monte Carlo.......................... 23

2.6.2. Código PENELOPE......................................................................... 23

2.6.2.1. Processos de Interação.................................................................. 23 
2.6.2.2. Geometria Quádrica............................................................. 26

2.6.2.3. Estrutura do código PENELOPE.............................................. 30

2.6.2.4. Arquivo de dados dos materiais............................................... 33

2.6.2.5. Estrutura do programa MAIN................................................... 33

2.6.2.6. Estrutura do programa PENCYL............................................... 37

2.6.2.7. Estrutura do programa PENDOSES............................................ 39

2.7. Comparação entre Teoria e Experimento........................................................... 39

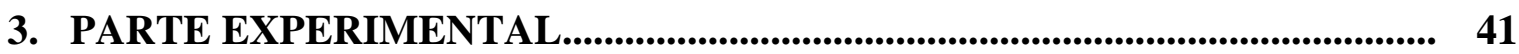

3.1. Radionuclídeos utilizados nos experimentos.............................................. 41

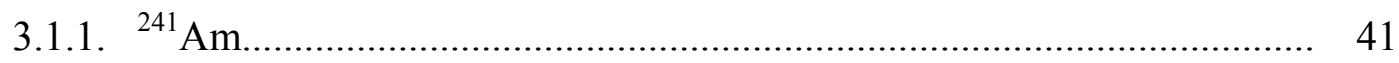

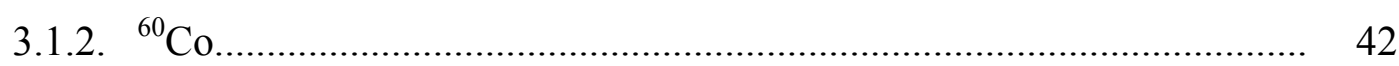

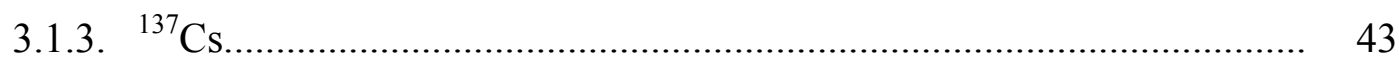

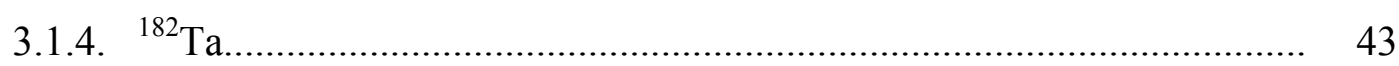

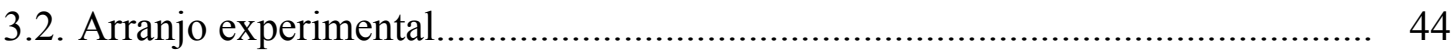

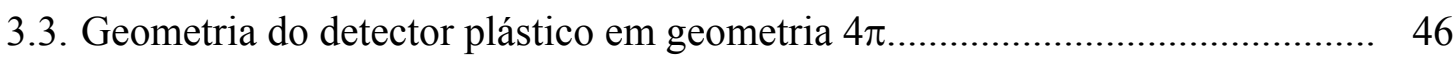

3.4. Parte eletrônica............................................................................................ 47

3.5. Preparação das amostras radioativas................................................................ 50

3.6. Cálculo da atividade................................................................................ 50

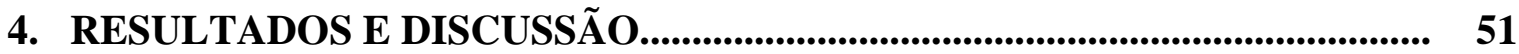

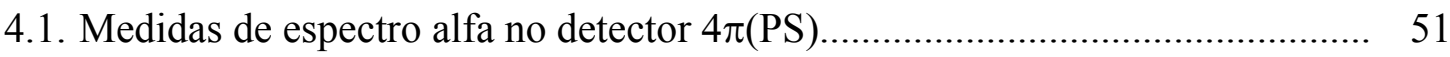

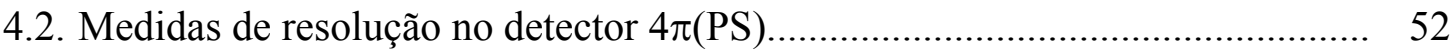

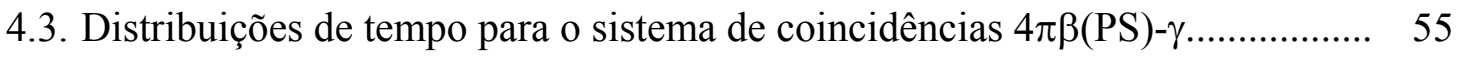

4.4. Resultados de atividade com o sistema de coincidências $4 \pi \beta(\mathrm{PS}) \gamma \ldots \ldots \ldots \ldots \ldots \ldots . . . . . . .58$

4.4.1. Dados experimentais obtidos com o sistema do presente trabalho........ 58

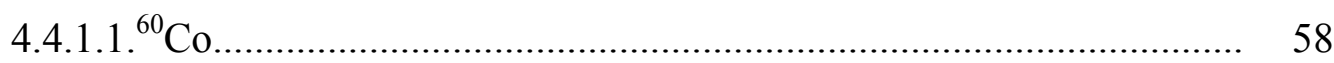

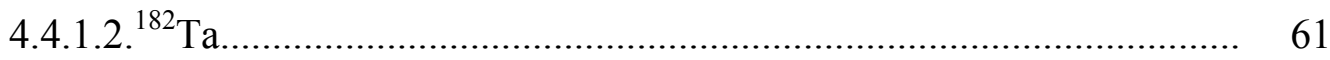

4.4.2. Cálculos de Monte Carlo aplicados ao sistema de Baccarelli............... 62

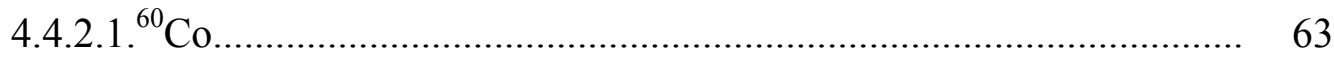

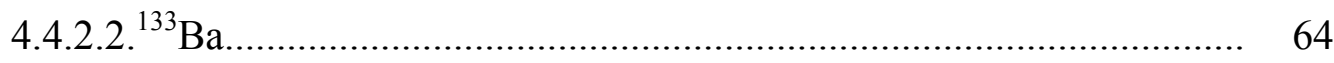

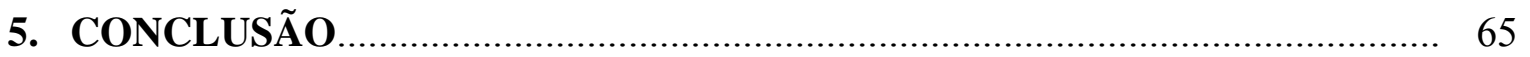


APÊNDICE A - Uso do PENELOPE para geometrias cilíndricas - programa

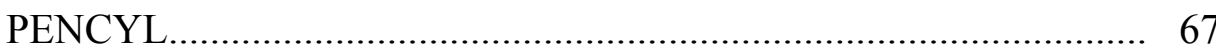

APÊNDICE B - Uso do PENELOPE para geometrias complexas - programa

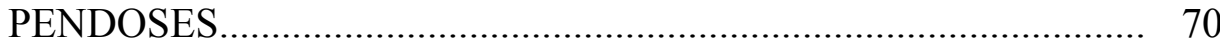

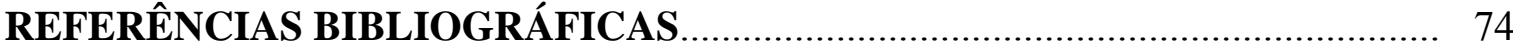




\section{Lista de Tabelas}

Tabela 4-1 Resultados de resolução em energia para o detector $4 \pi(\mathrm{PS})$................... 55

Tabela 4-2 Resultados de atividade para a nova geometria. Ajuste linear com dados experimentais e simulação por Monte Carlo desenvolvida no presente trabalho............................................................................... 59

Tabela 4-3 Resultados de atividade para a geometria original ${ }^{[29]}$, comparados com simulações por Monte Carlo desenvolvidas no presente trabalho............ 


\section{Lista de Figuras}

Figura 2-1 Diagrama simplificado de um sistema de coincidência............................ 18

Figura 2-2 Esquema de desintegração simples para um emissor $\beta-\gamma$ genérico............ 19

Figura 2-3 Deflexão angular numa colisão simples................................................. 26

Figura 2-4 Superfícies quádricas não planares e seus índices ${ }^{[31]}$................................ 29

Figura 2-5 Diretório com a estrutura de arquivos do PENELOPE............................. 31

Figura 2-6 Estrutura de arquivos para simulação com o PENELOPE.......................... 32

Figura 3-1 Esquema de desintegração do ${ }^{241} \mathrm{Am}^{[32]}$................................................. 42

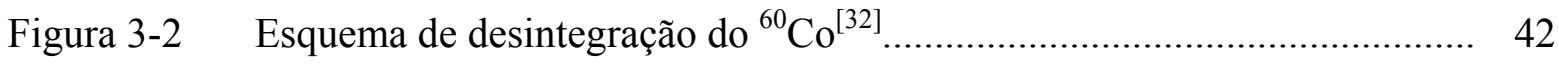

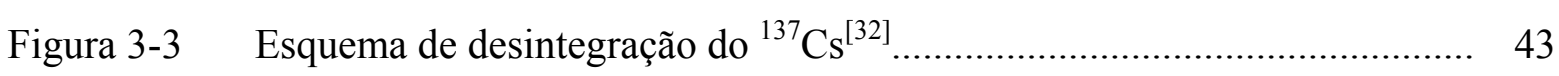

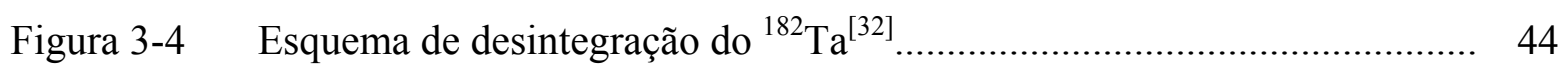

Figura 3-5 Diagrama esquemático do sistema de coincidências $4 \pi \beta(\mathrm{PS})-\gamma$ desenvolvido no presente trabalho (a sigla VFM corresponde a válvula fotomultiplicadora) ..................................................................... 45

Figura 3-6 Foto do sistema de coincidências $4 \pi \beta(\mathrm{PS})-\gamma$ desenvolvido no presente

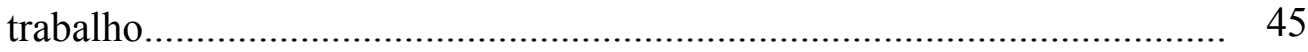

Figura 3-7 Diagrama do detector $4 \pi(\mathrm{PS})$ com a fonte radioativa.............................. 46

Figura 3-8 Sistema eletrônico para contagens de coincidência, aplicável a um único intervalo de energia gama.................................................................. 48

Figura 3-9 Sistema eletrônico para contagens de coincidência aplicável a dois intervalos de energia gama.

Figura 4-1 Espectros alfa para o ${ }^{241} \mathrm{Am}$, obtidos com o uso de uma ou duas fotomultiplicadoras

Figura 4-2 Espectro de alturas de pulso para a radiação gama do ${ }^{241} \mathrm{Am}$, obtido com o cintilador plástico, em geometria $4 \pi$.

Figura 4-3 Espectro de alturas de pulso para a radiação gama do ${ }^{137} \mathrm{Cs}$, obtido com o cintilador plástico, em geometria $4 \pi$

Figura 4-4 Espectro de alturas de pulso para a radiação gama do ${ }^{60} \mathrm{Co}$, obtido com o cintilador plástico, em geometria $4 \pi$. 
Figura 4-5 Espectro diferencial para o ${ }^{241} \mathrm{Am}$, obtido com o cintilador plástico. Os pontos azuis correspondem aos dados experimentais e os pontos vermelhos ao ajuste de uma distribuição normal com larguras diferentes para cada lado do pico

Figura 4-6 Espectro diferencial para o ${ }^{137} \mathrm{Cs}$, obtido com o cintilador plástico. Os pontos azuis correspondem aos dados experimentais e os pontos vermelhos ao ajuste de uma distribuição normal com larguras diferentes para cada lado do pico

Figura 4-7 Espectro diferencial para o ${ }^{60} \mathrm{Co}$ obtido com o cintilador plástico. Os pontos azuis correspondem aos dados experimentais e os pontos vermelhos ao ajuste de uma distribuição normal com larguras diferentes para cada lado do pico. Observa-se um dubleto, composto pelas energias de 1173 e $1332 \mathrm{keV}$

Figura 4-8 Espectro de tempo do ${ }^{60} \mathrm{Co}$. O pico central corresponde a coincidências beta-gama.

Figura 4-9 Espectro de tempo para o ${ }^{60} \mathrm{Co}$. O pico central, à esquerda, corresponde a coincidências (beta-beta)-gama e o pico central, à direita, a coincidências beta-gama.

Figura 4-10 Espectro de tempo para o ${ }^{182}$ Ta. Os índices 1 e 2 correspondem ao primeiro e segundo intervalos de energia gama, respectivamente.

Figura 4-11 Espectro gama do ${ }^{182} \mathrm{Ta}$, obtido por meio do cintilador de $\mathrm{NaI}(\mathrm{Tl})$.

Figura 4-12 Comportamento da função para $N_{\beta} N_{\gamma} / N_{c}$ em função do parâmetro $\left(1-N_{c} / N_{\gamma}\right) /\left(N_{c} / N_{\gamma}\right)$ para o ${ }^{60} \mathrm{Co}$, com a nova geometria. Os pontos cheios são dados experimentais e os vazios obtidos por Monte Carlo.

Figura 4-13 Comportamento da função para $N_{\beta} N_{\gamma} / N_{c}$ em função do parâmetro( $\left(1-N_{c} /\right.$ $\left.N_{\gamma}\right) /\left(N_{c} / N_{\gamma}\right)$ para o ${ }^{182} \mathrm{Ta}$, com a nova geometria. Os pontos em cor preta são dados experimentais e os coloridos por Monte Carlo, todos obtidos no presente trabalho.

Figura 4-14 Arranjo do sistema $4 \pi(\mathrm{PS}) \beta-\gamma$ desenvolvido por Baccarelli ${ }^{[29]}$. A sigla VFM corresponde a válvula fotomultiplicadora. 
Figura 4-15 Comportamento da função para $N_{\beta} N_{\gamma} / N_{c}$ em função do parâmetro $\left(1-N_{c} / N_{\gamma}\right) /\left(N_{c} / N_{\gamma}\right)$ para o ${ }^{60}$ Co na geometria original. Os pontos cheios são dados experimentais obtidos por Baccarelli ${ }^{[29]}$ e os vazios obtidos por Monte Carlo, no presente trabalho

Figura 4-16 Comportamento da função para $N_{\beta} N_{\gamma} / N_{c}$ em função do parâmetro $\left(1-N_{c} / N_{\gamma}\right) /\left(N_{c} / N_{\gamma}\right)$ para o ${ }^{133} \mathrm{Ba}$ na geometria original. Os pontos cheios são dados experimentais ${ }^{[29]}$ e os vazios obtidos por Monte Carlo, no presente trabalho 


\section{INTRODUÇÃO}

\subsection{Revisão da Literatura}

A palavra Metrologia deriva do grego Metro Logo e significa Ciência da Medição. Ela se destina ao desenvolvimento de padrões em todas as áreas de conhecimento e sua rastreabilidade. Os padrões são classificados em primários, secundários, terciários etc., de acordo com a sua posição na cadeia metrológica. Os primários são aqueles que possuem maior exatidão e servem para calibrar os padrões secundários que, por sua vez, são usados para calibrar os terciários etc., estabelecendo uma cadeia metrológica, que possui rastreabilidade. Os sistemas primários são também denominados absolutos, porque não dependem de outros sistemas para produzir os seus padrões. O órgão que coordena o estabelecimento de padrões primários em escala mundial é o BIPM (Bureau International des Poids et Mesures) ${ }^{[1]}$. No Brasil, esta função é ocupada pelo INMETRO (Instituto Nacional de Metrologia) ${ }^{[2]}$, que delegou ao IRD (Instituto de Radioproteção e Dosimetria) ${ }^{[3]}$ a tarefa de estabelecer padrões na área de radiações ionizantes.

A Metrologia Nuclear é o ramo da Metrologia destinado ao estabelecimento de campos de radiação padronizados em energia e intensidade, principalmente relacionados às propriedades dos radionuclídeos, denominada Metrologia de Radionuclídeos. Nesta área, os interesses principais são: a determinação da atividade de uma fonte radioativa e a determinação de parâmetros nucleares relacionados com o processo de desintegração do radionuclídeo, tais com: meia-vida, probabilidades de emissão de raios-X e gama, coeficientes de conversão interna etc.

$\mathrm{Na}$ literatura, observa-se uma evolução nos diversos métodos de padronização primários aplicados à Metrologia de Radionuclídeos, sendo que todos eles apresentam vantagens e limitações. Por esta razão, o BIPM recomenda aos diferentes laboratórios do mundo uma diversificação nos métodos de padronização de radionuclídeos, de modo a evitar resultados tendenciosos, que poderiam ocorrer na utilização de um único método de medidas. 
Desde a década de 50, um dos métodos principais de padronização de radionuclídeos tem sido o de coincidências $4 \pi(\mathrm{PC}) \beta-\gamma$, empregando detector proporcional em geometria $4 \pi$ (Proportional Counter - PC), a gás fluente ou pressurizado, associado a detectores gama, constituídos por cintiladores de $\mathrm{NaI}(\mathrm{Tl})$, $\mathrm{Ge}(\mathrm{Li})$ ou HPGe ${ }^{[4-15]}$. Em condições favoráveis de medida, este método pode atingir incertezas da ordem de $0,05 \%{ }^{[16]}$.

O detector proporcional em geometria $4 \pi$, possui alta eficiência para a detecção de partículas carregadas, tais como: alfas, betas, elétrons, fragmentos de fissão etc. Neste caso, a fonte radioativa possui como substrato um filme plástico muito fino (10 a $20 \mu \mathrm{g} . \mathrm{cm}^{-2}$ ), confeccionado em VYNS ou COLLODION, e é colocada no interior do volume sensível do detector.

Uma das dificuldades deste sistema de medidas está na confecção da fonte, que deve possuir o substrato de filme plástico previamente recoberto com uma camada metálica (usualmente de ouro) para torná-lo parcialmente condutor. Esta característica é necessária para que o campo elétrico no interior do volume sensível do detector proporcional não seja distorcido pela presença do filme plástico, que possui altíssima resistividade elétrica $\left(>10^{10} \mathrm{ohm}\right)$.

Outra dificuldade é garantir a pureza do gás durante as medidas, uma vez que o processo de introdução da fonte faz com que o ar ambiente se misture com o gás do detector, reduzindo a amplitude do pulso. Este tipo de sistema possui também uma limitação associada ao valor da atividade da fonte radioativa, que não deve ultrapassar a alguns milhares de desintegrações por segundo $(\mathrm{kBq})$, para que não provoque uma saturação no campo elétrico do detector $4 \pi$ proporcional, acarretando um aumento exagerado no tempo morto do sistema.

Com o desenvolvimento de válvulas fotomultiplicadoras de alto desempenho, tornou-se popular o detector $4 \pi$ empregando cintilador líquido. Estes detectores têm sido largamente empregados, em razão de sua alta eficiência para a detecção de partículas carregadas, principalmente elétrons de baixa energia ${ }^{[17]}$. 
Neste contexto, um método primário que tem sido muito difundido é o denominado CIEMAT/NIST ${ }^{[18]}$. Este método utiliza o radionuclídeo ${ }^{3} \mathrm{H}$ como referência para a determinação da atividade do radionuclídeo de interesse, que é misturado no coquetel cintilador, juntamente com o ${ }^{3} \mathrm{H}$. Embora este método não seja rigorosamente absoluto, pois utiliza o ${ }^{3} \mathrm{H}$ como referência, ele é considerado primário, em razão de sua grande exatidão (apresenta incertezas abaixo de 1\%).

Outro método primário, que emprega o cintilador líquido como detector $4 \pi$, é denominado TDCR (Triple to Double Coincidence Ratio) ${ }^{[19]}$. Este método utiliza três válvulas fotomultiplicadoras, operando em coincidência. Neste caso, o radionuclídeo de interesse é medido isoladamente e a razão entre o número de coincidências triplas e duplas permite a determinação da atividade do radionuclídeo de forma absoluta. Uma dificuldade deste método é atingir a igualdade entre os ganhos das fotomultiplicadoras, para que o método não produza resultados inexatos.

Foi desenvolvido, no Japão, um sistema de coincidências $4 \pi \beta-\gamma$ que emprega cintiladores plásticos em geometria $4 \pi^{[20]}$. Neste sistema, a fonte radioativa é depositada diretamente no cintilador plástico, que é colocado juntamente com outro cintilador plástico, sob a forma de sanduíche. O sistema utiliza duas válvulas fotomultiplicadoras para aumentar o ganho na coleção de luz. A vantagem deste sistema de medidas é a alta eficiência conseguida para a detecção de elétrons, porém apresenta a desvantagem de necessitar da confecção de um novo cintilador para cada fonte que for calibrada, tornando o método relativamente dispendioso.

O Laboratório de Metrologia Nuclear (LMN), do IPEN-CNEN/SP, está sediado em São Paulo e desde a sua fundação, em 1964, tem-se dedicado ao desenvolvimento de padrões nas áreas de Metrologia de Radionuclídeos e de Nêutrons. Este laboratório faz parte da cadeia metrológica do Brasil, participando de intercomparações com outros laboratórios do mundo, em colaboração com o IRD, sediado no Rio de Janeiro ${ }^{[21-26]}$.

O LMN iniciou a implementação de sistemas primários com a instalação de um sistema de coincidências $4 \pi \beta(\mathrm{PC})-\gamma$, que emprega um detector proporcional em 
geometria $4 \pi$, associado a cintiladores de $\mathrm{NaI}(\mathrm{Tl})$ para a medida de radiação gama. Outro sistema, empregando um detector proporcional em geometria $4 \pi$ pressurizado, foi também instalado, em complementação ao primeiro ${ }^{[14,21]}$. Estes sistemas continuam operacionais atualmente.

No período de 1976 a 1978, foi desenvolvido outro sistema de coincidências no LMN, denominado $4 \pi \beta(\mathrm{LS})-\gamma$, que empregava um cintilador líquido como detector $4 \pi$ associado a um cintilador de $\mathrm{NaI}(\mathrm{Tl})$, para detecção da radiação gama ${ }^{[27]}$. Este sistema apresentava dificuldades em manter a estabilidade química no coquetel cintilador, para alguns radionuclídeos, e problemas com ruído nas fotomultiplicadoras acopladas ao cintilador líquido.

Posteriormente, entre 1981 e 1988, foi desenvolvido no LMN outro sistema de coincidências, denominado $4 \pi \beta(\mathrm{SB})-\gamma$, que utilizava detectores de barreira de superfície em geometria $4 \pi$, para a detecção de partículas alfa e elétrons ${ }^{[28]}$. Este sistema também apresentava dificuldades, em razão dos danos de irradiação provocados nos detectores de barreira de superfície, colocados muito próximos da fonte radioativa, com o objetivo de obter uma alta eficiência de detecção.

Mais recentemente, o LMN implantou um sistema de coincidências, denominado $4 \pi \beta(\mathrm{PS})-\gamma$, que emprega um cintilador plástico em geometria $4 \pi$, como detector de partículas carregadas, associado a um cintilador de $\mathrm{NaI}(\mathrm{Tl})$ para a detecção da radiação gama $^{[29]}$. Este sistema apresenta algumas vantagens, tais como: dispensa a necessidade da metalização dos filmes e da utilização de gases especiais, para o seu funcionamento.

Com este sistema foram padronizados alguns radionuclídeos, a saber: ${ }^{18} \mathrm{~F},{ }^{60} \mathrm{Co}$, ${ }^{133} \mathrm{Ba} \mathrm{e}{ }^{241} \mathrm{Am}$. Entretanto, este sistema apresenta limitações relacionadas com a coleção da luz produzida nos cintiladores plásticos, em razão de empregar apenas uma válvula fotomultiplicadora. Esta limitação motivou o desenvolvimento do presente trabalho. 


\subsection{Objetivo}

O presente trabalho tem como objetivo propor melhorias no sistema de coincidências $4 \pi \beta(\mathrm{PS})-\gamma$, existente no LMN do IPEN. Inicialmente, a melhoria se dá pela previsão teórica da curva de extrapolação, utilizada na padronização da fonte. Deste modo, torna-se possível a determinação da atividade da fonte, sem a necessidade de construir-se uma curva de extrapolação. Isto pode ser conseguido por meio da simulação teórica de todo o processo de medida de atividade, utilizando o método de Monte Carlo ${ }^{[30,31]}$. A atividade é obtida por meio de um ajuste pelo método dos Mínimos Quadrados, entre os resultados teóricos e experimentais.

Outra proposta de melhoria está associada ao aumento na eficiência de coleção da luz produzida nos cintiladores plásticos, introduzindo no sistema uma nova válvula fotomultiplicadora. Com isto, torna-se possível o aumento na eficiência de detecção para partículas carregadas, permitindo a padronização de radionuclídeos que emitam elétrons de baixa energia como, por exemplo, aqueles que decaem por captura eletrônica. Este novo sistema também tem a sua modelagem teórica desenvolvida no presente trabalho, possibilitando a previsão da curva de extrapolação que determina a atividade da fonte. 


\section{FUNDAMENTOS TEÓRICOS}

\subsection{Transições Atômicas}

Quando um átomo está em um estado excitado, ele tende a emitir a energia excedente sob duas formas de radiação: raios-X e elétrons Auger. A probabilidade de cada uma está associada ao número atômico do material emissor.

\subsubsection{Emissão de Raios-X}

Os elétrons orbitais populam diferentes níveis de energia, denominados $\mathrm{K}, \mathrm{L}, \mathrm{M}$ etc. A transição de um elétron partindo de um nível de energia mais alta para outro, de energia mais baixa, dá origem à emissão de radiação eletromagnética, denominada raios- $X$. A energia destes raios-X é determinada pela diferença de níveis entre o estado inicial e final da transição. A probabilidade de emissão, denominada rendimento de fluorescência $(W)$, cresce de acordo com o número atômico. Para o $\mathrm{Na}, \mathrm{W}$ é da ordem de $1,8 \%$, enquanto que, para o $\mathrm{Hg}$, este parâmetro possui o valor de $96,7 \%^{[32,33]}$.

\subsubsection{Emissão de Elétrons Auger}

Quando uma vacância é produzida em um dos níveis de energia dos elétrons orbitais, os demais elétrons tendem a ocupar esta vacância, gerando um excesso de energia que deve ser emitido pelo átomo. Uma das formas é a emissão de raios-X. Uma forma alternativa é transferir a energia que foi disponibilizada, em razão da ocupação da vacância, para outro elétron orbital, que é emitido do átomo. Este elétron é denominado elétron Auger.

Para uma dada transição, os elétrons Auger são emitidos com uma energia mais baixa, em relação ao raio-X correspondente, uma vez que parte da energia disponível está associada à energia de ligação do elétron no átomo. Como os processos de emissão de raios-X e elétrons Auger são complementares, a probabilidade de emissão de elétrons 
Auger $(1-W)$ decresce com o número atômico. Para o $\mathrm{Na}$, esta probabilidade é de $98,2 \%$, enquanto que, para o $\mathrm{Hg}$, seu valor é $3,7 \%{ }^{[32,33]}$.

\subsection{Transições Nucleares}

Um núcleo atômico, quando está em desequilíbrio na sua proporção ideal entre o número de prótons e nêutrons, ou esteja com excesso de massa, torna-se instável, ou radioativo, emitindo um ou mais tipos de radiação, até atingir sua condição de estabilidade. Os principais processos de desintegração radioativa são descritos a seguir.

\subsubsection{Desintegração Alfa}

Este processo tem maior probabilidade de ocorrer para núcleos pesados, tipicamente com massa superior à do chumbo. Neste caso, o núcleo radioativo emite um núcleo de hélio $\left({ }^{4} \mathrm{He}^{++}\right)$, denominado partícula alfa. Estas partículas são emitidas com espectro discreto e possuem, em geral, energias entre 4 e $7 \mathrm{MeV}$. A maior parte da energia disponível no processo é levada pela partícula alfa, enquanto o núcleo residual sofre um pequeno recuo, em razão da conservação do momento. A equação que descreve o processo é dada por:

$$
{ }_{Z}^{A} \mathrm{X} \rightarrow{ }_{Z-2}^{A-4} \mathrm{Y}+{ }_{2}^{4} \mathrm{He}+\mathrm{Q}
$$

\subsubsection{Desintegração Beta}

Os núcleos com excesso de nêutrons tendem a converter um nêutron em próton, com a emissão de uma partícula beta negativa e um anti-neutrino, que carregam a energia disponível no processo. Como a energia é compartilhada entre estas duas partículas, o espectro de energia de cada uma resulta contínuo, desde zero até a energia máxima disponível. A equação que descreve o processo é dada por:

$$
{ }_{Z}^{A} X \rightarrow{ }_{Z+1}^{A} Y+\beta^{-}+\bar{v}+Q
$$


Quando o núcleo possui excesso de prótons, um deles é convertido em nêutron, com emissão de uma partícula beta positiva (pósitron) e um neutrino. Também neste caso, os espectros destas duas radiações são contínuos. A energia disponível no processo deve ser superior a 1,022 MeV, de modo a permitir a criação do par elétronpósitron, no interior do núcleo. A equação que descreve o processo é dada por:

$$
{ }_{Z}^{A} X \rightarrow{ }_{Z-1}^{A} Y+\beta^{+}+v+Q
$$

O espectro de energia das partículas beta pode ser descrito pela Teoria de Fermi ${ }^{[33-35]}$. Neste contexto, o número de betas emitidos com energia $W$ pode ser dado por:

$$
N(W)=\frac{g}{2 \pi^{3}} W\left(W^{2}-1\right)^{1 / 2}\left(W_{0}-W\right)^{2} F(W, Z) C_{n}
$$

Nesta expressão, $\mathrm{g}=1,41 \times 10^{-56} \mathrm{~J} \cdot \mathrm{cm}^{3}$, é a constante de acoplamento para interações fracas; $W_{0}$ é a energia máxima do beta $\left(W_{0}=(Q+1)\right.$, para transições $\beta^{-} ; W_{0}=(Q-1)$, para transições $\beta^{+}$, e $Q$ é a energia total disponível no processo); $F(W, Z)$ é a função de Fermi e $C_{n}$ é o fator de forma. Para transições permitidas, o fator de forma é constante e para transições proibidas, este fator depende do valor de $W$.

\subsubsection{Captura Eletrônica}

Um processo alternativo, quando o núcleo possui excesso de prótons, é a captura de um elétron orbital pelo núcleo, denominada Captura Eletrônica (CE). O elétron ao penetrar no núcleo combina-se com um próton, o par converte-se em um nêutron, com a emissão de um neutrino monoenergético. Este processo pode ser descrito pela seguinte expressão:

$$
{ }_{Z}^{A} X+e^{-} \rightarrow{ }_{Z-1}^{A} Y+v+Q
$$

A probabilidade de captura depende do nível de energia em que o elétron se encontra, sendo maior para a camada $\mathrm{K}$ e decrescendo para as camadas $\mathrm{L}$, M etc. 


\subsubsection{Transições Gama}

Sempre que núcleo atingir um dos seus estados excitados, ele tende a emitir esta energia excedente, dando origem a uma transição gama. Estas transições gama são classificadas de acordo com a variação do momento angular do núcleo (L) durante o processo: para $\mathrm{L}=0$, a transição é dita monopolo, para $\mathrm{L}=1$, dipolo, $\mathrm{L}=2$ quadrupolo etc. Pode haver transições denominadas elétricas, quando a mudança de paridade é $(-1)^{\mathrm{L}}$ e magnéticas, quando a mudança de paridade é $(-1)^{\mathrm{L}+1}$. Neste tipo de processo, o núcleo tende a emitir, principalmente, dois tipos de radiação: gama e elétrons de conversão interna. Existe um terceiro processo, a produção de par elétron-pósitron, que normalmente tem probabilidade muito pequena (da ordem de $10^{-4}[33]$ ) e pode ser desprezado.

\subsubsection{Emissão Gama}

É um processo no qual a energia da transição gama é emitida sob a forma de uma radiação eletromagnética (fóton), denominada radiação gama ou raio gama. A energia deste gama corresponde à diferença entre as energias dos estados inicial e final do núcleo considerado. Ela possui um espectro discreto e energias típicas na faixa de 30 $\mathrm{keV}$ a $3 \mathrm{MeV}$. Para transições com energia muito maiores que as energias de ligação do elétron no átomo, este é o processo dominante de desexcitação do núcleo.

\subsubsection{Conversão Interna}

Um processo alternativo com relação à emissão gama é a emissão de um elétron de conversão interna. Neste caso, a energia em excesso do núcleo é transferida a um elétron orbital, e ele é emitido com uma energia dada por:

$$
E_{C I}=E_{\gamma}-E_{X}
$$

Nesta expressão, $E_{X}$ é energia de ligação do elétron do orbital $X(K . L, M . N \ldots)$. 
O processo de conversão interna ocorre, com maior probabilidade, quando a energia da transição se aproxima da energia de ligação do elétron. Portanto, para altas energias este processo possui probabilidade muito pequena.

\subsection{Interação da Radiação com a Matéria}

As interações da radiação com a matéria dependem da natureza da radiação, da sua energia e das propriedades do meio material ${ }^{[34-37]}$. A seguir é feita uma breve descrição dos processos, considerados relevantes no contexto do presente trabalho.

\subsubsection{Partículas Carregadas}

As partículas carregadas perdem energia ao longo da trajetória, em um meio material, de maneira contínua, até atingir o repouso. Durante o percurso, elas podem interagir por diferentes processos, sendo os principais: colisão (ionização e excitação) e Bremsstrahlung. Para energias superiores à energia de ligação por nucleon do núcleo, (7 a $8 \mathrm{MeV}$ ) podem ocorrer reações nucleares. Para os processos discutidos no presente trabalho, a probabilidade dessas reações nucleares é pequena.

A perda de energia por unidade de trajetória percorrida é denominada Potencial de Freiamento e é dado por:

$$
\left(\frac{d E}{d x}\right)_{T}=\left(\frac{d E}{d x}\right)_{C}+\left(\frac{d E}{d x}\right)_{B}
$$

Nesta expressão, os índices $T, C$ e $B$ representam: Total, Colisão e Bremsstrahlung, respectivamente.

A ionização ocorre quando a energia transferida ao átomo do meio é superior à energia de ligação do elétron. Neste caso, forma-se um par-de-íons: o átomo, que perdeu o elétron, e o elétron emitido. O processo de excitação se dá quando a energia transferida é menor que a energia de ligação do elétron. Neste caso, o elétron é promovido a um dos níveis de energia superiores e a energia em excesso é emitida sob a forma de raios-X ou elétrons Auger. Estes dois processos são dominantes na interação 
de partículas carregadas pesadas, tais como: partículas alfa, prótons, dêuterons, fragmentos de fissão etc. Para elétrons, estes processos são dominantes em baixas energias. Para energias maiores, o processo dominante é o Bremsstrahlung.

O processo de perda de energia por Bremsstrahlung ou Radiação de Freiamento, corresponde a uma desaceleração brusca da partícula carregada, ao se aproximar do núcleo atômico. A partícula é defletida e perde uma parte de sua energia, que é função do parâmetro de impacto da partícula. Esta perda de energia pode variar desde zero até um valor máximo, que corresponde à energia inicial da partícula carregada. Durante o processo, é emitido um raio-X com espectro contínuo, denominado: Radiação de Freiamento ou Bremsstrahlung. A energia da radiação de Bremsstrahlung varia desde zero, até a energia inicial da partícula carregada.

A perda de energia por Bremsstrahlung depende do número atômico $(Z)$ do meio, da massa $(m)$ e da carga $(z)$, da partícula incidente. Este processo aumenta com $Z^{2}$, e inversamente com a massa $m$ da partícula. Por esta razão ele é importante para elétrons e pósitrons, porém, em geral, torna-se desprezível para partículas carregadas pesadas.

O pósitron, após perder sua energia no meio material, sofre o processo de aniquilação de pares ao combinar-se com um elétron do meio. Neste processo, ambas as partículas desaparecem, dando origem a dois fótons, cada um com $511 \mathrm{keV}$, denominados fótons (ou gamas) de aniquilação. Quando o pósitron se aniquila em repouso, os fótons são emitidos fazendo um ângulo de $180^{\circ}$ entre si.

\subsubsection{Radiações Gama e X}

Os fótons, gama e X, são radiações eletromagnéticas e interagem principalmente por meio de três processos: Absorção Fotoelétrica, Espalhamento Compton e Produção de Pares. Um processo adicional, denominado Espalhamento Elástico ou Rayleigh, também pode ocorrer, mas é pouco provável para as energias de fóton discutidas no presente trabalho. 
O efeito Fotoelétrico consiste na absorção total de um fóton por um átomo, transferindo toda a sua energia a um elétron orbital, que é emitido do átomo com uma energia $(E)$ dada por:

$$
E=h v-W
$$

Nesta expressão, $h v$ corresponde à energia do fóton incidente e $W$ corresponde à energia de ligação do elétron. Este efeito varia com $Z^{3}$ ou $Z^{4}$ e $(h v)^{-3}$ sendo, portanto, dominante para altos números atômicos e baixas energias de fóton.

O efeito Compton consiste no espalhamento inelástico do fóton incidente com dos elétrons das camadas mais externas no átomo. A energia transferida ao elétron depende da energia do fóton incidente e do ângulo de espalhamento. Para altas energias e ângulos de espalhamento maiores, a transferência de energia ao elétron é maior. A energia máxima transferida ao elétron, correspondente a um ângulo de espalhamento de $180^{\circ}$, é dada por:

$$
E_{m}=h v \frac{2 \alpha}{1+2 \alpha}
$$

Nesta equação, $\alpha=h v / 2 m_{0} c^{2}$.

A seção de choque para espalhamento diferencial ou total é dada pelo formalismo de Klein-Nishina ${ }^{[34,35]}$. Como o efeito Compton depende da densidade eletrônica no meio material, que é proporcional à razão $Z / A$, conclui-se que o efeito Compton praticamente independe de $Z$.

O efeito de Produção de Pares consiste na absorção total do fóton nas imediações do núcleo atômico, com a criação de um par elétron-pósitron. O par carrega a energia residual do processo $\left(E_{R}\right)$, sob a forma de energia cinética, dada por:

$$
E_{R}=E_{+}+E_{-}=h v-2 m_{0} c^{2}
$$




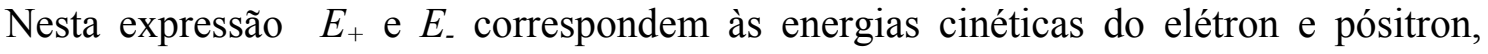
respectivamente; $h v$ é a energia do fóton e $m_{0} c^{2}$, a energia de repouso do elétron.

Pela lei da conservação da energia, este processo só é possível ocorrer acima de uma energia mínima, ou limiar, igual a 1,022 MeV. Acima deste limiar, a probabilidade para o processo de Produção de Pares cresce com a energia do fóton, sendo proporcional a $Z$ ou $Z^{2}$.

As probabilidades de ocorrência (seções de choque) dos três efeitos mencionados combinam-se para formar o coeficiente de atenuação linear $(\mu)$ :

$$
\mu=\tau+\sigma+\pi
$$

Nesta expressão, $\tau, \sigma$ e $\pi$ correspondem às seções de choque para os efeitos Fotoelétrico, Compton e Produção de Pares, respectivamente.

A descrição detalhada das interações mencionadas neste capítulo, normalmente, é feita por meio de métodos estocásticos, como o Método de Monte Carlo, a ser descrito na seção 2.5. Este método é capaz de seguir a trajetória da radiação desde o ponto de origem até a sua absorção ou escape do sistema. Para isto, faz uso das probabilidades de interação e das características físico-químicas e dimensionais do arranjo experimental.

\subsection{Detectores de Cintilação}

Embora exista uma variedade de detectores de radiação, a discussão a seguir se restringirá a detectores que operam pelo processo de cintilação, porque apenas estes foram utilizados no presente trabalho.

\subsubsection{Processo de detecção da radiação}

Os cintiladores baseiam-se na conversão da energia depositada pela radiação incidente em luz ${ }^{[36]}$. Para radiações diretamente ionizantes, tais como: elétrons, prótons e partículas alfa, a deposição de energia ocorre essencialmente pelos processos de 
ionização, excitação e produção de bremsstrahlung. Para o caso de radiações indiretamente ionizantes, tais como fótons e nêutrons, a deposição de energia se faz pelas partículas secundárias produzidas no processo: elétrons, para o caso de fótons e produtos de reações nucleares, para o caso de nêutrons.

A luz produzida deve ser convertida em um pulso elétrico. Para isto, é necessário que os fótons de luz possam ser transmitidos ao longo do cintilador, que deve ser, portanto, transparente para o comprimento de onda da luz gerada no material. A conversão normalmente ocorre por meio de uma válvula fotomultiplicadora ${ }^{[36]}$.

Este dispositivo possui uma superfície, o fotocatodo, caracterizado pela propriedade de emitir elétrons ao ser bombardeado por fótons com comprimento de onda compatível. O número inicial de elétrons produzidos no fotocado passa por um sistema de eletrodos (os dinodos), sofrendo um processo de multiplicação até o eletrodo final (o anodo), de onde o pulso elétrico segue, para ser processado eletronicamente.

Para um cintilador ideal, a quantidade de luz produzida deve ser linear com a energia depositada. Isto só ocorre quando a partícula secundária possui um valor do poder de freiamento $(d E / d x)$ pequeno, como é o caso de elétrons. Para o caso de partículas pesadas, como prótons e alfas, o valor desse parâmetro é alto, fazendo com que parte da energia que seria convertida em luz seja dissipada por outros processos, que produzem danos ao longo da sua trajetória. Como conseqüência, a dependência entre a energia depositada e a luz produzida torna-se não linear ${ }^{[36]}$.

Outra característica desejável é o tempo de decaimento da luminescência produzida, que deve ser pequeno, para evitar a ocorrência de superposição dos pulsos produzidos por eventos distintos. Além disso, para possibilitar um bom acoplamento ótico com a válvula fotomultiplicadora, o índice de refração do cintilador deve ser próximo ao do vidro.

Há diversos materiais com estas propriedades, onde se destacam os cristais alcalinos, tais como NaI, CsI, etc, e os cintiladores orgânicos, plásticos ou líquidos, tais como: NE102, NE110, NE213, Pilot B etc ${ }^{[36]}$. 


\subsubsection{Cintiladores inorgânicos utilizando NaI(Tl)}

No presente trabalho foi utilizado um detector de $\mathrm{NaI}(\mathrm{Tl})$, que é adequado para a detecção da radiação gama em razão de sua alta eficiência. Por ser selado hermeticamente não é adequado para a detecção de elétrons, o que constitui uma vantagem para a utilização do método de coincidências, por evitar a detecção simultânea de eventos beta e gama, provenientes da mesma desintegração.

O uso de detectores de cintilação, como espectrômetros gama de alta eficiência de detecção, tem sido possível pela disponibilidade de grandes cristais de $\mathrm{NaI}(\mathrm{Tl})$ e do desenvolvimento de fotomultiplicadoras de alta sensibilidade. O mecanismo de cintilação em materiais inorgânicos depende do seu estado energético, que é determinado pela rede cristalina do material. Utilizando-se os termos de banda de energia nos materiais isolantes e semicondutores, os elétrons podem ocupar apenas bandas discretas de energia ${ }^{[36]}$.

A banda de energia denominada banda de valência, corresponde aos elétrons que estão ligados à rede cristalina. A banda de energia denominada banda de condução, corresponde aos elétrons que possuem energia suficiente para transitarem livremente ao longo do cristal. Existem, também, bandas intermediárias, denominadas bandas proibidas, em que elétrons nunca são encontrados no cristal puro. Nesta banda podem ser criados níveis de energia intermediários, ao se adicionar impurezas no cristal, neste caso o $\mathrm{Tl}$.

A absorção de energia resulta na elevação de um elétron da banda de valência para a banda de condução. No cristal puro, o retorno do elétron para sua camada original é um processo pouco eficiente para a emissão de fótons. Entretanto, com a existência de níveis de energia intermediários, os elétrons podem retornar à banda de valência, criando lacunas que, ao serem preenchidas com elétrons que estão na banda de condução, emitem fótons de maneira mais eficiente. 


\subsubsection{Cintiladores orgânicos utilizando plásticos}

Os cintiladores plásticos orgânicos são na sua maioria moléculas de hidrocarbonetos aromáticos que contém em sua estrutura anéis-benzeno. Estas moléculas contêm estruturas ressonantes. O processo de luminescência em materiais orgânicos é um processo molecular e surge das transições na estrutura de níveis de energia de uma única molécula.

A energia absorvida se dá por promoção do elétron para qualquer um dos estados de maior energia. A série de níveis energéticos possíveis, para spin 0 , são denominados singletos. Outro conjunto de níveis energéticos possíveis, para spin 1, são denominados tripletos. O intervalo de energia entre os singletos é de aproximadamente $4 \mathrm{eV}$. Estes níveis se subdividem em outros níveis menores em intervalos de energia de aproximadamente $0,15 \mathrm{eV}$ correspondendo a estados vibracionais.

A absorção de energia de radiação é a conversão em energia cinética da molécula (estado vibracional). Os elétrons que ocupam os estados vibracionais, ao receberem energia ficarão em desequilíbrio térmico passando aos seus vizinhos parte da energia vibracional. A principal emissão de luz se dá por transições entre os estados vibracionais e o estado fundamental.

O número de fótons de luz $n_{p}$ emitidos em determinado período de tempo $(\mathrm{t})$ pode ser expresso pela lei de crescimento exponencial ${ }^{[37]}$ :

$$
n_{p}=n_{p i}\left(1-e^{-\frac{t}{\tau}}\right)
$$

Onde $\tau$ representa o tempo necessário para emissão de uma fração de $63,2 \%$ da luz e é chamado de tempo de decaimento. Este tempo, em cintiladores orgânicos, é da ordem de nano segundo.

O tempo do primeiro estado vibracional num dos tripletos é consideravelmente maior que num dos singletos e, por meio de uma transição denominada transição 
cruzada, alguns estados excitados no singleto podem se converter para o tripleto. Caso a emissão luminosa ocorra pela transição do tripleto para o singleto então ela é denominada fosforescência, possuindo um tempo de decaimento mais longo. Caso a emissão ocorra pela desexcitação dos subníveis vibracionais entre singletos (sem a ocorrência de cruzamento) então é denominada fluorescência, neste caso com tempos mais curtos e da ordem de $10 \mathrm{~ns}$.

\subsection{Método de Coincidências $4 \pi \beta-\gamma$}

\subsubsection{Introdução}

O método de coincidências $4 \pi \beta-\gamma$ é um dos métodos absolutos mais utilizados na padronização de radionuclídeos, uma vez que possibilita a obtenção de resultados de taxa de desintegração com grande exatidão. Isto é conseguido por meio das taxas de contagens, sem o conhecimento dos parâmetros inerentes ao processo de desintegração ou ao sistema de medidas utilizado. Este método é aplicável nas padronizações de radionuclídeos que se desintegram pela emissão de duas radiações simultâneas e de natureza diferente, tais como: $\alpha-\gamma, \beta-\gamma$, e- $\gamma$ ou X- $\gamma$.

O método baseia-se no uso de dois detectores estáveis no tempo, cada um adequado a apenas um dos tipos de radiação (ex. beta ou gama), além de um módulo para a determinação dos eventos coincidentes, isto é, detectados simultaneamente nos dois detectores, conforme ilustrado na Figura 2-1. 


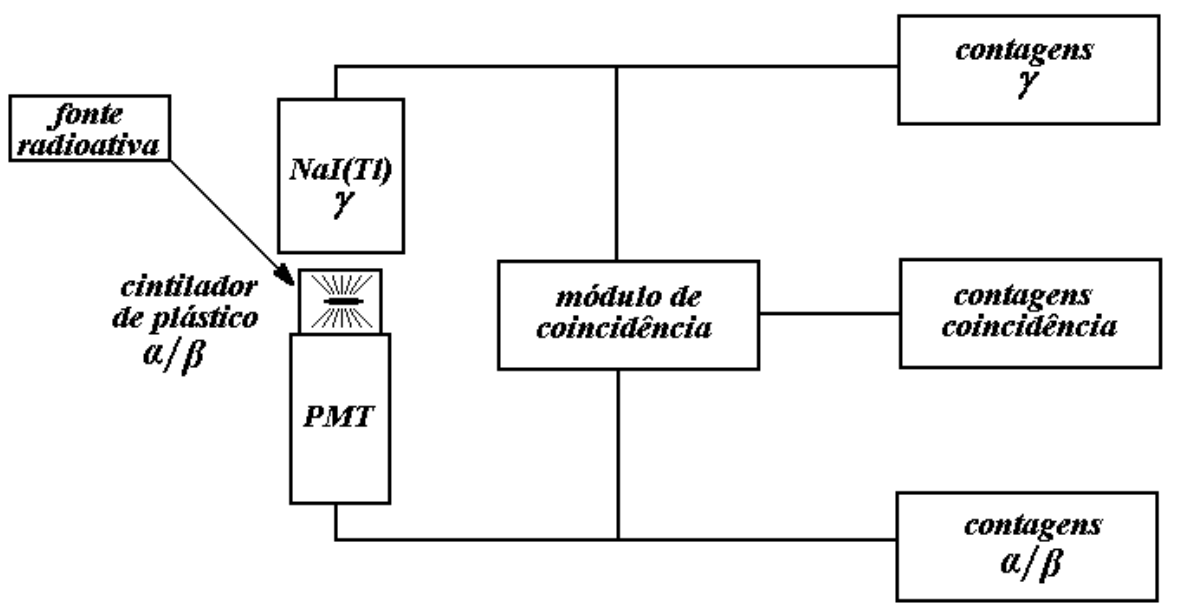

Figura 2-1: Diagrama simplificado de um sistema de coincidência

\subsubsection{Equações do Método de Coincidências}

Considere-se inicialmente uma fonte radioativa puntiforme, com atividade $N_{0}$, em que a desintegração se dá pela emissão de uma partícula $\beta^{-}$, seguida por um fóton $\gamma$ (Figura 2-2).

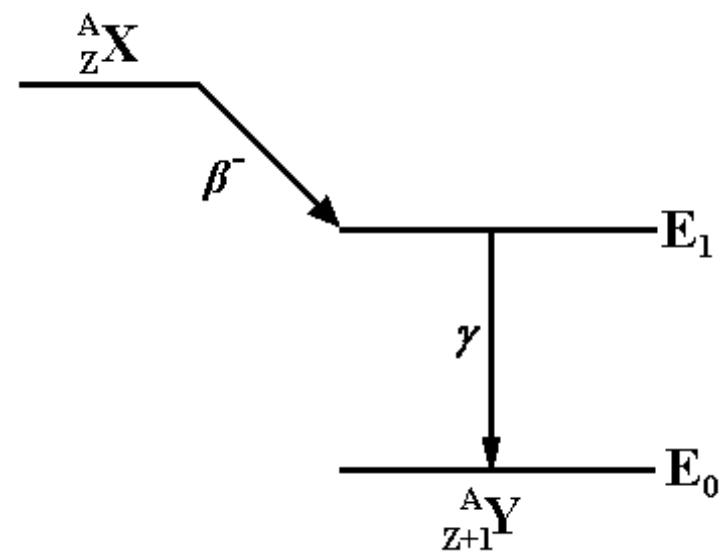

Figura 2-2: Esquema de desintegração simples para um emissor $\beta-\gamma$ genérico.

As taxas de contagem registradas em cada uma das vias de detecção: beta $\left(N_{\beta}\right)$, gama $\left(N_{\gamma}\right)$ e coincidência $\left(N_{c}\right)$, são dadas por:

$$
N_{\beta}=N_{0} \cdot \varepsilon_{\beta}
$$




$$
\begin{aligned}
& N_{\gamma}=N_{0} \cdot \varepsilon_{\gamma} \\
& N_{c}=N_{0} \cdot \varepsilon_{\beta} \cdot \varepsilon_{\gamma}
\end{aligned}
$$

Nestas equações, $\varepsilon_{\beta}$ e $\varepsilon_{\gamma}$ são as probabilidades de detecção (eficiências) beta e gama, respectivamente.

Fazendo o produto das equações (2-13) e (2-14) e dividindo-se pela equação $(2-15)$, tem-se:

$$
N_{0}=\frac{N_{\beta} \cdot N_{\gamma}}{N_{c}}
$$

Assim, a atividade da fonte $N_{0}$ pode ser obtida em função apenas das taxas de contagens observadas. Utilizando-se a equação (2-16) nas equações (2-13) e (2-14), é possível determinar as respectivas eficiências, em função das taxas de contagens:

$$
\begin{gathered}
\varepsilon_{\beta}=\frac{N_{c}}{N_{\beta}} \\
\varepsilon_{\gamma}=\frac{N_{c}}{N_{\gamma}}
\end{gathered}
$$

O processo de desintegração apresentado no esquema anterior (Figura 2-2) corresponde a uma condição ideal, que é raramente alcançada. Geralmente, os radionuclídeos apresentam esquemas de desintegração mais complexos, com vários ramos beta, seguidos de transições gama ou da emissão de elétrons de conversão interna. Desse modo, diversas correções devem ser aplicadas ${ }^{[4-10,12]}$, tais como: sensibilidade de um dos detectores ao outro tipo de radiação, a qual ele não se destina, uso de fontes não puntiformes, tempos de resposta diferentes para cada detector etc.

No caso de um radionuclídeo que apresenta um esquema de desintegração complexo, i.e., desintegra por emissão $\beta-\gamma$, (ou CE- $\gamma$ ), com vários ramos betas, as equações (2-13), (2-14) e (2-15) podem ser escritas como: 


$$
\begin{aligned}
& N_{\beta}=N_{0} \cdot \sum_{r=1}^{n} a_{r}\left[\varepsilon_{\beta_{r}}+\left(1-\varepsilon_{\beta_{r}}\right) \cdot\left(\frac{\alpha \varepsilon_{e c}+\varepsilon_{\beta_{\gamma}}}{1+\alpha}\right)_{r}\right] \\
& N_{\gamma}=N_{0} \cdot \sum_{r=1}^{n} a_{r}\left[\frac{\varepsilon_{\gamma_{r}}}{1+\alpha_{r}}\right] \\
& N_{c}=N_{0} \cdot \sum_{r=1}^{n} a_{r}\left[\varepsilon_{c_{r}} \cdot\left(1-\varepsilon_{\beta_{r}}\right)+\left(\frac{\varepsilon_{\beta_{r}}+\varepsilon_{\gamma_{r}}}{1+\alpha_{r}}\right)_{r}\right]
\end{aligned}
$$

Nestas equações, tem-se:

$a_{r}$ abundância relativa do r-ésimo ramo beta;

$\varepsilon_{\beta_{r}}$ eficiência para o r-ésimo ramo beta;

$\varepsilon_{e c}$ eficiência do detector beta para elétrons de conversão interna;

$\varepsilon_{\beta_{\gamma}}$ eficiência do detector beta para radiação gama;

$\alpha_{r}$ coeficiente de conversão interna total da r-ésima transição gama;

$\varepsilon_{\gamma_{r}}$ eficiência para a r-ésima transição gama;

$\varepsilon_{c_{r}}$ probabilidade de se registrar contagens de coincidência gama-gama.

Desta forma, a equação (2-16) passa a ser escrita como:

$$
\frac{N_{\beta} \cdot N_{\gamma}}{N_{c}}=N_{0} \cdot \frac{\sum_{r=1}^{n} a_{r}\left[\varepsilon_{\beta_{r}}+\left(1-\varepsilon_{\beta_{r}}\right) \cdot\left(\frac{\alpha \cdot \varepsilon_{e c}+\varepsilon_{\beta_{\gamma}}}{1+\alpha}\right)_{r}\right] \cdot \sum_{r=1}^{n} a_{r}\left[\frac{\varepsilon_{\gamma_{r}}}{1+\alpha_{r}}\right]}{\sum_{r=1}^{n} a_{r}\left[\varepsilon_{c_{r}} \cdot\left(1-\varepsilon_{\beta_{r}}\right)+\left(\frac{\varepsilon_{\beta_{r}}+\varepsilon_{\gamma_{r}}}{1+\alpha_{r}}\right)_{r}\right]}
$$




\subsubsection{Técnica da Extrapolação Linear}

Verifica-se que, pela equação (2-22), que para obtermos $N_{0}$ é necessário o conhecimento dos parâmetros do esquema de desintegração e das probabilidades de detecção. Para contornar esta dificuldade, utiliza-se a Técnica da Extrapolação da Eficiência $^{[6]}$.

De acordo com esta técnica, a determinação da taxa de desintegração de um radionuclídeo com esquema de desintegração complexo, sem o conhecimento prévio dos parâmetros do esquema de desintegração e das eficiências de detecção, só é possível se houver uma relação funcional entre a contagem no detector beta, $N_{\beta}$, e o parâmetro de eficiência beta, tal que $N_{\beta} \rightarrow N_{0}$ quando $\varepsilon_{\beta_{S}} \rightarrow 1$.

Esta condição pode ser estabelecida quando a eficiência dos vários ramos beta $\left(\varepsilon_{\beta_{r}}\right)$ puder ser representada como função de uma única eficiência $\left(\varepsilon_{\beta_{S}}\right)$ : $\varepsilon_{\beta_{r}}=f_{r}\left(\varepsilon_{\beta_{S}}\right)$. É necessário que esta relação se conserve para o caso em que $f_{\mathrm{r}}$ tender a 1 , quando uma das eficiências beta, $\varepsilon_{\beta_{S}}$, tender para a unidade $\left(f_{\mathrm{r}} \rightarrow 1\right.$ quando $\varepsilon_{\beta_{S}} \rightarrow 1$ para $\mathrm{r}=1,2, \ldots, \mathrm{n})$, e também as probabilidades $\varepsilon_{\gamma_{r}}, \varepsilon_{\beta_{\gamma_{r}}}, \varepsilon_{c_{r}}$ e $\varepsilon_{e c_{r}}$ sejam constantes no intervalo de variação da eficiência beta.

Portanto, $N_{\beta}$ resulta uma função $F$ do parâmetro de eficiência beta, tal que:

$$
\frac{N_{\beta} N_{\gamma}}{N_{c}}=N_{0} \cdot F\left(\frac{N_{c}}{N_{\gamma}}\right)
$$

Onde $F \rightarrow 1$ e $N_{\beta} \rightarrow N_{0}$ quando $\frac{N_{c}}{N_{\gamma}} \rightarrow 1$

A equação (2-23), também denominada fórmula de coincidência generalizada, pode ser colocada em uma forma mais conveniente, para solução gráfica 
ou analítica. Usando-se $\frac{N_{\beta} \cdot N_{\gamma}}{N_{c}}$ como variável dependente e $\left(1-\frac{N_{c}}{N_{\gamma}}\right) /\left(\frac{N_{c}}{N_{\gamma}}\right)$ como parâmetro variável, obtém-se uma função de eficiência, $G$, cuja variação é mais lenta do que a função $F$. Assim esta equação pode ser reescrita como:

$$
\frac{N_{\beta} \cdot N_{\gamma}}{N_{c}}=N_{0} \cdot G\left(\left(1-\frac{N_{c}}{N_{\gamma}}\right) /\left(\frac{N_{c}}{N_{\gamma}}\right)\right)
$$

Nesta equação, quando $G \rightarrow 1$, tem-se que $\frac{N_{\beta} \cdot N_{\gamma}}{N_{c}} \rightarrow N_{0}$, quando $\left(1-\frac{N_{c}}{N_{\gamma}}\right) /\left(\frac{N_{c}}{N_{\gamma}}\right) \rightarrow 1$.

Alguns fatores provocam variações na eficiência, tais como, uso de absorvedores externos, auto-absorção, discriminação eletrônica etc. Utilizando estes fatores pode-se determinar a taxa de desintegração $N_{0}$ por meio da extrapolação a partir do gráfico de $\frac{N_{\beta} \cdot N_{\gamma}}{N_{c}} \operatorname{por}\left(1-\frac{N_{c}}{N_{\gamma}}\right) /\left(\frac{N_{c}}{N_{\gamma}}\right)$, no limite quando $N_{c} / N_{\gamma}$ tender à unidade.

\subsection{Método de Monte Carlo}

A denominação Método de Monte Carlo (MMC) foi inspirada na cidade de Monte Carlo, onde se encontram os cassinos. Nesses locais são praticados jogos diversos, onde estão implícitos conceitos estocásticos, tais como: sorteio, aleatoriedade e a probabilidade de sucesso, que constituem a base de funcionamento do MMC.

No presente trabalho, o MMC é utilizado sob duas formas: numa primeira etapa, para simular o transporte da radiação emitida pela fonte radioativa desde a sua origem, até depositar a sua energia no detector de interesse, ser absorvida em outra parte do arranjo experimental ou escapar do sistema. Nesta etapa, as tabelas de resposta dos detectores foram obtidas em função da energia da radiação, tanto para elétrons como para fótons, conforme descrito nas secções seguintes. 
Em uma segunda etapa, o MMC foi utilizado para simular todo o processo de desintegração radioativa, incluindo os parâmetros do esquema de desintegração, possibilitando com isso a obtenção dos espectros de altura de pulso dos detectores utilizados e a curvas de extrapolação, aplicadas para a determinação da atividade da fonte radioativa.

\subsubsection{Transporte da Radiação pelo Método de Monte Carlo}

Há diversos códigos disponíveis na literatura para o transporte de radiação, utilizando o Método de Monte Carlo, tais como: MCNP ${ }^{[38]}, \operatorname{GEANT}^{[39]}, \operatorname{EGS}^{[40]}$, FLUKA $^{[41]}$ e PENELOPE ${ }^{[31]}$. O presente trabalho utilizou o código PENELOPE, por atender às necessidades do presente trabalho, pelo sucesso que tem obtido em diversas aplicações $^{[42-44]}$ e pela facilidade de obtenção deste código pelo IPEN. A seguir são apresentadas as características básicas deste código.

\subsubsection{Código PENELOPE}

\subsubsection{Processos de Interação}

A história de uma partícula é constituída por diversas interações (eventos) que são simuladas cronologicamente, cada uma delas com um caráter aleatório, de acordo com as probabilidades de interação. Desta forma, os resultados estão associados a uma incerteza estatística, podendo esta ser reduzida pelo aumento no número de histórias. Para o transporte de radiação, o MMC é estruturado como uma solução para a equação de Boltzmann ${ }^{[31]}$.

Em uma simulação é necessário descrever os materiais (i.e. densidade, estado físico, etc.) nos quais as moléculas sofrerão colisões pela radiação incidente. A composição química dos materiais envolvidos é determinada pelo número atômico $Z$ e o número de átomos por molécula. Para o caso de materiais compostos, é necessário que seja feito um ajuste de percentuais, considerando a quantidade proporcional de cada elemento. A descrição a seguir é baseada no manual do código PENELOPE ${ }^{[31]}$.

A massa molecular do material de interesse $A_{m}$, é dada por: 


$$
A_{m}=\sum n_{i} A_{i}
$$

na qual $A_{i}$ é o peso atômico do i-ésimo elemento. O número de moléculas por unidade de volume $(N)$, é dado por:

$$
N=N_{A} \frac{\rho}{A_{M}}
$$

em que $N_{A}$ corresponde ao Número de Avogadro e $\rho$ é a densidade do material.

Em cada interação, a partícula perde parte de sua energia $(W)$ e pode (ou não) mudar de direção. A deflexão angular é determinada pelo ângulo $\theta$ entre as direções da partícula, antes e depois da interação, e o ângulo azimutal $\phi$. O modelo de espalhamento é especificado de forma completa por meio da seção de choque diferencial (DCS):

$$
\frac{d^{2} \sigma}{d W d \Omega}(E ; W, \theta)
$$

em que $d \Omega$ é o ângulo sólido na direção $(\theta, \phi)$. Considerando que a molécula tem movimentos aleatórios no meio, a seção de choque diferencial fica independente do ângulo $\phi$, ou seja, distribuição angular do espalhamento da partícula é axialmente simétrica na direção de incidência. A secção de choque por molécula e dada por:

$$
\sigma(E)=\int_{0}^{E} d W \int_{0}^{\pi} 2 \pi \sin \theta d \theta \frac{d^{2} \sigma}{d W d \Omega}(E ; W, \theta)
$$

A função densidade de probabilidade (PDF) da energia perdida e ângulo de espalhamento é definida como:

$$
\rho(E ; W, \theta)=\frac{2 \pi \sin \theta}{\sigma(E)} \frac{d^{2} \sigma}{d W d \Omega}(E ; W, \theta)
$$

A trajetória que cada partícula descreve inicia-se no local onde foram descritas as características da fonte (i.e. energia, direção inicial, etc.). A situação da partícula imediatamente após uma interação é definida pelas coordenadas de posições $r=(x, y$, 
z), pela energia $(E)$ e pela direção de vôo $(\theta)$, ou seja, pelos componentes do vetor unitário $\hat{d}=(u, v, w)$. Cada trajetória simulada é então caracterizada por uma série de estado de $r_{n} E_{n}$ e $\hat{d}_{n}$, na qual $r_{n}$ é a posição da n-ésima do evento de espalhamento e $E_{n}$ e $\hat{d}_{n}$ são a energia e a direção do movimento logo após o evento.

Na geração de trajetórias aleatórias, o caminho-livre-médio entre colisões é dado por:

$$
s=-\lambda_{T} \ln \xi
$$

em que $\lambda_{T}$ é o trecho livre no meio entre duas interações e $\xi$ é um número aleatório uniformemente distribuído no intervalo $] 0,1[$.

A próxima interação ocorrerá na posição:

$$
r_{n+1}=r_{n}+s \hat{d}_{n}
$$

A Figura 2-3 mostra as deflexões angulares em uma colisão simples. A energia da partícula, para a próxima colisão, é reduzida para:

$$
E_{n+1}=E_{n}-W
$$

A direção do movimento, após a colisão, é dada por $\hat{d}_{n+1}=\left(u^{\prime}, v^{\prime}, w^{\prime}\right)$ e é obtida pela rotação $\hat{d}_{n}=(u, v, w)$. 


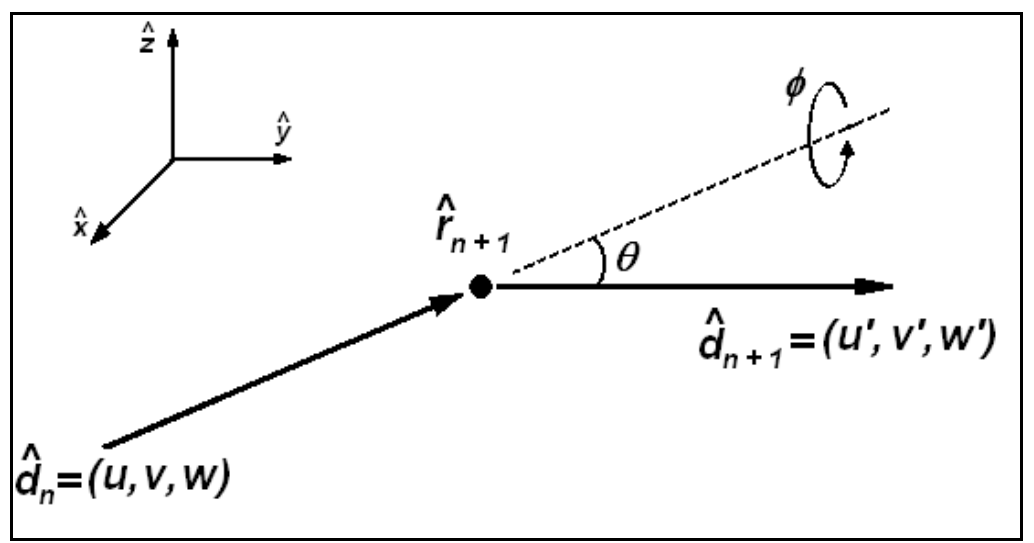

Figura 2-3: Deflexão angular numa colisão simples.

A matriz de rotação é determinada pelos ângulos de espalhamento polar e azimutal. A direção do vetor $\hat{d}_{n+1}=\left(u^{\prime}, v^{\prime}, w^{\prime}\right)$, após a interação, é dada (ao longo do eixo $\mathrm{x}$ ) por:

$$
\left(\begin{array}{c}
\sin \theta \cos \phi \\
\sin \theta \sin \phi \\
\cos \theta
\end{array}\right)=R_{z}(\phi) R_{y}(\theta) \hat{z}
$$

em que $\hat{z}=(0,0,1)$ e

$$
R_{y}(\theta)=\left(\begin{array}{ccc}
\cos \theta & 0 & \sin \theta \\
0 & 1 & 0 \\
-\sin \theta & 0 & \cos \theta
\end{array}\right) \text { e } R_{z}(\phi)=\left(\begin{array}{ccc}
\cos \phi & -\sin \phi & 0 \\
\sin \phi & \cos \phi & 0 \\
0 & 0 & 1
\end{array}\right)
$$

são as matrizes de rotação, correspondentes aos ângulos $\theta$ e $\phi$, sobre os eixos y e z respectivamente.

\subsubsection{Geometria Quádrica}

A simulação do transporte de radiação em sistemas materiais envolve dois tipos de operações diferentes, uma denominada física, em que se descrevem as condições físicas do material, e outra denominada geométrica, em que são feitas as descrições do espaço e interfaces envolvidos. 
Um sistema material é composto de um número de corpos homogêneos, com superfícies limitadas e bem definidas. O caminho que a partícula descreve dentro do sistema material é ditado por rotinas de simulação, que operam como se as partículas estivessem se movendo num meio infinito com composição definida. Normalmente, as rotinas que operam na parte física são preparadas para muitos tipos de materiais. As rotinas que operam a parte geométrica são preparadas para proceder a simulação do movimento da partícula várias vezes, constituindo assim as histórias da simulação, no material escolhido pela rotina física.

A definição de várias partes do sistema material envolve rotações e translações. Num sistema de coordenadas cartesianas onde o ponto de referência é a origem dos eixos e os vetores unitários são $\hat{x}=(1,0,0), \hat{y}=(0,1,0)$ e $\hat{z}=(0,0,1)$, a translação $\tau(t)$, é definida pelo vetor deslocamento $t=\left(t_{x}, t_{y}, t_{z}\right)$, que transforma $\mathrm{o}$ vetor $r=(x, y, z)$ em

$$
\tau(t) r=r+t=\left(x+t_{x}, y+t_{y}, z+t_{z}\right)
$$

O inverso da translação $\tau^{-1}(t)$ corresponde ao deslocamento do vetor $-t$, ou seja, $\tau^{-1}(t)=\tau(-t)$.

A rotação $R(\omega, \theta, \phi)$ é definida pelos ângulos $\omega$ (para o eixo x), $\theta$ (para o eixo y) e $\phi$ (para o eixo z). Esta rotação transforma o vetor $r=(x, y, z)$ para o vetor:

$$
r^{\prime}=R(\omega, \theta, \phi) r=\left(x^{\prime}, y^{\prime}, z^{\prime}\right)
$$

em que as coordenadas são dadas por:

$$
\left(\begin{array}{l}
x^{\prime} \\
y^{\prime} \\
z^{\prime}
\end{array}\right)=R(\omega, \theta, \phi)\left(\begin{array}{l}
x \\
y \\
z
\end{array}\right)
$$

em que 


$$
R(\omega, \theta, \phi)=\left(\begin{array}{lll}
R_{x x} & R_{x y} & R_{x z} \\
R_{y x} & R_{y y} & R_{y z} \\
R_{z x} & R_{z y} & R_{z z}
\end{array}\right)
$$

é a matriz de rotação. Para se obter uma forma explicita, atribui-se as matrizes de rotação nos eixos z e y, obtêm-se:

$R(\omega, \theta, \phi)=\left(\begin{array}{ccc}\cos \phi \cos \theta \cos \omega-\sin \phi \sin \omega & -\cos \phi \cos \theta \sin \omega-\sin \phi \sin \omega & \cos \phi \sin \theta \\ \sin \phi \cos \theta \cos \omega+\cos \phi \sin \omega & -\sin \phi \cos \theta \sin \omega+\cos \phi \cos \omega & \sin \phi \sin \theta \\ -\sin \theta \cos \omega & \sin \theta \cos \omega & \cos \theta\end{array}\right)$

Considera-se uma transformação $C=T(t) R(\omega, \theta, \phi)$ que produz uma rotação $R(\omega, \theta, \phi)$ e uma translação $T(t)$. Esta transformação converte o ponto $r$ em

$$
r^{\prime}=C(r)=T(t) R(\omega, \theta, \phi) r
$$

Como já mencionado, o sistema de materiais é constituído por um número de corpos homogêneos, definido por suas composições e limites de superfície. Os limites de superfície são descritas por equações quádricas dada por:

$$
F(x, y, z)=A_{x x} x^{2}+A_{y y} y^{2}+A_{z z} z^{2}+A_{x y} x y+A_{x z} x z+A_{y z} y z+A_{x} x+A_{y} y+A_{z} z+A_{0}=0
$$

Esta equação inclui planos, pares de planos, esferas, cilindros, cones, elipsóides, parabolóides, hiperbolóides, etc. Cada superfície quádrica pode ser especificada tanto pela equação implícita, como pela sua forma reduzida, a qual define a forma de uma superfície (Figura 2-4).

A equação quádrica reduzida é dada por:

$$
F_{r}(x, y, z)=I_{1} x^{2}+I_{2} y^{2}+I_{3} z^{2}+I_{4} z+I_{5}=0
$$


em que os coeficientes $I_{1}$ até $I_{5}$ pode somente assumir valores -1, 0 ou 1. Esta forma reduzida tem centro de simetria sobre o eixo $z$, i.e. $F_{r}(-x,-y, z)=F_{r}(x, y, z)$.

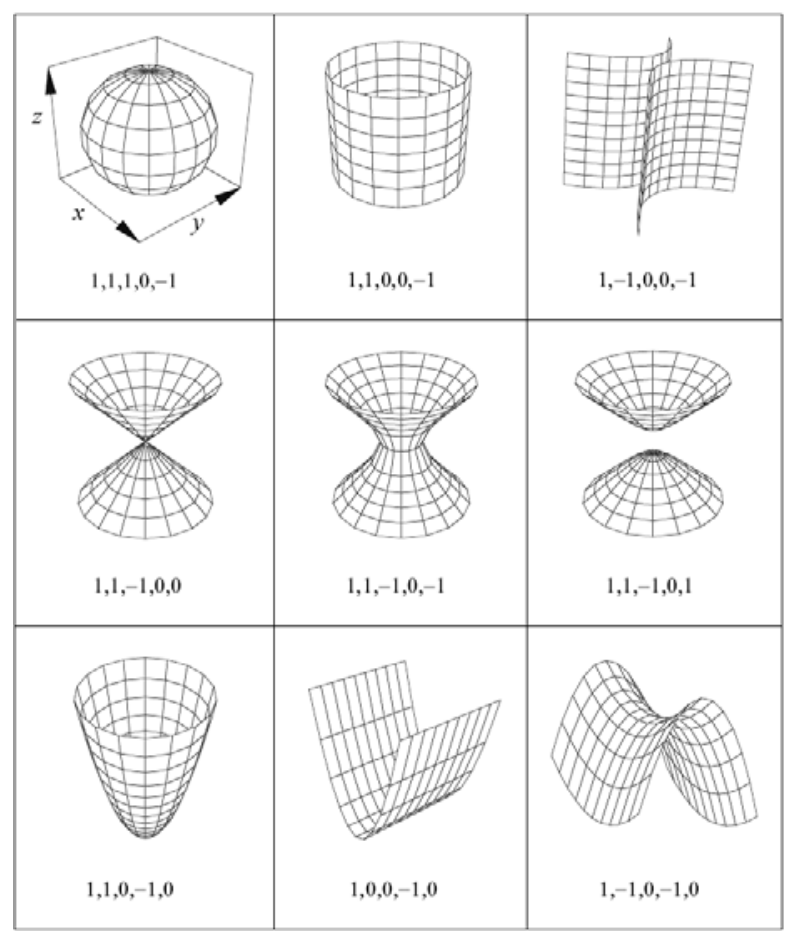

Figura 2-4: Superfícies quádricas não planares e seus índices ${ }^{[31]}$.

Uma equação quádrica generalizada pode ser obtida da forma reduzida aplicando as transformações seguintes:

i. Uma expansão ao longo dos eixos:

$\mathrm{X}-\mathrm{SCALE}=a, \mathrm{Y}-\mathrm{SCALE}=b$ e Z-SCALE $=c$ é dada por:

$$
F_{s}(x, y, z)=I_{1}\left(\frac{x}{a}\right)^{2}+I_{2}\left(\frac{y}{b}\right)^{2}+I_{3}\left(\frac{z}{c}\right)^{2}+I_{4} \frac{z}{c}+I_{5}=0
$$

ii. A rotação, $R(\omega, \theta, \phi)$, é definidas pelos ângulos:

$$
\mathrm{OMEGA}=\omega, \mathrm{THETA}=\theta \text { e } \mathrm{PHI}=\phi .
$$

iii. Uma translação é definida pelos componentes de deslocamento do vetor $t$ :

$$
\left(\mathrm{X}-\mathrm{SHIFT}=t_{x}, \mathrm{Y}-\mathrm{SHIFT}=t_{y}, \mathrm{Z}-\mathrm{SHIFT}=t_{z}\right)
$$


Uma superfície quádrica $F(x, y, z)=0$ divide o espaço entre duas regiões identificadas pelo sinal de $F(x, y, z)$, ou seja, o ponteiro lateral de superfície. Um ponto com coordenadas $\left(x_{0}, y_{0}, z_{0}\right)$ é dito dentro da superfície, se $F\left(x_{0}, y_{0}, z_{0}\right) \leq 0$ (ponteiro lateral -1), e fora da superfície, se $F\left(x_{0}, y_{0}, z_{0}\right)>0$ (ponteiro lateral +1$)$.

A geometria pode ser definida diretamente no programa principal, ou com auxílio do pacote geométrico PENGEOM. As rotinas do programa PENELOPE simulam trajetórias de partículas no interior de uma grande variedade de materiais. Para simular a trajetória é necessário um modelo de interação, que é definido pela seção de choque de interação correspondente ao processo físico envolvido.

Um corpo é definido como um espaço volumétrico limitado por superfícies quádricas e preenchido por um material homogêneo. Para especificar um corpo é necessário definir os limites das superfícies quádricas com seus respectivos ponteiros laterais. O pacote geométrico PENGEOM contém uma sub-rotina chamada LOCATE onde se descreve um ponto $r$, ou seja, um corpo que o contém. É necessário, então descrever os ponteiros laterais e só então descrever os corpos em ordem ascendente do primeiro ao último ponteiro lateral descrito. Uma segunda sub-rotina chamada STEP movimenta a partícula simulada da posição $r_{0}$ para um corpo $B$ a uma distância $s$ numa direção $d$. A razão para se utilizar somente superfícies quádricas é que suas intersecções são fáceis de calcular, bastando resolver as respectivas equações quádricas.

\subsubsection{Estrutura do código PENELOPE}

O código PENELOPE apresenta a estrutura esquematizada na Figura 2-5 e seu conteúdo está disposto da seguinte forma:

- Subdiretório FSOURCE com os arquivos:

> MANUAL.TXT : Manual simplificado.

$>$ PENELOPE.F : Sub-rotinas de simulação.

$>$ PENGEOM.F : Sub-rotinas geométricas.

$>$ PENVARED.F : Sub-rotinas para redução variacional.

$>$ MATERIAL.F : Gerador do arquivo de materiais.

$>$ TABLES.F : Gerador das tabelas de interação de partículas. 


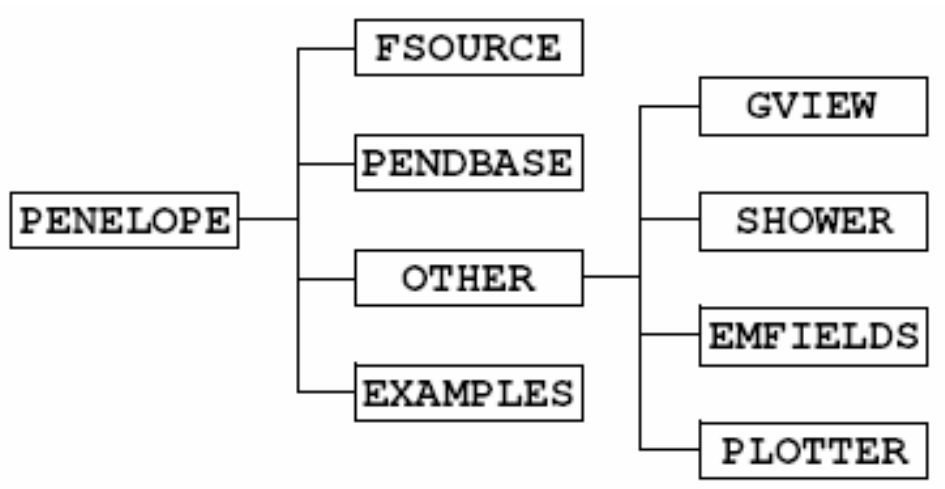

Figura 2-5: Diretório com a estrutura de arquivos do PENELOPE.

- Subdiretório EXAMPLES com os arquivos:

$>$ PENSLAB.F : Programa para o transporte de partículas num bloco.

$>$ PENSLAB.IN : Exemplo de arquivo de entrada do PENSLAB.

$>$ AL.MAT : Arquivo de materiais para o PENSLAB.

$>$ PENCYL.F : Programa para geometrias cilíndricas.

$>$ PENCYL.IN : Exemplo de arquivo de entrada do PENCYL.

$>$ PENDOSES.F : Programa para geometrias quadráticas.

$>$ PENDOSES.IN : Exemplo de arquivo de entrada do PENDOSES.

$>$ PENDOSES.GEO : Definição da geometria para o PENDOSES.

> NAIAL.MAT : Arquivo de materiais para o PENCYL e PENDOSES.

$>$ TIMER.F e NOTIMER.F : Sub-rotina para mostrar o tempo de execução.

- Subdiretório PENDBASE : Base de dados de materiais do PENELOPE.

- Subdiretório OTHER. Contém os subdiretórios:

> GVIEW : Contém os programas de visualização GVIEW2D, GVIEW3D e GVIEWC.

EMFIELDS : Programa simulador do transporte de elétrons e pósitrons.

SHOWER : Gerador de trajetórias de elétrons e fótons.

PLOTTER : Os programas PENSLAB E PENCYL geram vários arquivos com funções densidade de probabilidade simuladas. Cada arquivo contém um cabeçalho descrevendo seu conteúdo, o qual está em um formato para visualização gráfica. Este diretório contém scripts que para visualização gráfica das funções simuladas. 
A simulação feita pelo PENELOPE cria virtualmente feixes de elétrons e fótons, que são réplicas dos reais. As trajetórias dos elétrons/fótons são repetidas de maneira a contabilizar a quantidade de histórias a serem simuladas. Partículas secundárias emitidas são armazenadas e simuladas após o término da simulação do caminho da partícula inicial. Partículas secundárias são produzidas em interações diretas (colisões inelásticas, Bremsstrahlung, aniquilação de pares, Compton, absorção fotoelétrica e produção de pares) ou como radiação fluorescente (raios-X característicos e elétrons Auger). O PENELOPE simula radiação fluorescente que resulta de vacâncias produzidas nas camadas $\mathrm{K}$ e subcamadas L por absorção fotoelétrica, espalhamento Compton de fótons e por impacto de elétrons ou pósitrons. As vacâncias são acompanhadas até que as camadas K e L sejam totalmente preenchidas.

Sendo o PENELOPE um conjunto de sub-rotinas, é necessário efetuar alterações no programa principal (MAIN), para que este coordene a simulação. Este programa controla as histórias e respectivas evoluções da simulação efetuada pelo PENELOPE e as armazena. Para arranjos com geometrias arbitrárias, inclusive quádricas, as alterações devem ser introduzidas no programa PENGEOM.

A estrutura de arquivos necessária para a simulação usando o PENELOPE está apresentada na Figura 2-6. O programa MAIN necessita das informações de entrada contidas nos arquivos entrada.in, geometria.geo e material.mat e por sua vez será criado o arquivo saída.dat, com as informações da simulação.

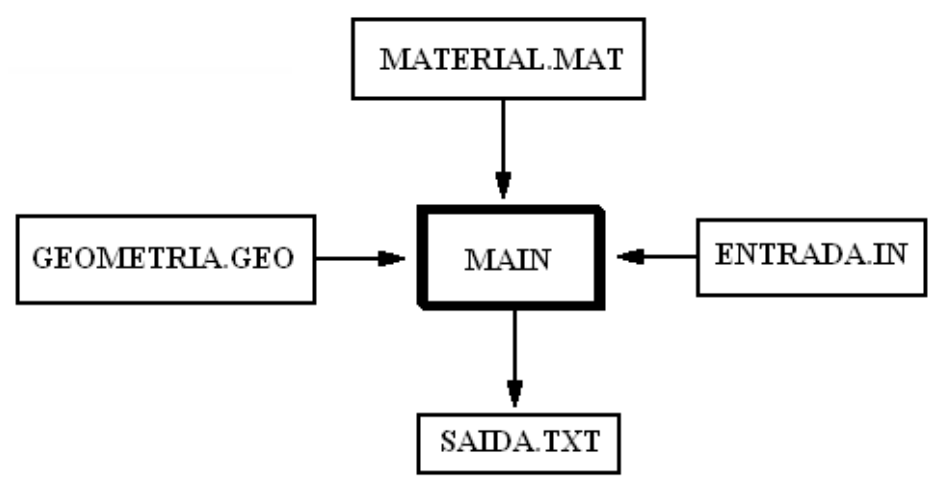

Figura 2-6: Estrutura de arquivos para simulação com o PENELOPE. 


\subsubsection{Arquivo de dados dos materiais}

O programa MATERIAL extrai os dados das interações da base de dados PDCOMPOS.TAB, compondo assim o conjunto de informações necessárias para a simulação desejada. Estas informações podem ser fornecidas pelo usuário, porém, no presente trabalho, estas informações foram extraídas da base de dados contida no sistema PENELOPE .

Para compostos e misturas é usada uma aproximação aditiva, onde a seção de choque "molecular" é a soma das seções de choque atômicas balanceadas pelo índice estequiométrico dos elementos. Ligas e misturas são tratadas como compostos, com índices estequiométricos iguais ou proporcionais à concentração percentual de átomos de cada elemento.

\subsubsection{Estrutura do programa MAIN}

O programa MAIN controla a evolução dos eventos simulados, armazena as quantidades de interesse e calcula valores médios ao final da simulação. A ligação do programa MAIN é feita por meio da estrutura common block:

- COMMON/TRACK/E,X,Y,Z,U,V,W,WGHT,KPAR,IBODY,MAT,ILB(5), que contém as seguintes variáveis de estado:

$>$ KPAR : Tipo de partícula (1: elétron, 2: fóton, 3: pósitron);

$>\mathrm{E}$ : Energia da partícula (cinética para elétrons e pósitrons) (eV);

X, Y, Z : Coordenadas de posição $(\mathrm{cm})$;

$>\mathrm{U}, \mathrm{V}, \mathrm{W}$ : cossenos direcionais do movimento;

$>$ WGHT : Armazena o peso associado à partícula quando se usa redução variacional;

IBODY : Identifica diferentes corpos em materiais com estruturas complexas;

$>$ MAT : Material onde a partícula se move (no corpo identificado com IBODY).

$>\operatorname{ILB}(5)$ : Vetor auxiliar com 5 índices que indicam a origem da partícula quando esta é secundária. É importante na consideração de contribuições parciais de partículas para um dado processo; 
Quando uma partícula se move no material M, é considerada absorvida quando sua energia torna-se menor que o valor $\operatorname{EABS}(\mathrm{KPAR}, \mathrm{M})$ especificado pelo usuário. A lógica para transporte para elétrons/pósitrons em cada material $\mathrm{M}$ é controlado pelos seguintes parâmetros:

> C1(M) : Deflexão angular média produzida por espalhamento elástico múltiplo, ao longo de um percurso igual ao livre caminho médio entre colisões elásticas consecutivos.

D $\mathrm{C} 2(\mathrm{M})$ : Perda média de energia entre eventos elásticos consecutivos.

$>$ WCC : Energia de corte para colisões inelásticas $(\mathrm{eV})$.

WCR(M) : Energia de corte para Bremsstrahlung ( eV).

Estes parâmetros determinam a velocidade e exatidão da simulação. Para garantir uma boa exatidão, os valores de $\mathrm{C} 1(\mathrm{M})$ e $\mathrm{C} 2(\mathrm{M})$ devem ser pequenos. Com valores maiores destas variáveis, a simulação fica mais rápida, porém com exatidão comprometida. As energias de corte $\mathrm{WCC}(\mathrm{M})$ e $\mathrm{WCR}(\mathrm{M})$ influenciam principalmente a distribuição de energia simulada. A simulação fica mais rápida, com valores maiores das energias de corte. No presente trabalho as energias de corte foram analisadas de modo que não houvesse distorções nas simulações.

O programa MAIN é iniciado com o comando:

\section{CALL PEINIT(EPMAX,NMAT,IRD,IWR,INFO)}

A sob-rotina PEINIT avalia as propriedades de espalhamento relevantes e prepara tabelas de energia que são usadas durante a simulação. Os parâmetros de entrada são:

$>$ EPMAX : Energia máxima das partículas;

$>$ NMAT : Número de materiais;

$>$ IRD : Arquivo de entrada;

$>$ IWR : Arquivo de saída

$>$ INFO : Determina a quantidade de informações que serão gravadas no arquivo de saída.

As energias de absorção, EABS(KPAR,M), e dos parâmetros de simulação, C1(M), C2(M), WCC(M) e WCR(M), podem ser necessárias para a sub-rotina PEINIT, 
dependendo da importância que se quer dar à simulação, e isto também interfere na sua velocidade e exatidão. Estas informações podem ser introduzidas através da estrutura:

\section{COMMON/CSIMPA/EABS(3,MAXMAT),C1(MAXMAT), C2(MAXMAT),WCC(MAXMAT),WCR(MAXMAT)}

O PENELOPE é estruturado de tal maneira que a trajetória de uma partícula é gerada como uma seqüência de segmentos. No final de cada segmento, a partícula sofre uma interação com o meio, onde ela perde energia, muda sua direção de movimento e em certos casos produz partículas secundárias. Feixes de elétrons/fótons são simulados por meio de chamadas sucessivas das seguintes sub-rotinas:

CLEANS(DSMAX,DS) : Limpa a pilha de execução secundário;

> START : Inicia os parâmetros da partícula;

$>$ JUMP(DSMAX,DS) : Determina o comprimento do segmento de caminho até a próxima interação;

$>$ KNOCK(DE,ICOL) : Simula um evento de interação, calcula a nova energia e direção do movimento, e guarda o estado inicial para a geração das partículas secundárias. Seus parâmetros de saída são:

o DE : energia depositada do evento em curso.

o ICOL : Tipo de evento que foi simulado, de acordo com a seguinte convenção:

- Elétrons $(\mathrm{KPAR}=1)$

- $\mathrm{ICOL}=1$, primeira interação;

- $\mathrm{ICOL}=2$, colisão elástica;

- $\mathrm{ICOL}=3$, colisão inelástica;

- $\mathrm{ICOL}=4$, emissão de Bremsstrahlung.

- Fótons $(\mathrm{KPAR}=2)$

- $\mathrm{ICOL}=1$, espalhamento coerente (Rayleigh);

- $\mathrm{ICOL}=2$, espalhamento incoerente (Compton);

- $\mathrm{ICOL}=3$, absorção fotoelétrica;

- $\mathrm{ICOL}=4$, produção de pares. 
- Pósitrons (KPAR=3)

- $\mathrm{ICOL}=1$, primeira interação;

- $\mathrm{ICOL}=2$, colisão elástica;

- $\mathrm{ICOL}=3$, colisão inelástica;

- $\mathrm{ICOL}=4$, emissão Bremsstrahlung;

- $\mathrm{ICOL}=5$, aniquilação.

SECPAR(LEFT): Ajusta o estado inicial da partícula secundária e a remove da pilha secundária. $\mathrm{O}$ valor de saída LEFT é o número de partículas secundárias que permanecem.

STORES(E,X,Y,Z,U,V,W,WGHT,KPAR,ILB): Armazena a partícula na pilha secundária.

A seqüência de chamadas para gerar uma trajetória é independente do tipo de partícula que está sendo simulada. A simulação acontece da seguinte forma:

$>$ Ajusta-se o estado inicial da partícula assumindo valores às variáveis de estado KPAR, E, posição e direção. Especifica-se o corpo e o material onde a partícula se move através dos valores de IBODY e MAT, respectivamente. Opcionalmente, pode-se também definir os valores de WGHT e ILB.

$>$ Executa rotina CLEANS.

$>$ Executa rotina START.

$>$ Executa rotina JUMP(DSMAX,DS) para determinar o comprimento DS do próximo segmento de caminho.

$>$ Calcula a posição dos eventos seguintes:

o Se a trajetória atravessar uma interface, pára-se a partícula onde a trajetória encontra a interface e diminui-se apropriadamente o comprimento DS. Muda-se para o novo material redefinindo as variáveis IBODY e MAT. Quando a partícula escapa do sistema, a simulação do caminho termina;

$>$ Executa a rotina $\mathrm{KNOCK}(\mathrm{DE}, \mathrm{ICOL})$ para simular os eventos seguintes:

o Se a energia for menor que EABS(KPAR,MAT), finaliza-se o caminho. 
Executa SECPAR(LEFT) para começar a simulação da trajetória de uma partícula na pilha secundária (esta partícula é automaticamente removida da pilha).

Nota-se que as sub-rotinas JUMP e KNOCK não alteram as coordenadas das partículas.

\subsubsection{Estrutura do programa PENCYL}

O programa PENCYL simula o transporte de elétrons e fótons em estruturas cilíndricas. A geometria descrita deve consistir de camadas formadas por anéis concêntricos. $\mathrm{O}$ centro dos anéis em cada camada é especificado pelas coordenadas $\mathrm{x}$ e y. O arquivo fonte PENCYL.F inclui um conjunto de geometrias compostas por camadas cilíndricas que podem ser visualizadas com o programa GVIEWC.

As informações fornecidas por este programa são: detalhes do transporte da radiação, energia depositada, distribuição angular, energias das partículas emergentes, distribuição em dose etc.

No presente trabalho a geometria original ${ }^{[29]}$, por ser estritamente cilíndrica, foi descrita para ser simulada neste programa. Segue aqui uma parte do arquivo e suas definições da geometria:

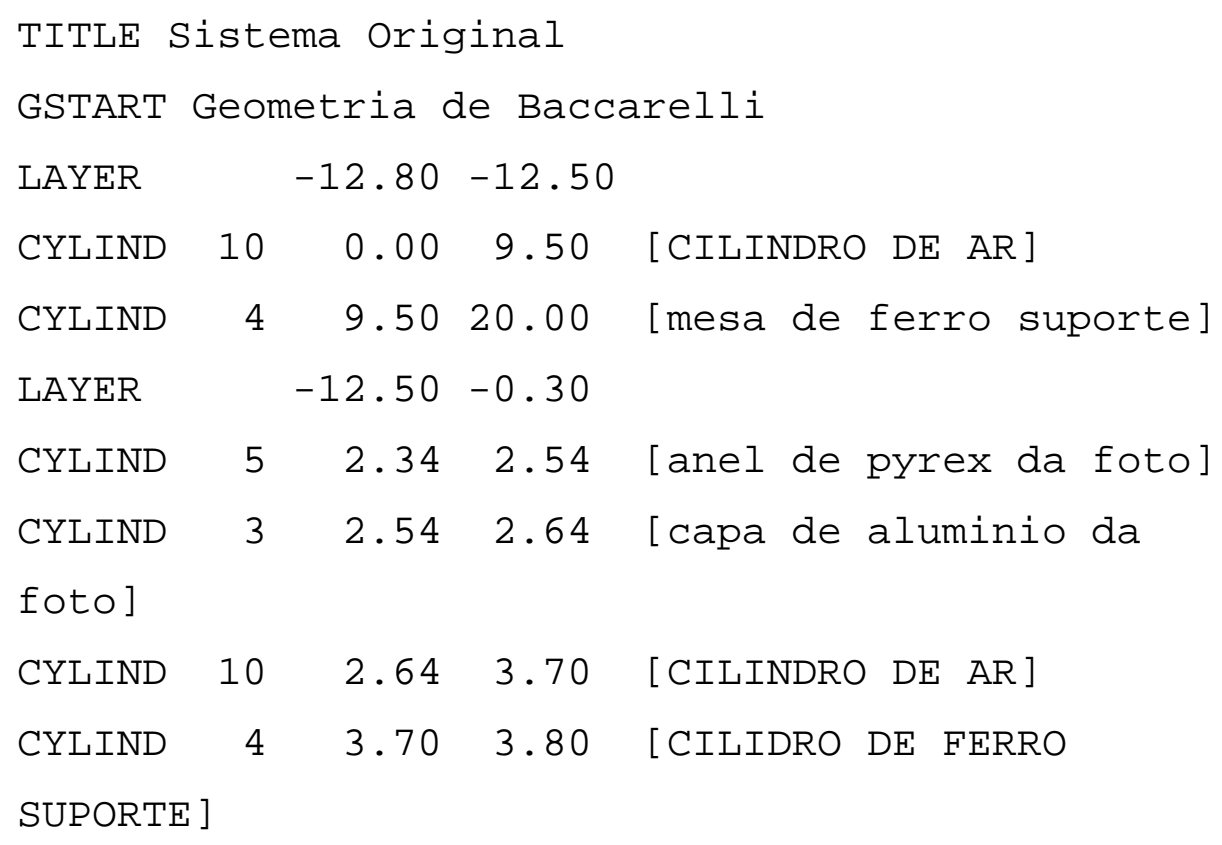




\section{CYLIND $10 \quad 3.80 \quad 9.50 \quad$ [CILINDRO DE AR] \\ $\begin{array}{lllll}\text { CYLIND } & 7 & 9.50 & 19.50 & \text { [BLINDAGEM DE CHUMBO] }\end{array}$}

TITLE - Inicio do arquivo;

GSTART - começo da lista de definição da geometria;

LAYER - espessura da camada (neste caso são 0,3 cm);

CYLIND - descrição do cilindro, cujo material é o de número 10 no arquivo de materiais e possui um raio interno nulo e outro, externo, de $9,5 \mathrm{~cm}$.

Ao lado de cada linha, procurou-se colocar uma breve descrição do parâmetro. Segue aqui uma parte do arquivo e as definições de interação na geometria anteriormente descrita:

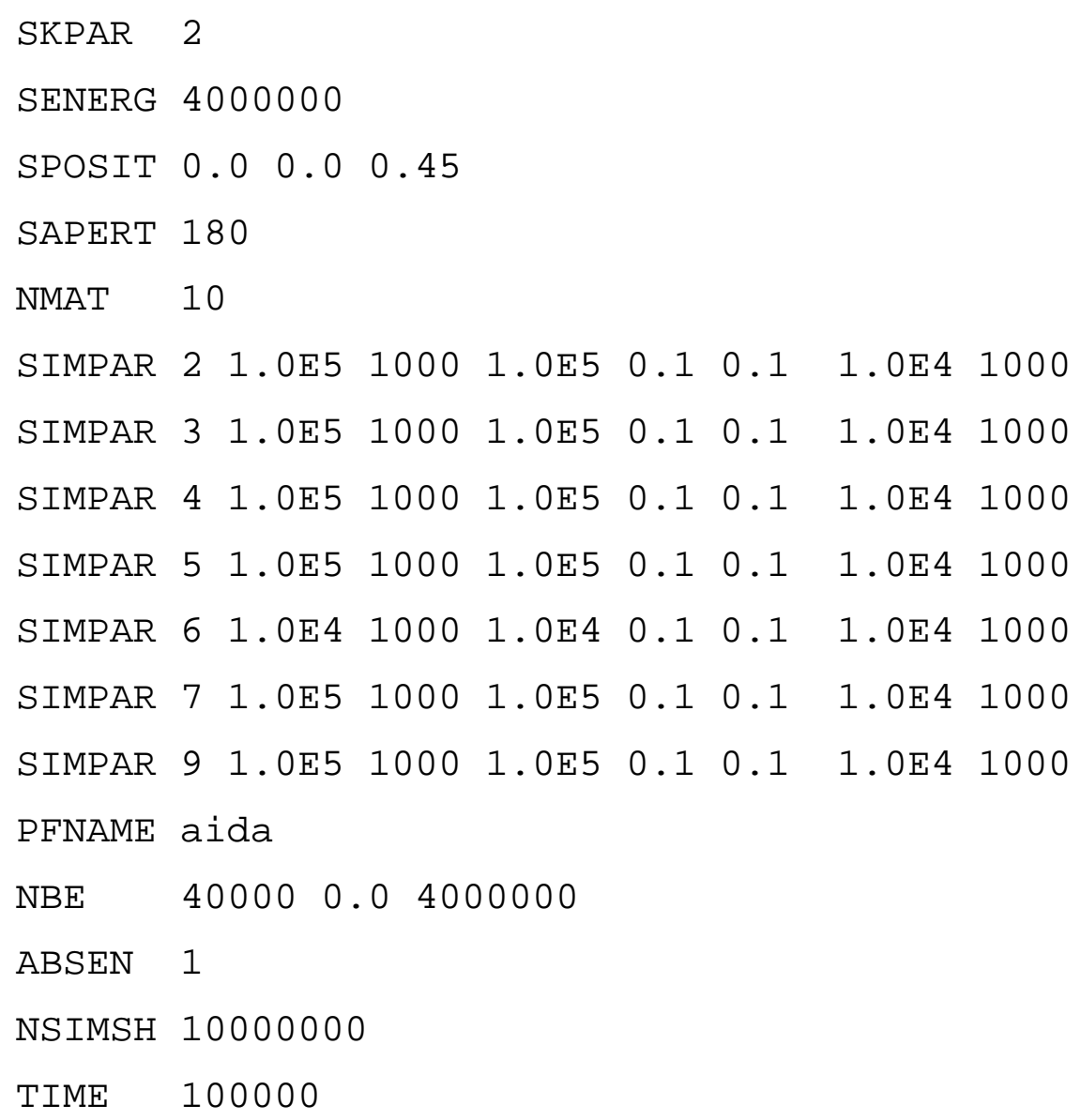

SKPAR - indica o tipo de radiação;

SENERG - energia inicial da radiação;

SPOSIT - coordenadas de posição $x, y$ e $z$ da fonte radioativa;

SAPERT - abertura, em graus, do cone do feixe de radiação; 
NMAT - número de materiais envolvidos na simulação;

SIMPAR - parâmetros para o material (i.e. energia de corte);

PFNAME - nome do arquivo que contém as informações de materiais;

$\mathrm{NBE}$ - número de canais para o feixe de energia;

ABSEN - define qual material deve ser feito o registro do depósito de energia;

NSIMSH - número de histórias (repetições).

\subsubsection{Estrutura do programa PENDOSES}

O novo arranjo experimental, desenvolvido no presente trabalho, não tem simetria cilíndrica, por esta razão foi utilizado o programa PENDOSES como parte do sistema PENELOPE. Este é um programa de simulação para geometrias complexas, formadas por superfícies quádricas. Considera-se uma fonte puntiforme de partículas primárias, na posição $(\mathrm{X} 0, \mathrm{Y} 0, \mathrm{Z} 0)$ e que emite partículas em direções uniformemente distribuídas em um cone com (semi)abertura SALPHA e eixo central na direção (STHETA,SPHI), ou seja, a mesma distribuição de direções do programa PENCYL. A geometria do sistema é descrita através do programa PENGEOM.

O programa PENDOSES calcula a energia total depositada em cada corpo por partícula primária. Para que forneça a distribuição de probabilidade da energia depositada em corpos selecionados ou grupo de corpos são necessárias algumas modificações.

\subsection{Comparação entre Teoria e Experimento}

As atividades das fontes foram determinadas de duas maneiras distintas. $\mathrm{Na}$ primeira, um ajuste de um polinômio de primeiro grau foi aplicado entre $N_{\beta} N_{\gamma} / N_{c}$ e o parâmetro $\left(1-\frac{N_{c}}{N_{\gamma}}\right) /\left(\frac{N_{c}}{N_{\gamma}}\right)$. O valor extrapolado para eficiência unitária $\frac{N_{c}}{N_{\gamma}} \rightarrow 1$ fornece o valor da atividade. 
No segundo caso, foi efetuado um ajuste por mínimos quadrados entre os dados experimentais e o cálculo de Monte Carlo, minimizando o valor do Qui-Quadrado $\left(\chi^{2}\right)$, dado pela seguinte equação:

$$
\chi^{2}=\left(\vec{y}_{\exp }-N_{0} \vec{y}_{M C}\right)^{T} V^{-1}\left(\vec{y}_{\exp }-N_{0} \vec{y}_{M C}\right)
$$

nesta equação,

$\vec{y}_{\exp }$

é o vetor experimental de $N_{\beta} N_{\gamma} / N_{c}$;

$\vec{y}_{M C} \quad$ é o vetor de $N_{\beta} N_{\gamma} / N_{c}$ calculado por Monte Carlo para atividade unitária;

$N_{0} \quad$ é a atividade específica da solução radioativa;

$V \quad$ é a matriz de covariância total, incluindo incertezas experimentais e as obtidas no cálculo por Monte Carlo;

T $\quad$ significa matriz transposta.

Uma série de valores de $\vec{y}_{M C}$ foram calculados por Monte Carlo para uma faixa grande de eficiências em intervalos pequenos. Os valores de $\vec{y}_{M C}$ usados na equação (2-44) correspondem a mesma eficiência beta obtida experimentalmente. Por meio deste ajuste, é possível obter a atividade $N_{0}$ da amostra radioativa. 


\section{PARTE EXPERIMENTAL}

\subsection{Radionuclídeos utilizados nos experimentos}

A parte experimental consistiu em diversos tipos de medidas. Inicialmente, efetuaram-se medidas comparativas entre os espectros do detector $4 \pi$ obtidos com uma e com duas fotomultiplicadoras. Para isto, utilizou-se uma fonte de ${ }^{241} \mathrm{Am}$. Em seguida, determinou-se a resolução do detector $4 \pi(\mathrm{PS})$ em função da energia, por meio do alargamento nos degraus Compton, obtidos utilizando radionuclídeos emissores gama com diferentes energias. Neste caso, foram medidos os radionuclídeos ${ }^{241} \mathrm{Am},{ }^{137} \mathrm{Cs} \mathrm{e}$ ${ }^{60} \mathrm{Co}$. Por fim, foram feitas medidas com o objetivo de determinar a atividade dos radionuclídeos ${ }^{60} \mathrm{Co} \mathrm{e}^{182} \mathrm{Ta}$.

As características destes radionuclídeos estão descritas nas seções seguintes.

\subsection{1 ${ }^{241}$ Am}

O radionuclídeo ${ }^{241} \mathrm{Am}$ se desintegra por emissão alfa, com uma meia-vida de $432,6(6)$ a , principalmente para o nível de $59,54 \mathrm{keV}$ do ${ }^{237} \mathrm{~Np}$, conforme mostra a Figura $3-1^{[45]}$. A energia da partícula alfa com maior intensidade é de 5578,27 keV, com probabilidade de emissão por desintegração de $0,8445(10)$. A detecção desta partícula alfa foi utilizada para comparar a forma dos espectros do detector $4 \pi$, correspondentes a uma e duas fotomultiplicadoras.

A transição gama mais intensa é a de $59,54 \mathrm{keV}$, com probabilidade de emissão gama por desintegração igual a 0,3578(9). Este gama foi utilizado para a determinação experimental da resolução do detector plástico com geometria $4 \pi$. Neste caso, a energia correspondente ao degrau Compton é de 11,25 keV. 


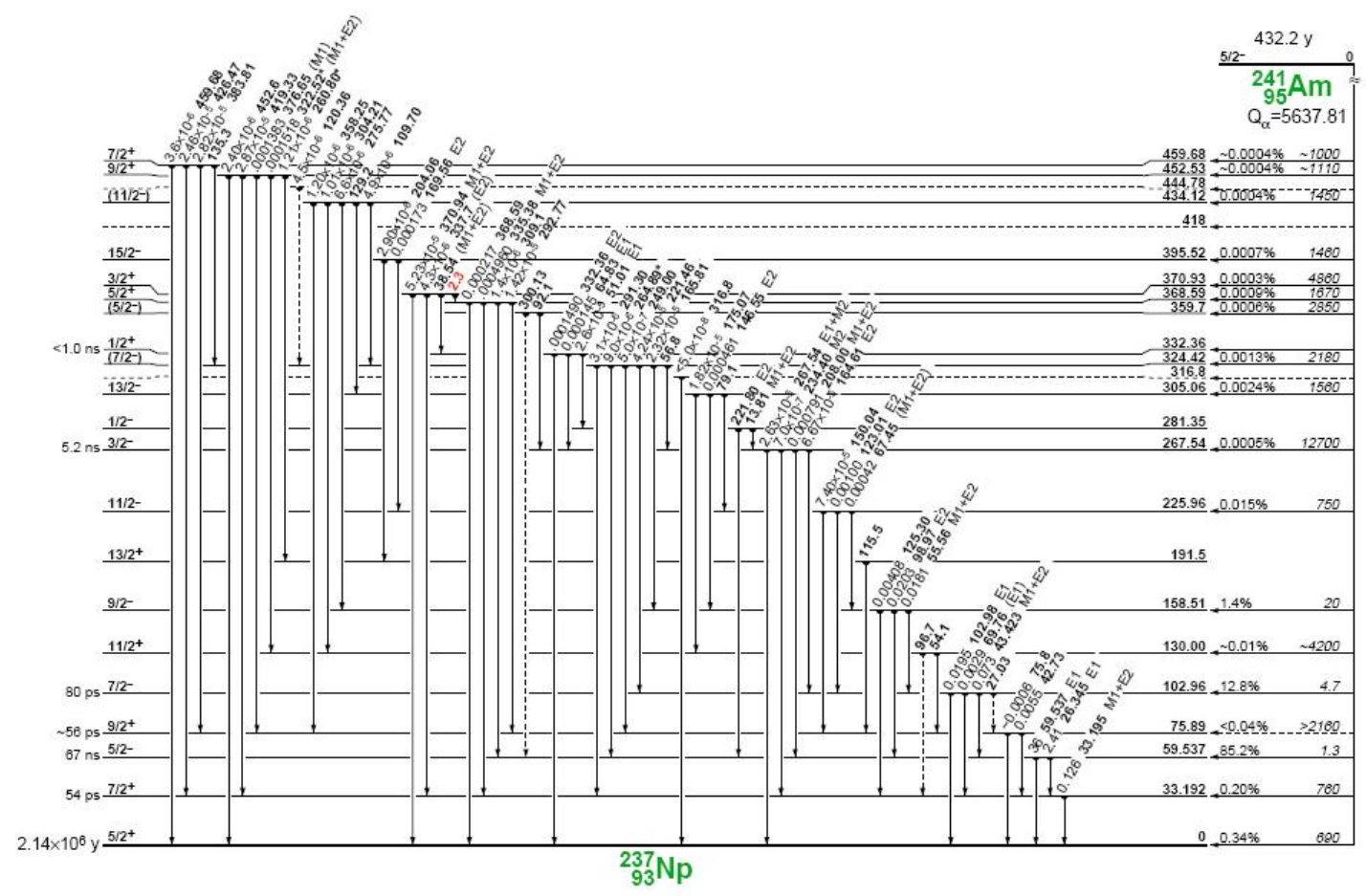

Figura 3-1: Esquema de desintegração do ${ }^{241} \mathrm{Am}^{[32]}$.

\subsection{2 ${ }^{60} \mathrm{Co}$}

O radionuclídeo ${ }^{60} \mathrm{Co}$ se desintegra por emissão beta negativa, com uma meiavida de 5,2714(20) a, populando os níveis excitados do ${ }^{60} \mathrm{Ni}$, conforme mostra a Figura $3-2^{[32,45]}$. A energia máxima do beta mais intenso é de $317,89(11) \mathrm{keV}$, com uma probabilidade de emissão de 0,99925(30). Os gamas mais intensos possuem energias de $1173,24 \mathrm{keV}$ e 1332,50 keV, com probabilidades de emissão de 0,9990(2) e 0,99982(6), respectivamente.

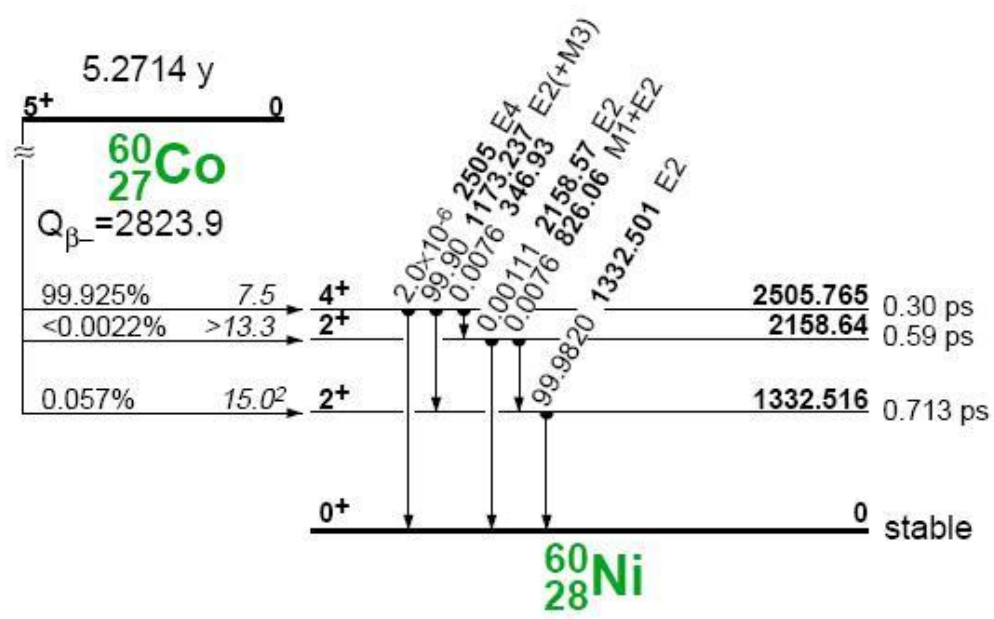

Figura 3-2: Esquema de desintegração do ${ }^{60} \mathrm{Co}^{[32]}$. 


\subsection{3 ${ }^{137} \mathrm{Cs}$}

O radionuclídeo ${ }^{137} \mathrm{Cs}$ se desintegra por emissão beta negativa, com uma meiavida de 30,07(8) a, populando os níveis excitados do ${ }^{137} \mathrm{Ba}$, conforme mostra a Figura $3-3^{[32,33]}$. A energia máxima do beta mais intenso é de $511,5(9) \mathrm{keV}$, com uma probabilidade de emissão de 0,944(3). O gama mais intenso possui energia de 661,66 $\mathrm{keV}$, com probabilidade de emissão de $0,851(2)$.

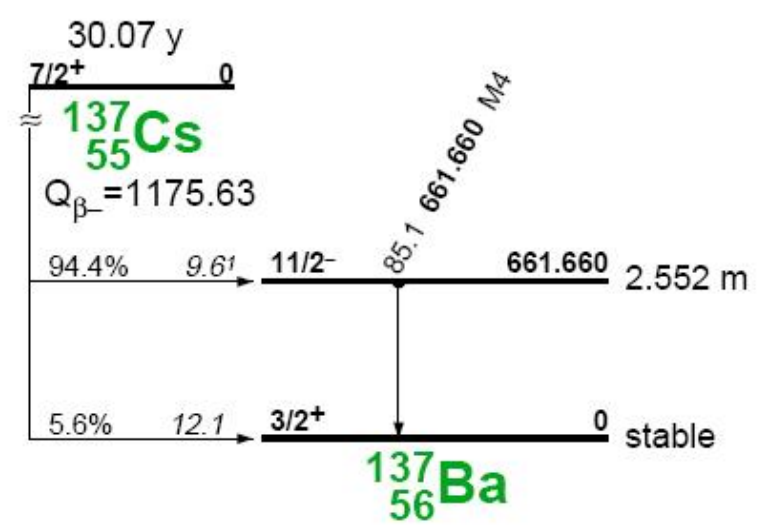

Figura 3-3: Esquema de desintegração do ${ }^{137} \mathrm{Cs}^{[32]}$.

\subsection{4 ${ }^{182}$ Ta}

O radionuclídeo ${ }^{182}$ Ta se desintegra por emissão beta negativa, com uma meiavida de $114,43 \mathrm{~d}$, populando os níveis excitados do ${ }^{182} \mathrm{~W}$, conforme mostra a Figura $3-4^{[32,33]}$. A energia máxima do beta mais intenso é de $524,44 \mathrm{keV}$, com uma probabilidade de emissão de 0,397. Os gamas mais intensos possuem energias de 67,75 e 1121,30 keV, com probabilidades de emissão de 0,412(7) e 0,349(6), respectivamente. 


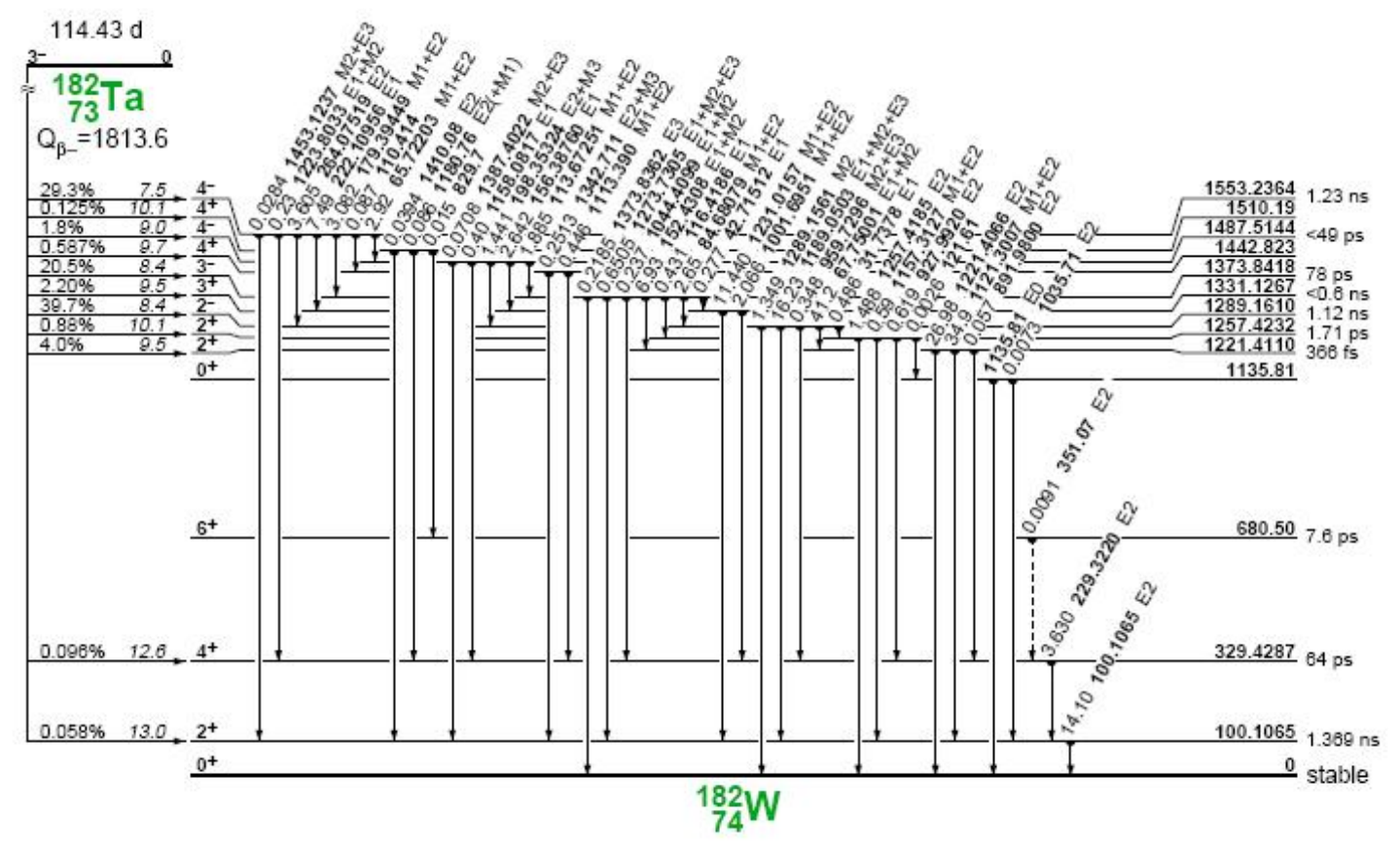

Figura 3-4: Esquema de desintegração do ${ }^{182} \mathrm{Ta}^{[32]}$.

\subsection{Arranjo experimental}

O arranjo experimental desenvolvido no presente trabalha para o sistema de coincidências $4 \pi \beta(P S)-\gamma$, é apresentado nas Figuras 3-5 e 3-6. Neste arranjo, utilizou-se o mesmo cintilador plástico em geometria $4 \pi$, desenvolvido por Baccarelli ${ }^{[29]}$.

Com o objetivo de reduzir a presença de ruído eletrônico, foi acrescentada uma fotomultiplicadora acoplada opticamente ao cintilador plástico, na forma de sanduíche. $\mathrm{O}$ detector de $\mathrm{NaI}(\mathrm{Tl})$ foi posicionado horizontalmente, à uma distância de aproximadamente $20 \mathrm{~mm}$ do tubo que blinda magneticamente as fotomultiplicadoras acopladas ao cintilador plástico. 


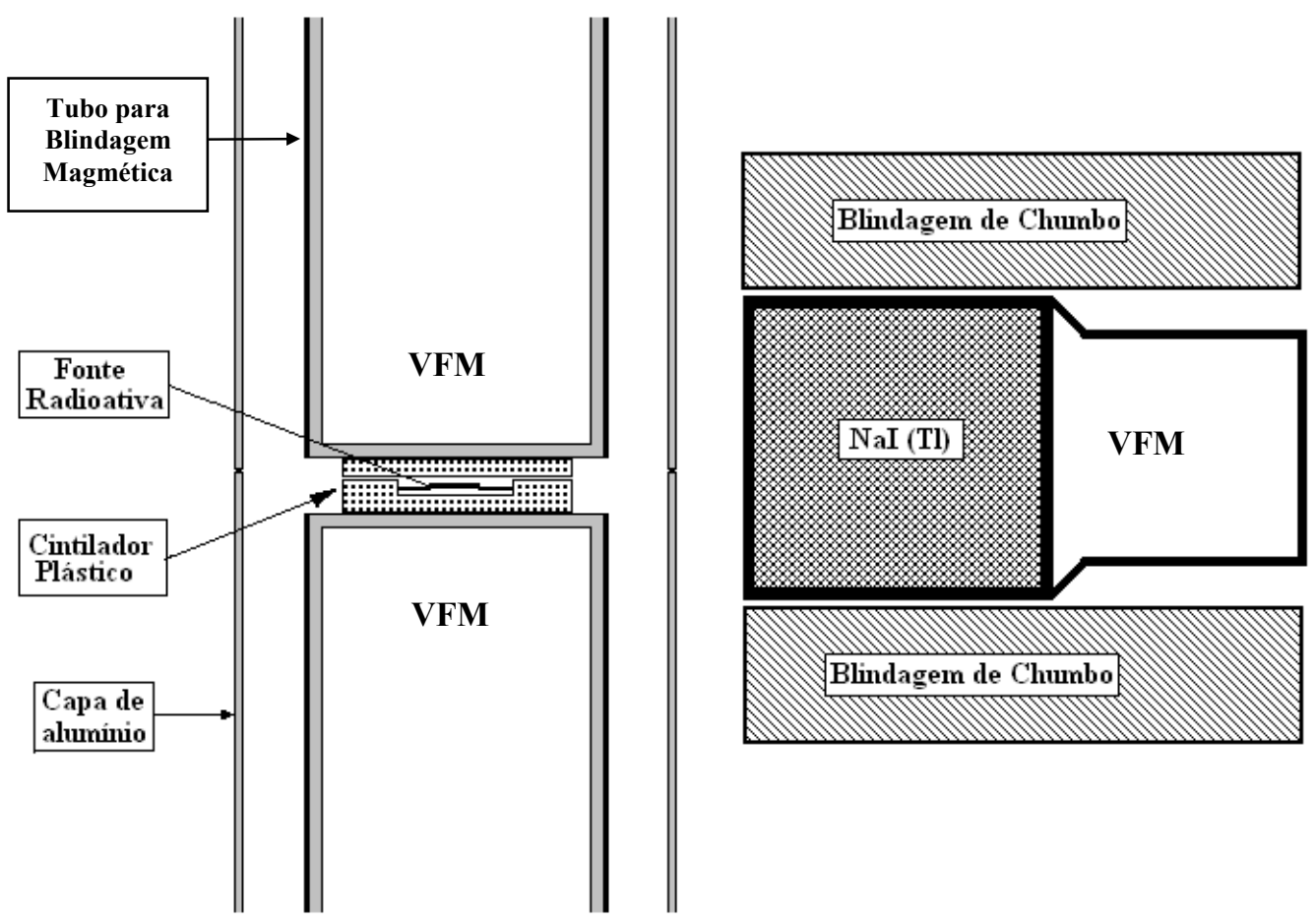

Figura 3-5: Diagrama esquemático do sistema de coincidências $4 \pi \beta(P S)-\gamma$ desenvolvido no presente trabalho (a sigla VFM corresponde a válvula fotomultiplicadora).

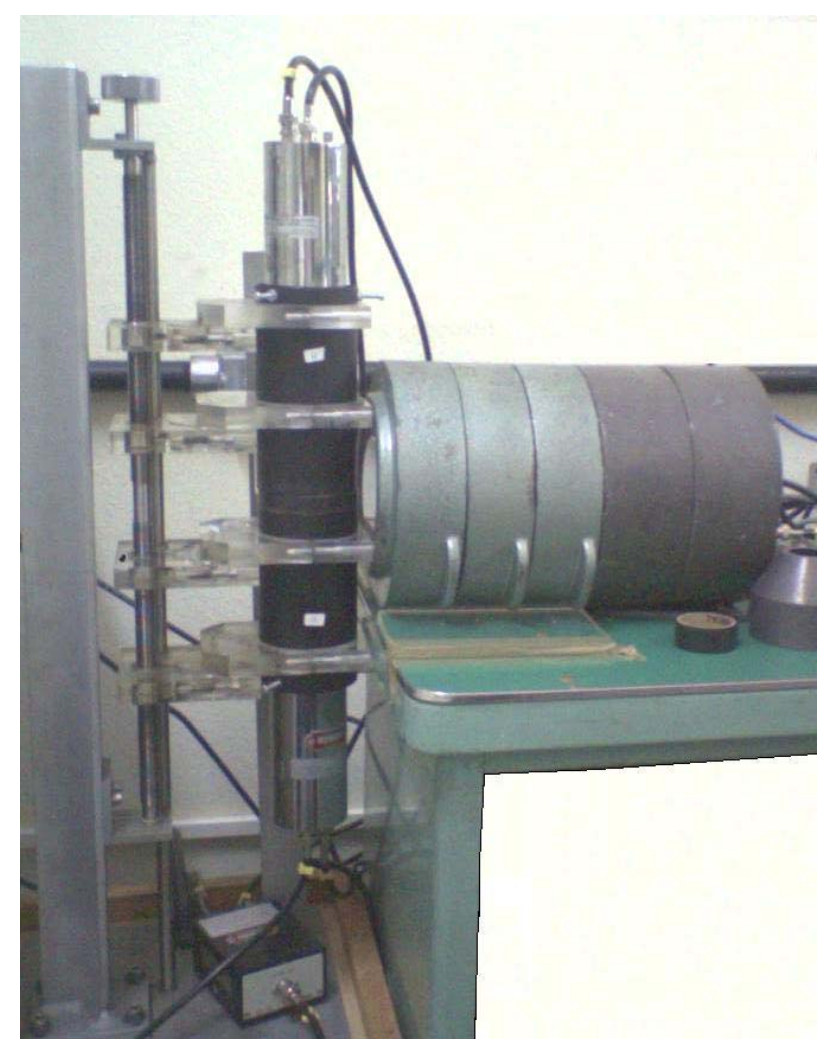

Figura 3-6: Foto do sistema de coincidências $4 \pi \beta(\mathrm{PS})-\gamma$ desenvolvido no presente trabalho. 
Com este novo arranjo, a troca de fontes foi facilitada, uma vez que o dispositivo que sustenta as fotomultiplicadoras é móvel e permite o ajuste do cintilador plástico na direção vertical. As dimensões, formatos e composição dos cintiladores plásticos foram preservados e uma nova eletrônica foi estabelecida.

\subsection{Geometria do detector plástico em geometria $4 \pi$}

O detector de cintilação plástico é constituído por três cilindros, conforme mostra a Figura 3-7. O cilindro superior acopla-se à fotomultiplicadora superior e o conjunto de cilindros intermediário e inferior, acopla-se à fotomultiplicadora inferior. $\mathrm{O}$ cilindro intermediário é vazado, e o espaço assim obtido é utilizado para a colocação da fonte radioativa. Esta fonte radioativa possui um substrato de Collodion, suportado por uma arandela de aço inox ou plástico, conforme a conveniência da medida.

Para os casos onde a fonte radioativa deva ser também calibrada no sistema de coincidências convencional, que utiliza detector proporcional em geometria $4 \pi$, a arandela escolhida foi de aço inox, em razão de ser um material condutor elétrico. Para casos onde esta comparação não fosse necessária, a arandela escolhida foi confeccionada em plástico transparente, com o objetivo de maximizar a transmissão de luz até as fotomultiplicadoras.

Estes conjuntos foram fabricados no IPEN $^{[46]}$ e são similares aos cintiladores importados $^{[47]}$. As dimensões dos três cilindros são de $40 \mathrm{~mm}$ de diâmetro por $3 \mathrm{~mm}$ de espessura, sendo que o disco intermediário é vazado, com diâmetro interno de $20 \mathrm{~mm}$.

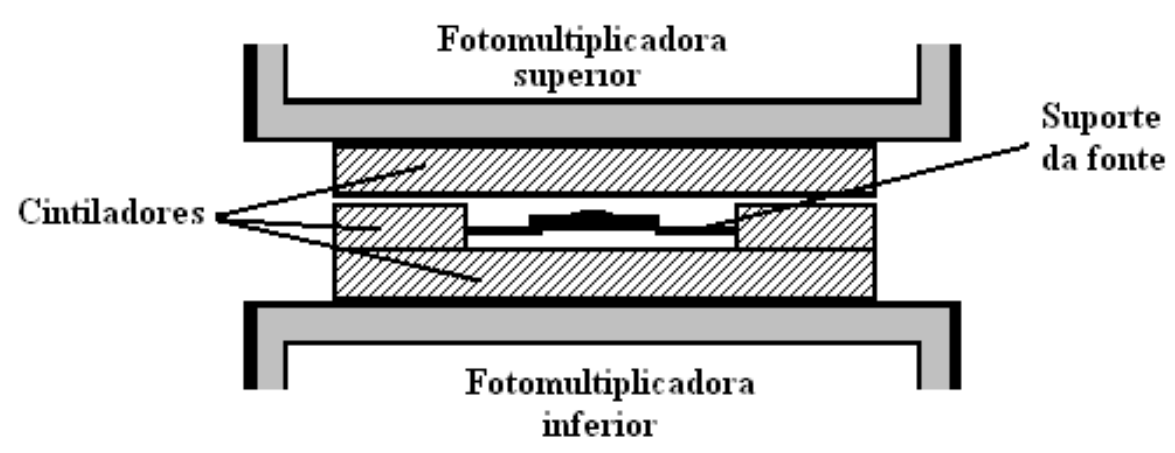

Figura 3-7: Diagrama do detector $4 \pi(\mathrm{PS})$ com a fonte radioativa. 
$\mathrm{O}$ disco inferior e o cilindro intermediário foram acoplados entre si e posteriormente este conjunto foi acoplado à uma fotomultiplicadora RCA 8850 usandose graxa de silicone, a fim de garantir o acoplamento ótico. O cilindro superior foi acoplado à outra fotomultiplicadora RCA 8850 utilizando o mesmo processo.

\subsection{Parte eletrônica}

Foram desenvolvidos dois sistemas eletrônicos no presente trabalho. O primeiro foi utilizado para radionuclídeos que apresentem apenas um intervalo de energia gama de interesse, como é o caso do ${ }^{60} \mathrm{Co}$, sendo apresentado na Figura 3-8.

Neste arranjo eletrônico, os sinais das fotomultiplicadoras, após passarem pelos estágios de amplificação, são somados e, em seguida enviados a um discriminador de pulsos, para eliminar o ruído eletrônico. Após passar por este discriminador, os sinais seguem para módulos de porta lógica e atraso, gerando os sinais de início e término (start e stop) que são enviados a um módulo de conversão de tempo em altura de pulso (TAC).

A este primeiro arranjo, foram acrescentados alguns módulos adicionais, constituídos por um módulo de coincidência e dois discriminadores, com o objetivo de gerar sinais de coincidência beta-beta, de modo a incluir eventos que ocorram na zona de ruído eletrônico. O tempo de resolução utilizado no módulo de coincidência foi de $0,5 \mu$ s. Os resultados sobre esta alteração são discutidos no capítulo 4. 


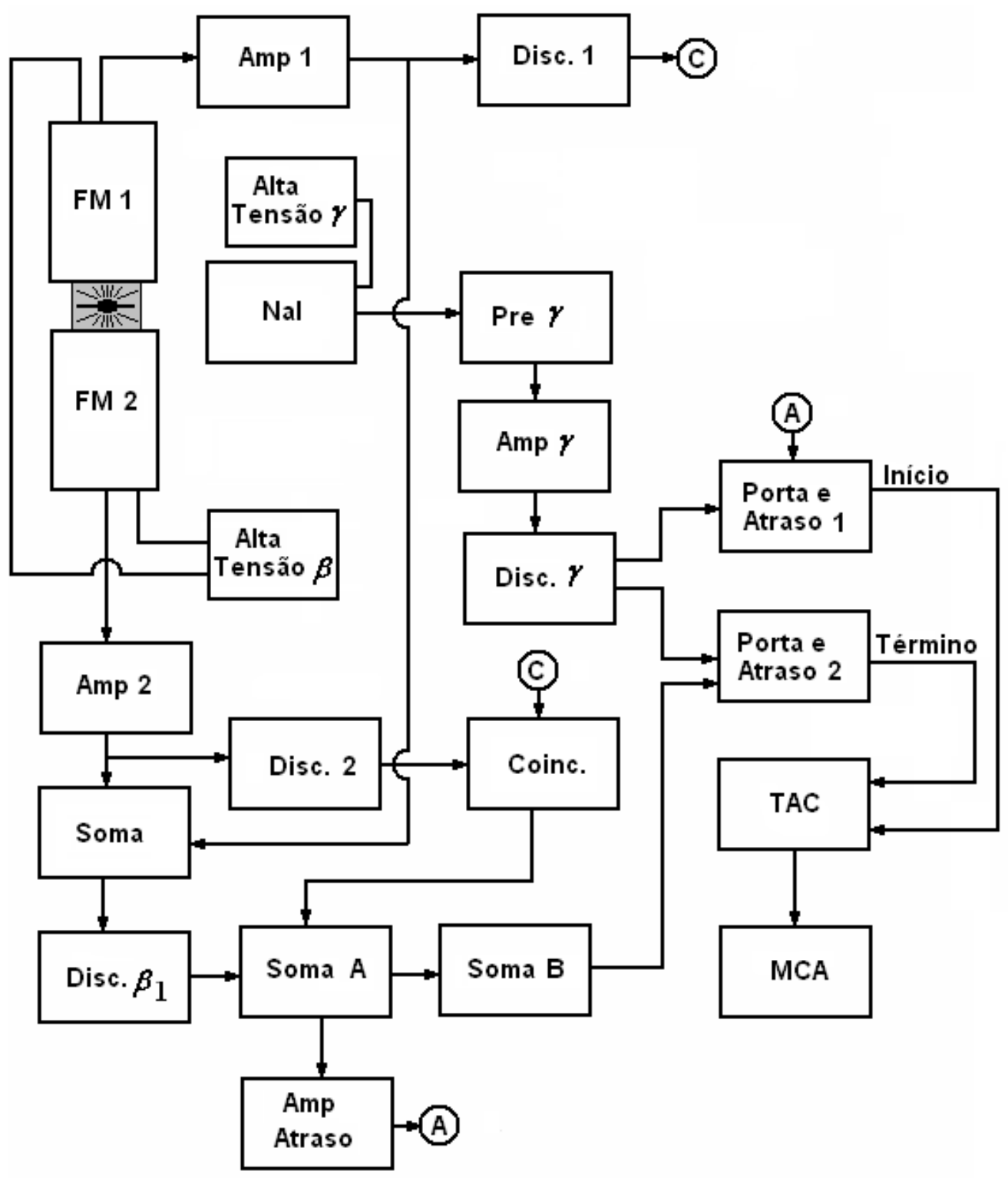

Figura 3-8: Sistema eletrônico para contagens de coincidência, aplicável a um único intervalo de energia gama.

Um segundo arranjo eletrônico foi desenvolvido, para radionuclídeos que apresentem dois intervalos de energia gama de interesse, como é o caso do ${ }^{182} \mathrm{Ta}$, sendo apresentado na Figura 3-9. 


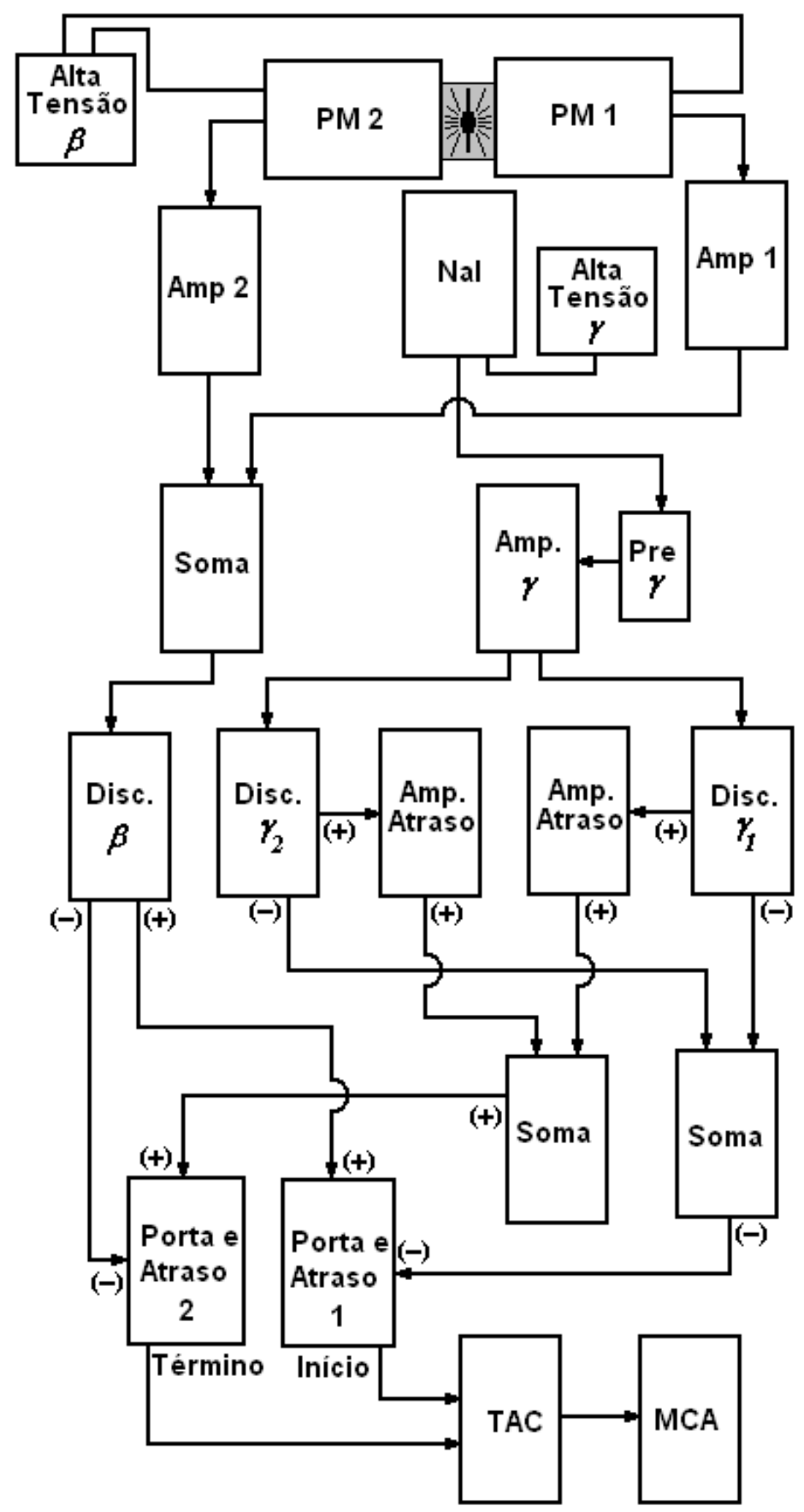

Figura 3-9: Sistema eletrônico para contagens de coincidência aplicável a dois intervalos de energia gama.

A necessidade de um intervalo de energia gama adicional implicou na utilização de um novo conjunto de módulos de discriminação, soma e atraso, de modo a separar os eventos correspondentes a cada um dos intervalos de energia gama. 


\subsection{Preparação das amostras radioativas}

As amostras foram preparadas depositando-se alíquotas de material radioativo em um substrato de Collodion, com espessura entre 10 e $20 \mu \mathrm{g} \mathrm{cm}^{-2}$. A massa considerada foi determinada utilizando-se uma balança Sartorius MC-21S, seguindo os procedimentos recomendados pelo BIPM (Bureau International des Poids et Mesures $)^{[48]}$. Para evitar a formação de cristais na fonte, foi adicionada uma alíquota de CYASTAT SN, que é um agente umectante.

Após a secagem da fonte, o conjunto foi transferido para uma arandela com espessuras de 0,1 mm, para o caso de aço inox, e 1,0 mm, para o caso de lucite. $\mathrm{O}$ diâmetro das arandelas foi de $20 \mathrm{~mm}$ na parte externa e $10 \mathrm{~mm}$ na parte interna.

\subsection{Cálculo da atividade}

A análise da atividade foi efetuada por meio do programa CONTAC ${ }^{[49]}$, que leva em conta as correções para a radiação de fundo, decaimento radioativo, coincidências acidentais e tempo morto, aplicando o formalismo de Cox-Isham ${ }^{[50]}$. 


\section{RESULTADOS E DISCUSSÃO}

\subsection{Medidas de espectro alfa no detector $4 \pi(\mathrm{PS})$}

A Figura 4-1 mostra a comparação entre espectros alfa obtidos com uma fonte de ${ }^{241} \mathrm{Am}$, no cintilador plástico, para o caso da geometria apresentada na Figura 3-5. Inicialmente foi feita uma medida utilizando apenas uma fotomultiplicadora. Neste caso, a parte superior do cintilador plástico foi revestida com teflon e protegida com a mesma tampa utilizada por Baccarelli ${ }^{[29]}$, no arranjo anterior. Observa-se que o espectro obtido para o ${ }^{241} \mathrm{Am}$ apresenta dois picos produzidos pelas partículas alfa. O primeiro corresponde aos eventos produzidos no cintilador superior e o segundo aos eventos produzidos no cintilador inferior.

Para a nova geometria, com duas fotomultiplicadoras, o espectro obtido por meio do cintilador plástico também é apresentado na Figura 4-1 e mostra que os dois picos se convertem em um único pico, correspondente à soma das alturas de pulso de cada uma das fotomultiplicadoras. Nota-se também um afastamento deste pico da região de discriminação, fato este, que reduz a contribuição do ruído para ganhos menores.

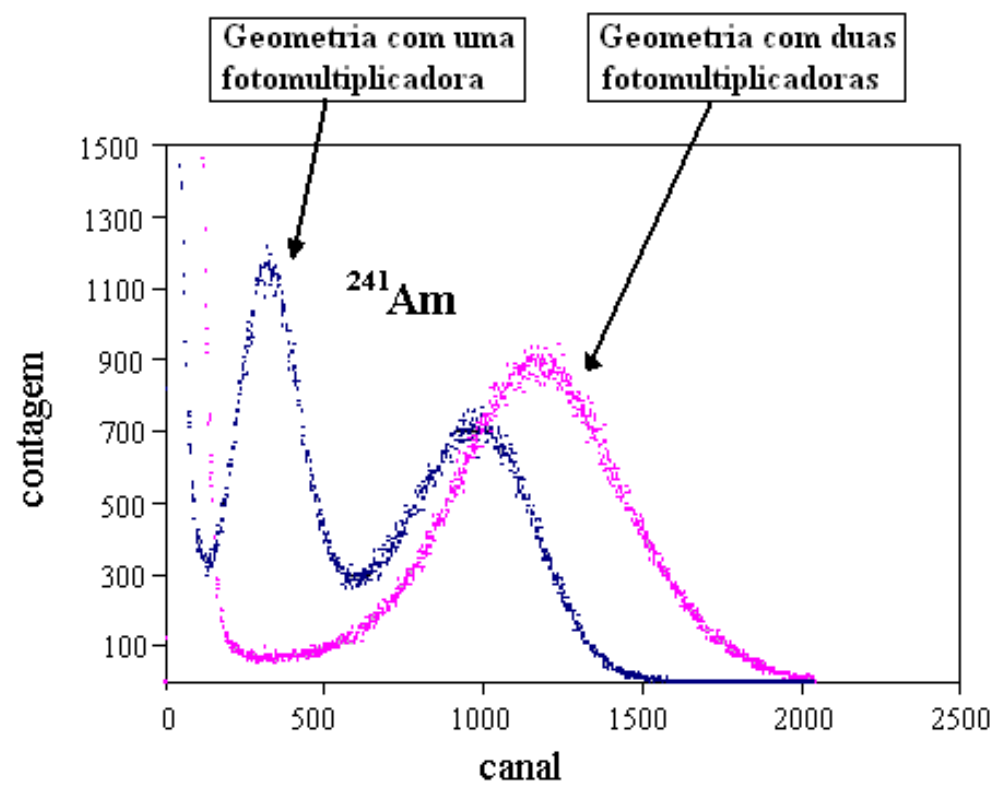

Figura 4-1: Espectros alfa para o ${ }^{241} \mathrm{Am}$, obtidos com o uso de uma ou duas fotomultiplicadoras. 


\subsection{Medidas de resolução no detector $4 \pi(\mathrm{PS})$}

Para a determinação do efeito de resolução no detector $4 \pi$ foram feitas medidas das radiações gamas mais intensas, emitidas pelos radionuclídeos ${ }^{241} \mathrm{Am},{ }^{137} \mathrm{Cs}$ e ${ }^{60} \mathrm{Co}$. Os resultados obtidos, para a medida direta das alturas de pulso, são apresentados nas Figuras 4-2, 4-3 e 4-4, respectivamente. Em cada espectro, pode-se observar o degrau Compton, com o efeito de arredondamento causado pelo efeito de resolução.

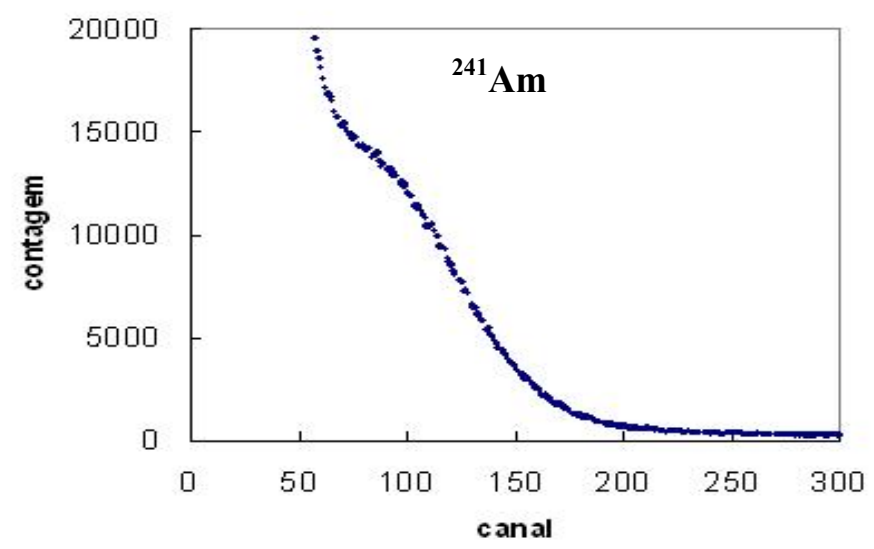

Figura 4-2: Espectro de alturas de pulso para a radiação gama do ${ }^{241} \mathrm{Am}$, obtido com o cintilador plástico, em geometria $4 \pi$.

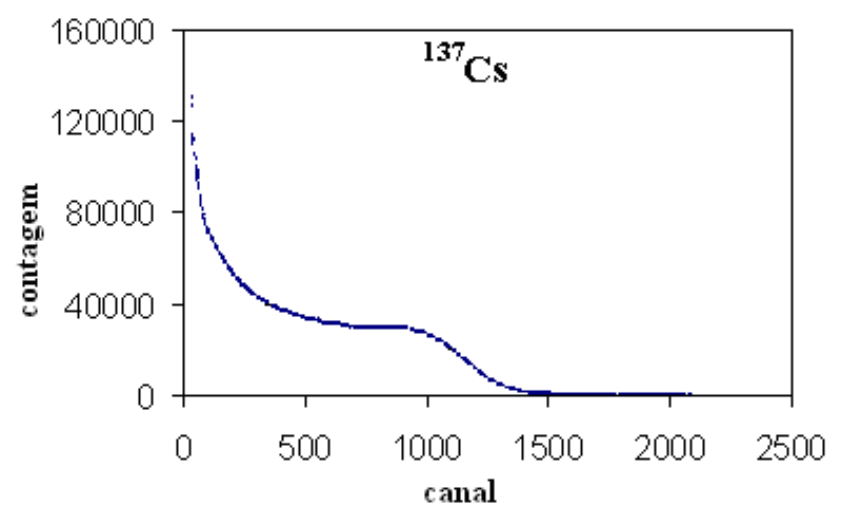

Figura 4-3: Espectro de alturas de pulso para a radiação gama do ${ }^{137} \mathrm{Cs}$, obtido com o cintilador plástico, em geometria $4 \pi$. 


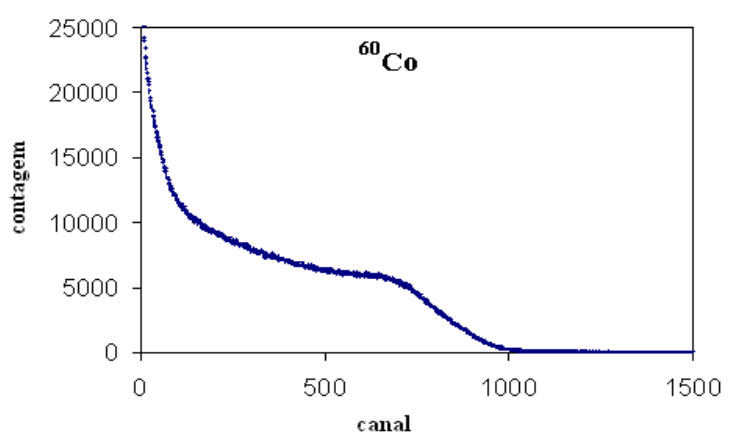

Figura 4-4: Espectro de alturas de pulso para a radiação gama do ${ }^{60} \mathrm{Co}$, obtido com o cintilador plástico, em geometria $4 \pi$.

Com o objetivo de obter valores mais precisos do efeito de resolução, foram determinados os espectros diferenciais, a partir dos espectros diretos apresentados nas Figuras 4-2, 4-3 e 4-4. Estes espectros diferenciais foram calculados, por meio de ajustes de polinômio de $2^{\circ}$ grau para canais vizinhos ao canal de interesse e calculandose a derivada da função obtida, para o canal considerado. Os pontos em azul correspondem aos dados experimentais e os pontos em vermelho ao ajuste de uma normal, com larguras diferentes para os lados esquerdo e direito do pico.

Os perfis resultantes aproximam-se aos de uma distribuição Normal, quando os degraus Compton dos espectros diretos possuem a região horizontal com inclinação próxima de zero. Os espectros diferenciais são apresentados nas Figuras 4-5, 4-6 e 4-7, para os radionuclídeos ${ }^{241} \mathrm{Am},{ }^{137} \mathrm{Cs}$ e ${ }^{60} \mathrm{Co}$, respectivamente. Para o caso do ${ }^{60} \mathrm{Co}$, observa-se a existência de um dubleto, que não é totalmente resolvido pelo detector plástico, correspondente às contribuições dos gamas de 1173 e $1332 \mathrm{keV}$.

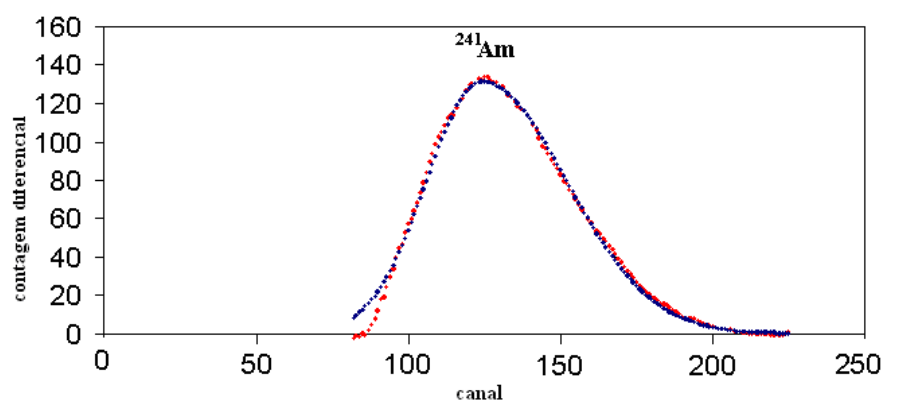

Figura 4-5: Espectro diferencial para o ${ }^{241} \mathrm{Am}$, obtido com o cintilador plástico. Os pontos azuis correspondem aos dados experimentais e os pontos vermelhos ao ajuste de uma distribuição normal com larguras diferentes para cada lado do pico. 


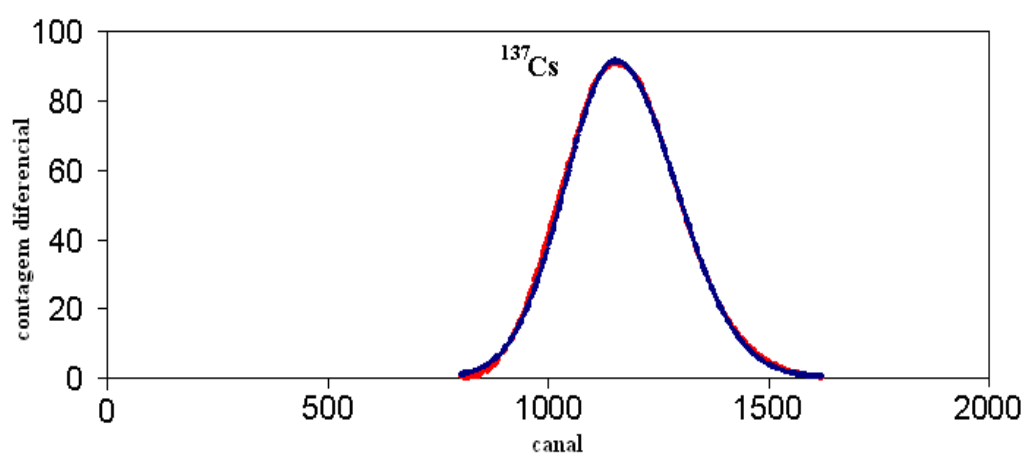

Figura 4-6: Espectro diferencial para o ${ }^{137} \mathrm{Cs}$, obtido com o cintilador plástico. Os pontos azuis correspondem aos dados experimentais e os pontos vermelhos ao ajuste de uma distribuição normal com larguras diferentes para cada lado do pico.

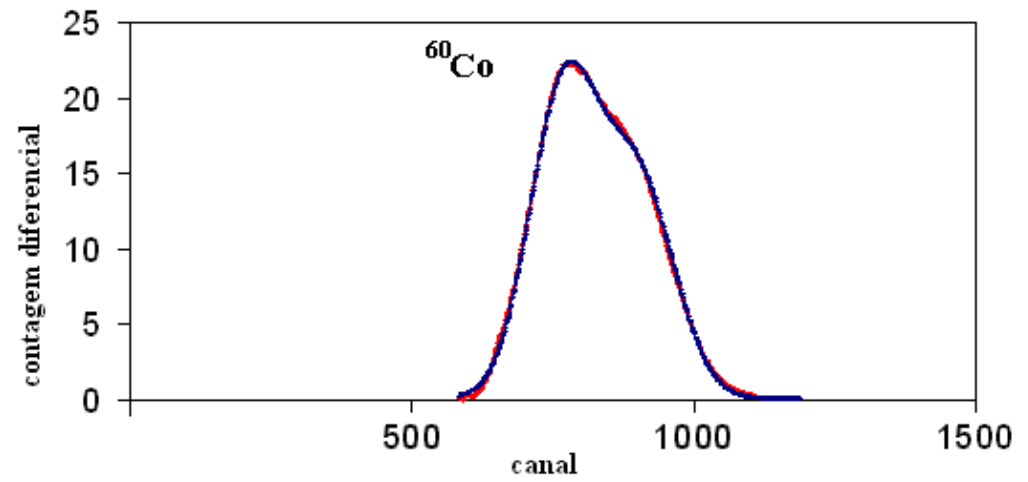

Figura 4-7: Espectro diferencial para o ${ }^{60} \mathrm{Co}$ obtido com o cintilador plástico. Os pontos azuis correspondem aos dados experimentais e os pontos vermelhos ao ajuste de uma distribuição normal com larguras diferentes para cada lado do pico. Observa-se um dubleto, composto pelas energias de 1173 e 1332 $\mathrm{keV}$.

A Tabela 4-1 apresenta os resultados de resolução obtidos para o detector $4 \pi(\mathrm{PS})$, utilizando os espetros gama diferenciais. A resolução apresentada corresponde à soma das meias larguras das distribuições normais obtidas para cada lado do pico. Os centróides mostrados para o ${ }^{60} \mathrm{Co}$ foram normalizados, porque foram obtidos com ganho de amplificação menor. A energia analisada para o ${ }^{241} \mathrm{Am}$, corresponde ao pico de absorção total, uma vez que, para esta energia, boa parte dos eventos depositam sua energia por efeito Fotoelétrico ou por espalhamento Compton múltiplo. 
Tabela 4-1: Resultados de resolução em energia para o detector $4 \pi(\mathrm{PS})$.

\begin{tabular}{c|c|c|c|c|c|c}
\hline Nuclídeo & $\begin{array}{c}\text { Energia } \\
\text { Gama } \\
(\mathrm{keV})\end{array}$ & $\begin{array}{c}\text { Energia do } \\
\text { Degrau } \\
\text { Compton } \\
(\mathrm{keV})\end{array}$ & $\begin{array}{c}\text { Energia } \\
\text { Analisada } \\
(\mathrm{keV})\end{array}$ & $\begin{array}{c}\text { Centróide } \\
\text { Normalizada } \\
(\text { Canal })\end{array}$ & $\begin{array}{c}\text { Centróide } \\
\text { Normalizada } \\
\text { Ajustada } \\
(\text { Canal })\end{array}$ & $\begin{array}{c}\text { Resolução } \\
(\%)\end{array}$ \\
\hline Am-241 & 59,4 & 11,20 & 59,40 & 124 & 125,0 & 19,2 \\
\hline Cs-137 & 661,6 & 477,28 & 477,28 & 1153 & 1148,5 & 11,7 \\
\hline Co-60 & 1173 & 963,20 & 963,20 & 2327 & 2338,7 & 7,7 \\
\hline & 1332 & 1117,62 & 1117,62 & 2725 & 2716,9 & 7,1 \\
\hline
\end{tabular}

Os valores de centróides foram ajustados de acordo com uma reta, pelo método dos Mínimos Quadrados e são apresentados na penúltima coluna. Observa-se um acordo geral bom com os dados experimentais, em particular para o ${ }^{241} \mathrm{Am}$, indicando que a energia analisada com o valor de 59,54 keV, é a correta.

\subsection{Distribuições de tempo para o sistema de coincidências $4 \pi \beta(P S)-\gamma$}

O espectro de distribuição de tempo para o ${ }^{60} \mathrm{Co}$, obtido por meio do arranjo eletrônico da Figura 3-8 é apresentado da Figura 4-8. O pico da esquerda corresponde a contagens beta sem as coincidências. O pico da direita corresponde a contagens gama sem as coincidências e o pico central refere-se às contagens de coincidências.

Para o caso do cintilador plástico, largura à meia altura do pico de coincidência corresponde a 46 ns. Este valor é muito menor que o obtido para o contador proporcional (PC), que possui uma largura à meia altura de 175 ns. Isto já era esperado, uma vez que o tempo de resposta para contadores proporcionais é muito maior quando comparado ao de cintiladores plásticos. Esta configuração permite uma maior taxa de contagens, em relação a medidas de coincidência utilizando contador proporcional. 


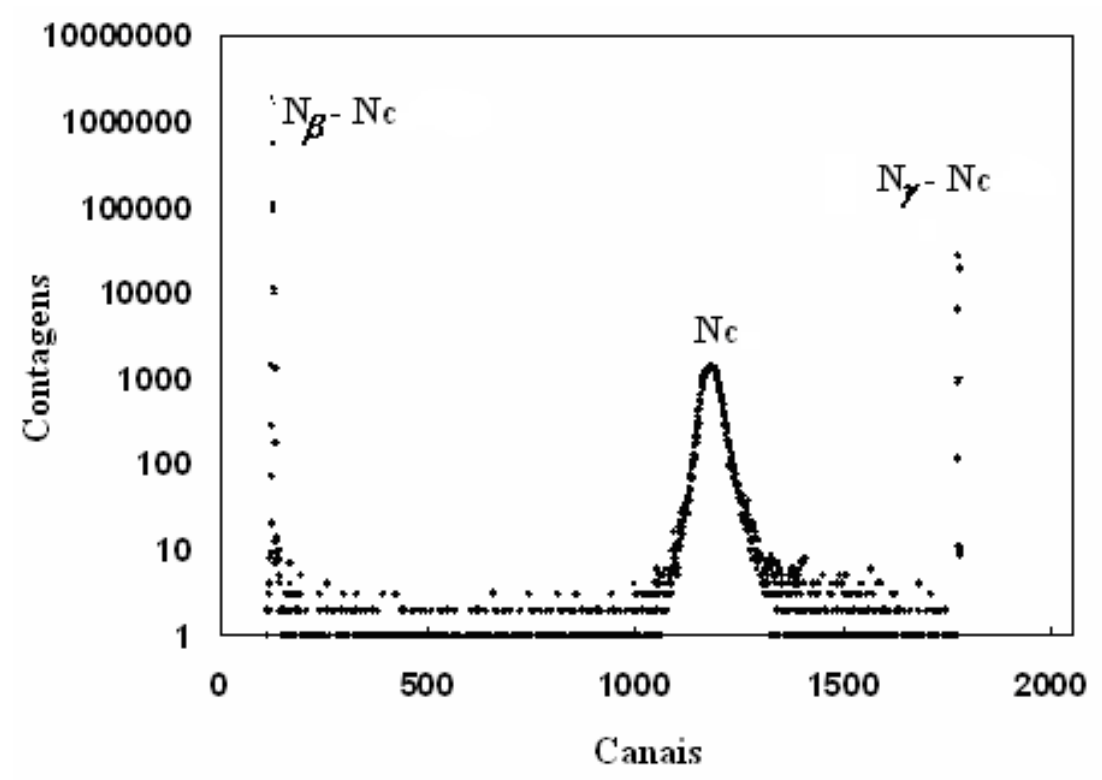

Figura 4-8: Espectro de tempo do ${ }^{60} \mathrm{Co}$. O pico central corresponde a coincidências beta-gama.

$\mathrm{O}$ espectro de distribuição de tempo para o ${ }^{60} \mathrm{Co}$, obtido por meio do arranjo eletrônico da Figura 3-9, é apresentado da Figura 4-9. Para este arranjo, que inclui módulos de atraso para separar as coincidências (beta-beta)-gama das coincidências beta-gama, o espectro resultante mostra dois picos de coincidência: o pico da esquerda, na região central, corresponde à coincidência entre eventos beta e gama. $\mathrm{O}$ pico da direita, também na região central, corresponde às coincidências entre eventos coincidentes (beta-beta), da região de ruído, com eventos gama.

A comparação com os resultados anteriores (Figura 4-8) demonstrou que parte das contagens de coincidências beta-beta é transferida ao pico de contagens de coincidência beta-gama. Isto pode ser explicado, uma vez que um pulso de contagem beta de baixa amplitude, localizado na região de ruído, é mais provável de estar em coincidência com um pulso beta de amplitude maior, localizado acima da região de ruído, vindo da outra face do cintilador plástico. Este último pulso seria normalmente detectado, e localizado no pico de coincidência beta-gama. Como resultado, as coincidências entre pulsos beta na região de ruído não acrescentam contagens significativas ao pico de coincidência beta-gama. 


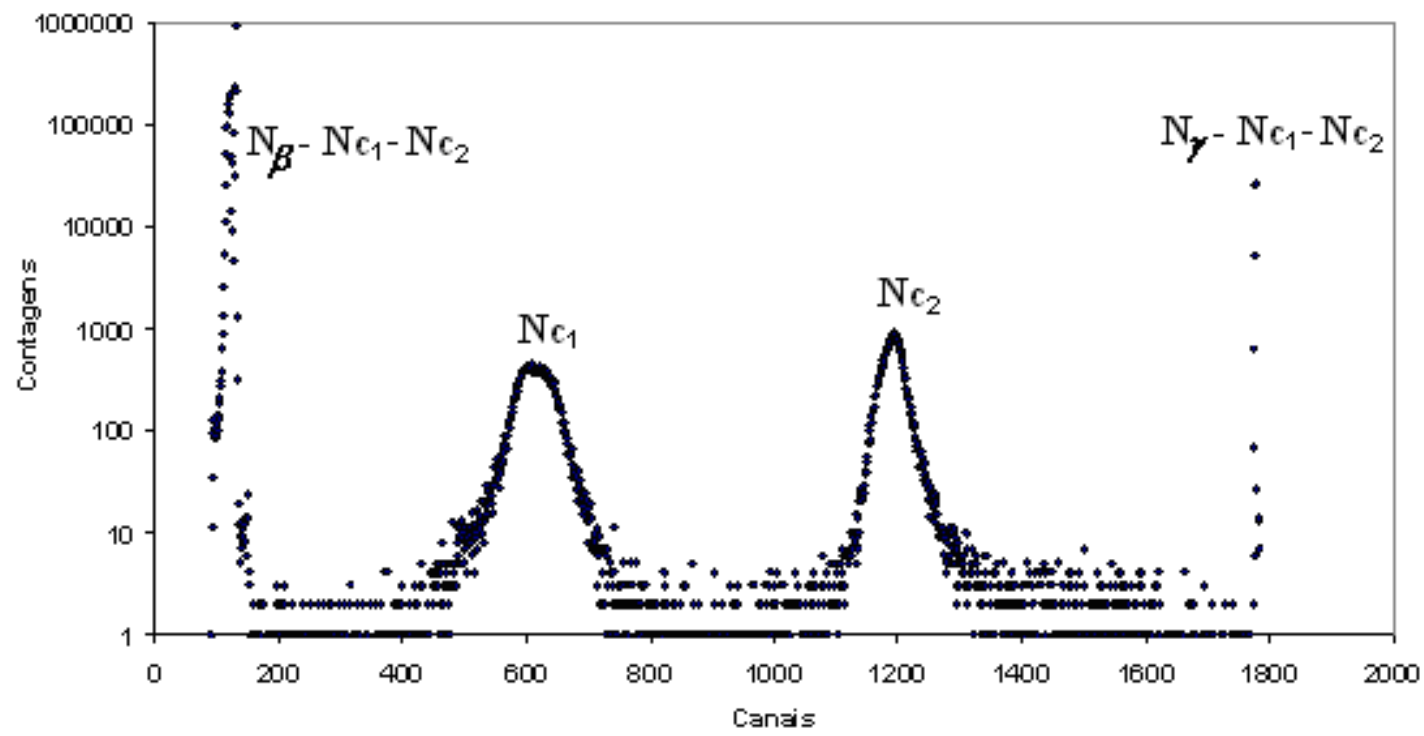

Figura 4-9: Espectro de tempo para o ${ }^{60} \mathrm{Co}$. O pico central, à esquerda, corresponde a coincidências (beta-beta)-gama e o pico central, à direita, a coincidências beta-gama.

O espectro de distribuição de tempo para o ${ }^{182} \mathrm{Ta}$, obtido por meio do arranjo eletrônico da Figura 3-9, é apresentado da Figura 4-10. Neste espectro, o pico à esquerda corresponde a eventos betas, sem as coincidências. O segundo e o quarto picos correspondem às coincidências no primeiro e segundo intervalos de energia gama, respectivamente. $\mathrm{O}$ terceiro e o quinto picos correspondem a eventos gama, sem as coincidências, para o primeiro e segundo intervalos de energia gama, respectivamente.

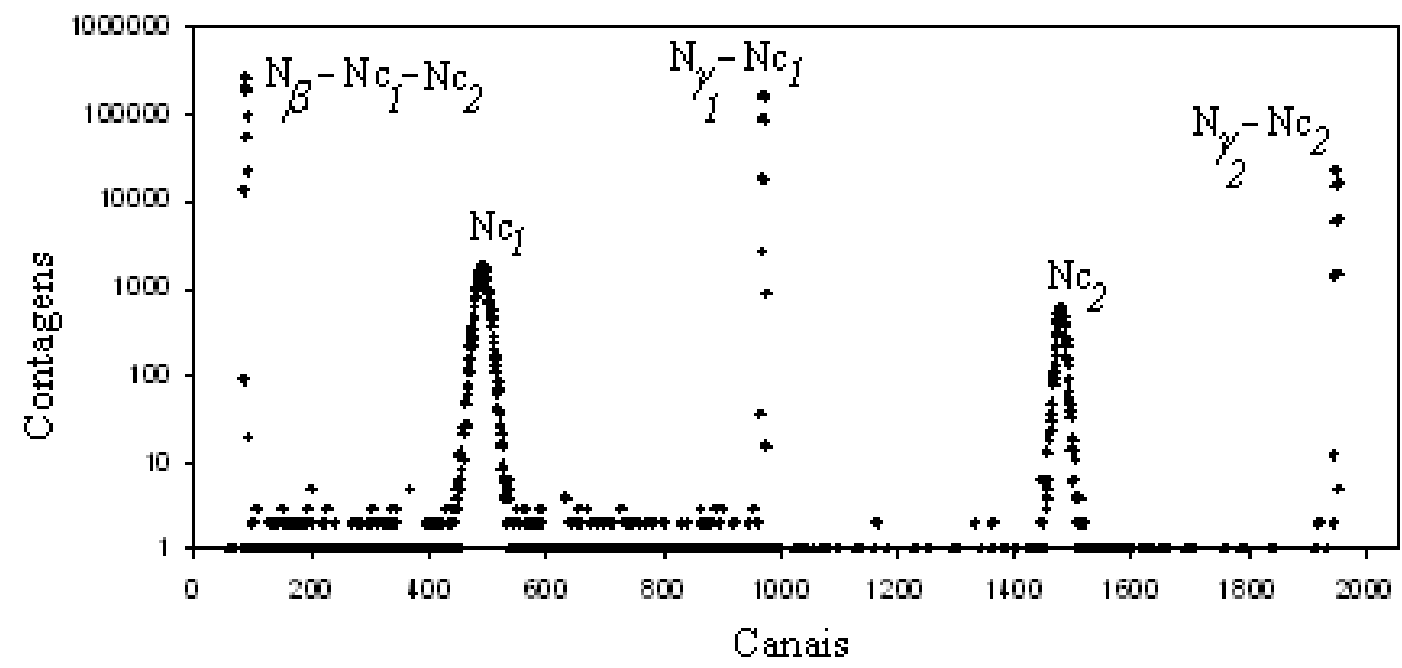

Figura 4-10: Espectro de tempo para o ${ }^{182}$ Ta. Os índices 1 e 2 correspondem ao primeiro e segundo intervalos de energia gama, respectivamente. 
O espectro de alturas de pulso da via gama para o ${ }^{182} \mathrm{Ta}$, detectado no cintilador de $\mathrm{NaI}(\mathrm{Tl})$, é apresentado na Figura 4-11. Os dois intervalos de energia gama adotados, para as medidas de coincidência, são indicados nesta figura.

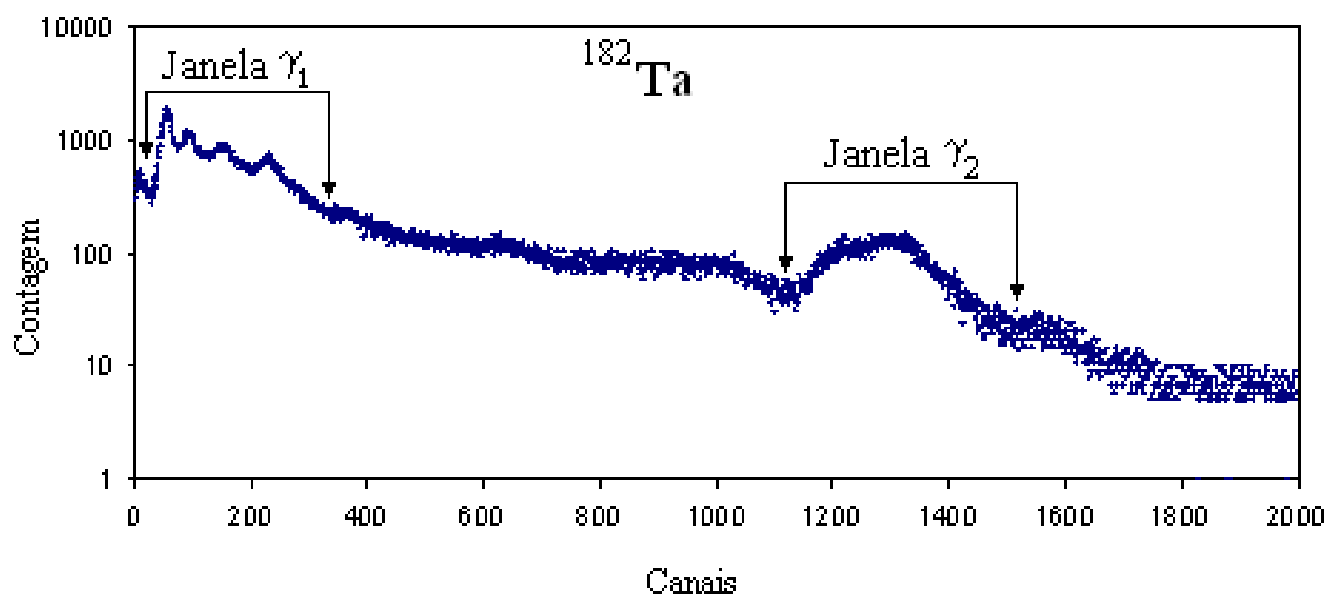

Figura 4-11: Espectro gama do ${ }^{182} \mathrm{Ta}$, obtido por meio do cintilador de NaI(Tl).

\subsection{Resultados de atividade com o sistema de coincidências $4 \pi \beta(P S)-\gamma$}

Os resultados apresentados nesta seção incluem dados experimentais obtidos no presente trabalho e comparações com o Método de Monte Carlo, tanto para o arranjo desenvolvido no presente trabalho, como para o arranjo original, desenvolvido por Baccarelli ${ }^{[29]}$.

\subsubsection{Dados experimentais obtidos com o sistema do presente trabalho}

\subsubsection{1 ${ }^{60} \mathrm{Co}$}

A Figura 4-12 apresenta a curva de extrapolação para ${ }^{60} \mathrm{Co}$ obtida com o arranjo experimental desenvolvido no presente trabalho. 


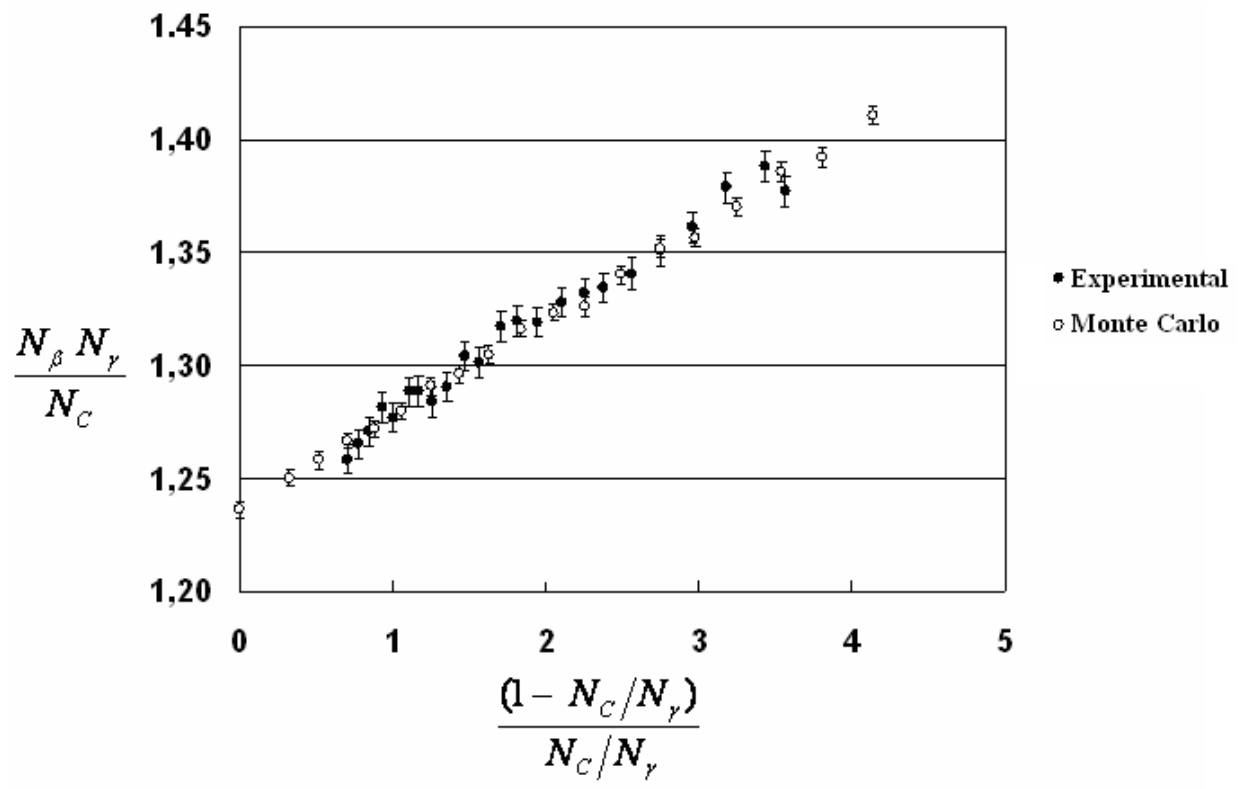

Figura 4-12: Comportamento da função para $N_{\beta} N_{\gamma} / N_{c}$ em função do parâmetro (1- $N_{c}$ $\left.N_{\gamma}\right) /\left(N_{c} / N_{\gamma}\right)$ para o ${ }^{60} \mathrm{Co}$, com a nova geometria. Os pontos cheios são dados experimentais e os vazios obtidos por Monte Carlo.

A Tabela 4-2 mostra uma comparação entre o ajuste linear efetuado com os pontos experimentais e o resultado teórico, utilizando a equação (2-44). Verifica-se um bom acordo entre os resultados. Note-se que o valor da inclinação não é indicado juntamente com o valor teórico, uma vez que a equação (2-44) fornece apenas um parâmetro, que é a atividade $N_{0}$ da fonte radioativa.

Tabela 4-2: Resultados de atividade para a nova geometria. Ajuste linear com dados experimentais e simulação por Monte Carlo desenvolvida no presente trabalho.

\begin{tabular}{ccccc}
\hline Radionuclídeo & Processo & Sistema & $\begin{array}{c}\text { Atividade } \\
(\mathrm{kBq} / \mathrm{g})\end{array}$ & $\begin{array}{c}\text { Inclinação } \\
(\%)\end{array}$ \\
\hline${ }^{60} \mathrm{Co}$ & Experimental & $4 \pi \beta(\mathrm{PS})-\gamma$ & $(1,2424 \pm 0,0061)$ & $(4,32 \pm 0,13)$ \\
${ }^{60} \mathrm{Co}$ & Monte Carlo & $4 \pi \beta(\mathrm{PS})-\gamma$ & $(1,2364 \pm 0,0010)$ & \\
\hline
\end{tabular}

A inclinação observada é de 4,32 \%, muito menor do que o valor da eficiência beta-gama calculada por Monte Carlo, que é próxima de 7,1\%, quando é acrescentada a contribuição das coincidências entre dois raios gama. Isto indica que existem 
coincidências entre um raio gama detectado no cintilador plástico e o outro raio gama detectado no detector de $\mathrm{NaI}(\mathrm{Tl})$. A curva de extrapolação experimental foi bem reproduzida pela nova versão do código ESQUEMA ${ }^{[30]}$, o qual leva em consideração coincidências gama-gama, como mostrado na Figura 4-12.

Como pode ser visto os procedimentos com Monte Carlo demonstram bons resultados e apresenta vantagens por ser baseado num comportamento realístico da curva de extrapolação em contraposição a uma aproximação convencional, usando ajustes polinomiais.

A eficiência beta-gama (eficiência gama no detector $4 \pi$ ) torna-se importante no atual sistema de coincidência, em razão da natureza sólida do detector $4 \pi$. Para o nível de discriminação zero, a efíciência calculada pelo código PENELOPE cresce de 4,7\% para energia de $4,5 \mathrm{keV}$, até um máximo de $12 \%$ para a energia de $50 \mathrm{keV}$, decrescendo para 4,0 \% em 1,4 MeV. Este efeito tende a aumentar a inclinação da curva de extrapolação entre a atividade observada $\left(\mathrm{N}_{\beta} \mathrm{N}_{\gamma} / \mathrm{N}_{\mathrm{c}}\right)$ e o parâmetro de ineficiência $\left(1-\mathrm{N}_{\mathrm{c}} / \mathrm{N}_{\gamma}\right) /\left(\mathrm{N}_{\mathrm{c}} / \mathrm{N}_{\gamma}\right)$. No entanto, para alguns casos, parte deste efeito é compensada por coincidências gama-gama.

Por exemplo, o ${ }^{60} \mathrm{Co}$ tem dois raios gama em cascata. Um pode ser detectado no cintilador plástico e o outro no detector de $\mathrm{NaI}(\mathrm{Tl})$, resultando em uma coincidência, que produz um decréscimo na inclinação da curva de extrapolação. Para esquemas de decaimento complexos, este efeito pode ter uma maior importância.

Foi efetuada uma comparação entre eficiências beta para ${ }_{0}{ }^{60} \mathrm{Co}$ para as geometrias correspondentes a uma ou duas fotomultiplicadoras acopladas ao detector $4 \pi(\mathrm{PS})$, respectivamente. Os resultados foram de $60 \%$, para o primeiro caso e $77 \%$ para o segundo caso, indicando que a inclusão de uma segunda fotomultiplicadora melhora significativamente a eficiência do detector $4 \pi$ para este radionuclídeo.

Simulações com o código PENELOPE mostraram que a maioria dos elétrons com energia abaixo de $1 \mathrm{keV}$ não alcançam o cintilador plástico, porque são absorvidos na reentrância de $3 \mathrm{~mm}$ de altura e $20 \mathrm{~mm}$ de largura, preenchida com ar. Esta 
reentrância está localizada entre as duas faces do cintilador plástico e é necessária para acomodação da fonte radioativa. Esta pode ser uma das causas da eficiência para o ${ }^{60} \mathrm{Co}$ não ter sido maior. Melhorias neste aspecto deverão ser introduzidas, no futuro, para reduzir ou eliminar esta reentrância.

\subsubsection{2 ${ }^{182}$ Ta}

A Figura 4-13 mostra resultados experimentais preliminares, obtidos para o ${ }^{182} \mathrm{Ta}$ (janela $\gamma_{2}$ conforme descrito no item 4-3). Nesta figura também foram colocados os resultados para a curva de extrapolação teórica, obtida por Monte Carlo utilizando os parâmetros de simulação para a geometria original.

A curva teórica foi normalizada em relação ao valor obtido com o sistema de coincidências convencional, $4 \pi(\mathrm{PC}) \beta-\gamma$, que resultou em 7,852(13) kBq. São apresentados também alguns valores experimentais obtidos na nova geometria.

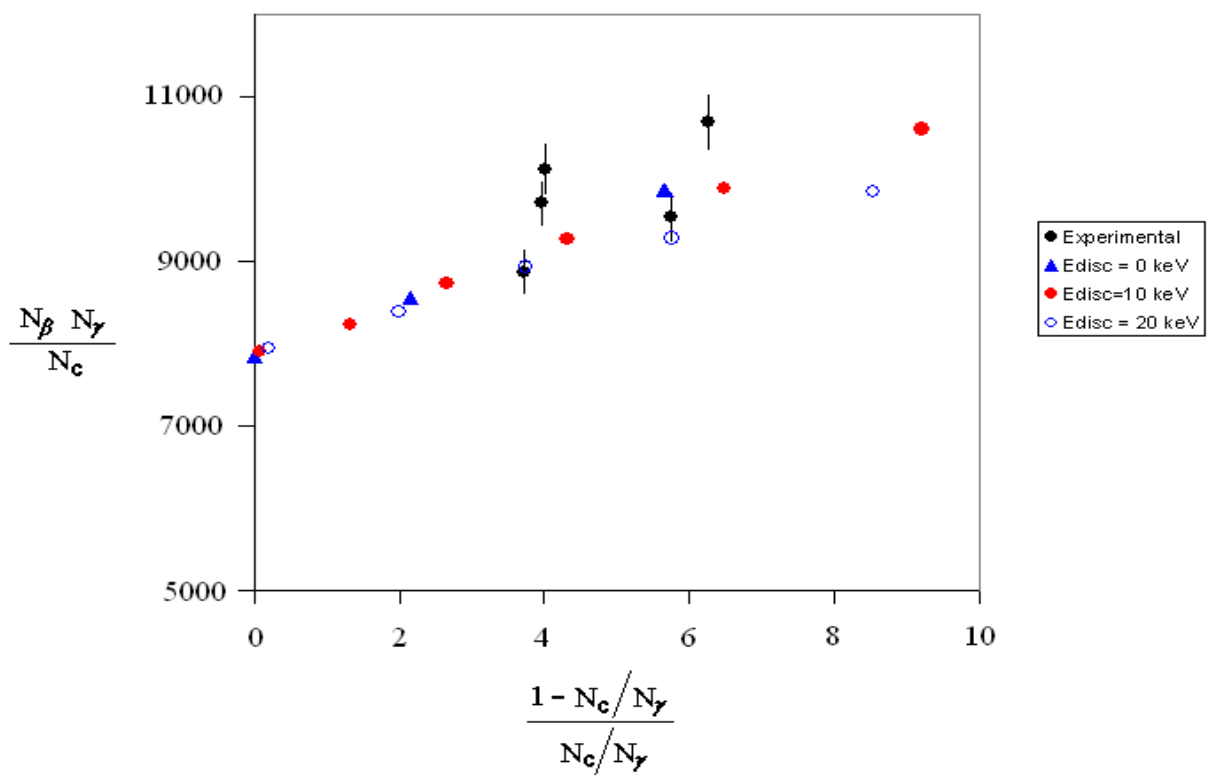

Figura 4-13: Comportamento da função para $N_{\beta} N_{\gamma} / N_{c}$ em função do parâmetro( $\left(1-N_{c}\right.$ $\left.N_{\gamma}\right) /\left(N_{d} / N_{\gamma}\right)$ para o ${ }^{182} \mathrm{Ta}$, com a nova geometria. Os pontos em cor preta são dados experimentais e os coloridos por Monte Carlo, todos obtidos no presente trabalho.

A concordância dos dados experimentais com os valores teóricos é apenas parcial, sendo que a curva teórica foi obtida variando-se os absorvedores para 3 níveis de discriminação: 0,10 e $20 \mathrm{keV}$. Os resultados obtidos no primeiro intervalo de 
energia (janela $\gamma_{1}$ conforme descrito no item 4-3) foram muito discrepantes, provavelmente em razão da alta contribuição da contagem de fundo, e não foram incluídos no presente trabalho. Sugere-se que, no futuro, sejam feitas novas medidas para complementar estes resultados e aplicada a simulação desenvolvida para a nova geometria.

\subsubsection{Cálculos de Monte Carlo aplicados ao sistema de Baccarelli}

A Figura 4-14 mostra a geometria do sistema $4 \pi(\mathrm{PS}) \beta-\gamma$ desenvolvido por Baccarelli ${ }^{[29]}$. Esta geometria caracteriza-se pelo uso de apenas uma fotomultiplicadora acoplada ao detector $4 \pi(\mathrm{PS})$ e com o detector de $\mathrm{NaI}(\mathrm{Tl})$ posicionado verticalmente, próximo ao detector $4 \pi$. Notam-se a inclusão dos componentes externos aos detectores, tais como: tubo para blindagem magnética em torno da fotomultiplicadora e blindagem de chumbo. Todos estes componentes foram considerados na modelagem por Monte Carlo, por meio do programa PENCYL, que faz parte do sistema de programas PENELOPE ${ }^{[31]}$. Nesta geometria foram simuladas as medidas de atividade para dois radionuclídeos: ${ }^{60} \mathrm{Co} \mathrm{e}{ }^{133} \mathrm{Ba}$, e os resultados são descritos a seguir.
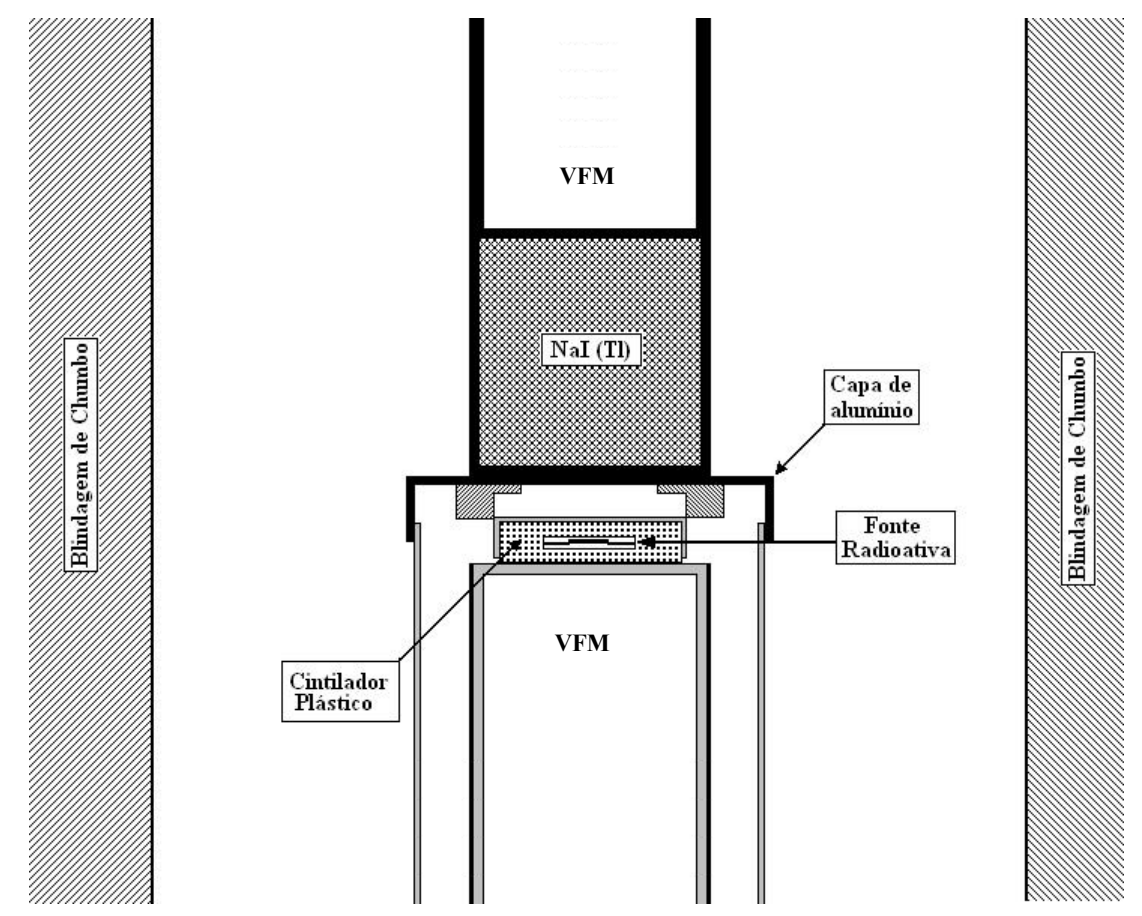

Figura 4-14: Arranjo do sistema $4 \pi(\mathrm{PS}) \beta-\gamma$ desenvolvido por Baccarelli ${ }^{[29]}$. A sigla VFM corresponde a válvula fotomultiplicadora. 


\subsubsection{1 ${ }^{60} \mathrm{Co}$}

A curva de extrapolação, para a obtenção da atividade do ${ }^{60}$ Co nesta geometria, é apresentada na Figura 4-15. Os pontos cheios representam os resultados experimentais, obtidos por Baccarelli ${ }^{[29]}$, e os pontos vazios correspondem aos cálculos de Monte Carlo, efetuados no presente trabalho. Pode-se observar que a concordância é boa em todo o intervalo de eficiências, obtidas experimentalmente.

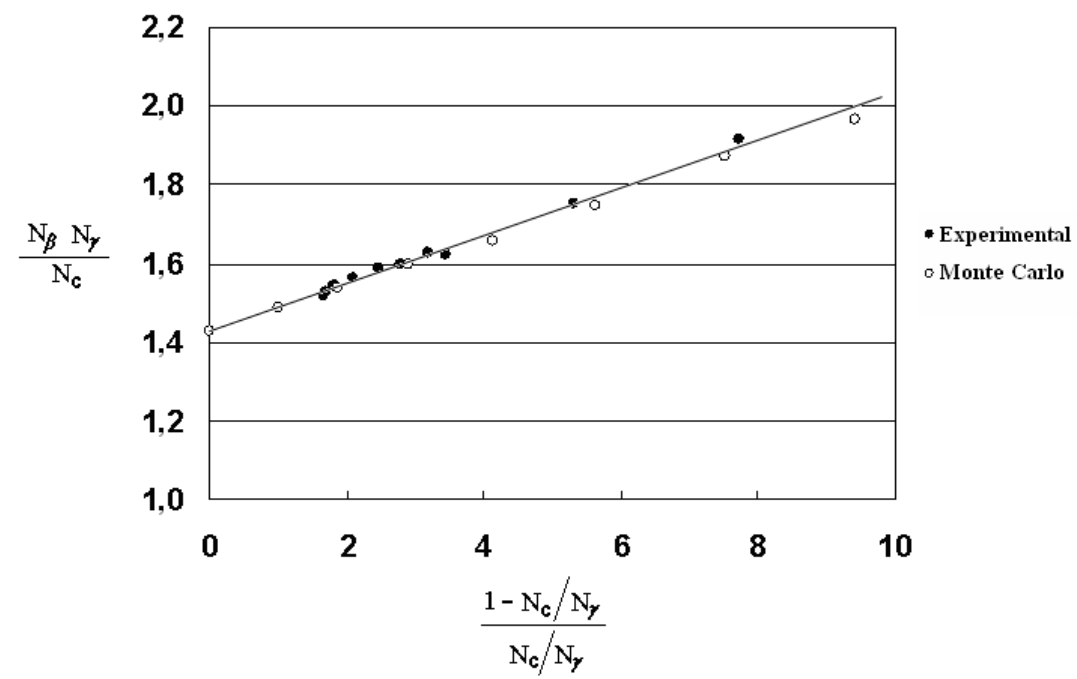

Figura 4-15: Comportamento da função para $N_{\beta} N_{\gamma} / N_{c}$ em função do parâmetro $\left(1-N_{c} / N_{\gamma}\right) /\left(N_{c} / N_{\gamma}\right)$ para o ${ }^{60} \mathrm{Co}$ na geometria original. Os pontos cheios são dados experimentais obtidos por Baccarelli[ ${ }^{[29]}$ e os vazios obtidos por Monte Carlo, no presente trabalho.

Os resultados numéricos para a atividade estão na Tabela 4-2. Uma boa concordância pode ser observada entre os resultados experimentais obtidos nos sistemas $4 \pi(\mathrm{PC}) \beta-\gamma$ e $4 \pi(\mathrm{PS}) \beta-\gamma$, com os resultados calculados por Monte Carlo no presente trabalho.

Tabela 4-2: Resultados de atividade para a geometria original ${ }^{[29]}$, comparados com simulações por Monte Carlo desenvolvidas no presente trabalho.

\begin{tabular}{ccccc}
\hline Radionuclídeo & Processo & Sistema & $\begin{array}{c}\text { Atividade } \\
(\mathrm{kBq} / \mathrm{g})\end{array}$ & $\begin{array}{c}\text { Inclinação } \\
\%\end{array}$ \\
\hline${ }^{60} \mathrm{Co}$ & Experimental $^{[29]}$ & $4 \pi \beta(\mathrm{PC})-\gamma$ & $(142,72 \pm 0,29)$ & \\
& Experimental $^{[29]}$ & $4 \pi \beta(\mathrm{PS})-\gamma$ & $(142,42 \pm 0,54)$ & $(4,32 \pm 0,13)$ \\
& Monte Carlo & $4 \pi \beta(\mathrm{PS})-\gamma$ & $(143,22 \pm 0,33)$ & \\
\hline
\end{tabular}




\subsubsection{2 ${ }^{133} \mathrm{Ba}$}

A Figura 4-16 mostra a curva de extrapolação para o ${ }^{133} \mathrm{Ba}$, na geometria original, obtidos experimentalmente por Baccarelli ${ }^{[29]}$. Neste caso, o comportamento não é totalmente linear e é bem reproduzido pela simulação de Monte Carlo. Os pontos experimentais também apresentam boa concordância com os calculados.

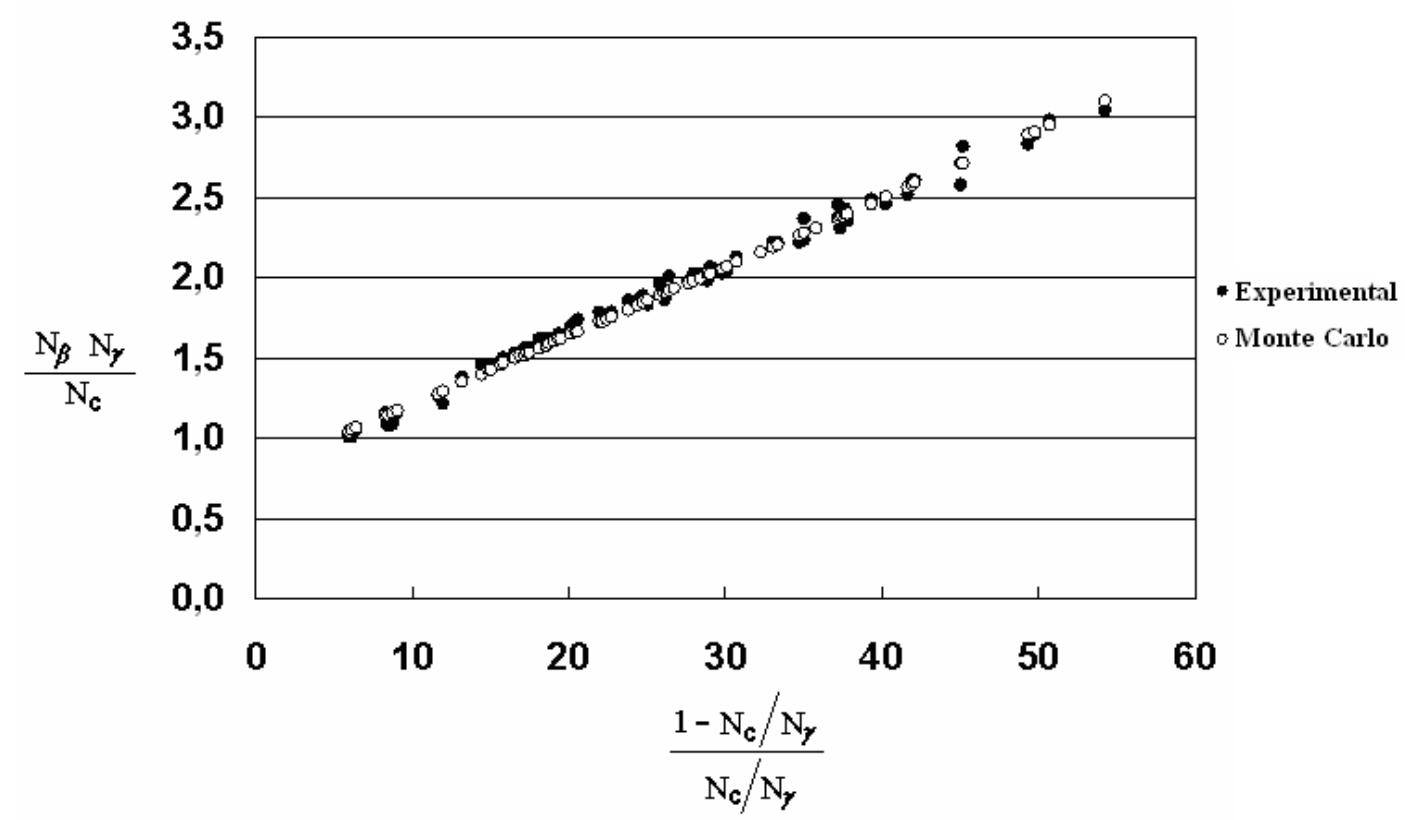

Figura 4-16: Comportamento da função para $N_{\beta} N_{\gamma} / N_{c}$ em função do parâmetro $\left(1-N_{c} / N_{\gamma}\right) /\left(N_{c} / N_{\gamma}\right)$ para o ${ }^{133}$ Ba na geometria original. Os pontos cheios são dados experimentais ${ }^{[29]}$ e os vazios obtidos por Monte Carlo, no presente trabalho.

Conforme mostra a Tabela 4-3, uma boa concordância foi obtida entre os valores de atividade simulados por Monte Carlo e os resultados obtidos no sistema convencional $4 \pi(\mathrm{PC}) \beta-\gamma$.

Tabela 4-3: Resultados de atividade para a geometria original ${ }^{[29]}$, comparados com simulações por Monte Carlo desenvolvidas no presente trabalho.

\begin{tabular}{ccccc}
\hline Radionuclídeo & Processo & Sistema & $\begin{array}{c}\text { Atividade } \\
(\mathrm{kBq} / \mathrm{g})\end{array}$ & $\begin{array}{c}\text { Inclinação } \\
\%\end{array}$ \\
\hline${ }^{133} \mathrm{Ba}$ & Experimental $^{[29]}$ & $4 \pi \beta(\mathrm{PC})-\gamma$ & $(755,5 \pm 2,5)$ & \\
& Experimental $^{[29]}$ & $4 \pi \beta(\mathrm{PS})-\gamma$ & $(750,3 \pm 4,5)$ & $(6,10 \pm 0,08)$ \\
& Monte Carlo & $4 \pi \beta(\mathrm{PS})-\gamma$ & $(752,7 \pm 2,1)$ & \\
\hline
\end{tabular}




\section{CONCLUSÃo}

Pelos resultados apresentados, pode-se concluir que a adição de uma segunda fotomultiplicadora produziu um aumento substancial na eficiência de coleção de luz, como conseqüência, aumentou a eficiência de detecção beta do sistema de medidas.

Algumas vantagens foram agregadas, quando se modificou a geometria para duas fotomultiplicadoras: diminuição do ruído eletrônico, com o aumento na eficiência de coleção de luz, utilizando a coincidência entre fotomultiplicadoras e de eletrônica rápida; redução na energia mínima detectável e um aumento na eficiência de detecção. Com estas modificações, tornou-se viável a padronização de radionuclídeos que emitem elétrons ou raios-X de baixa energia, ampliando substancialmente o número de radionuclídeos padronizáveis com este tipo de sistema. Além disso, com a mudança da disposição dos detectores, obteve-se uma melhor disposição no suporte da fonte radioativa, o que facilitou a sua troca.

Uma série de valores de $\vec{y}_{M C}$ foram calculados por Monte Carlo para uma faixa grande de eficiências em intervalos pequenos. Sendo assim possível prever o comportamento da curva de extrapolação do método de coincidência $4 \pi \beta-\gamma$. Estes resultados foram comparados com a metodologia anterior ${ }^{[29]}$ e com os resultados obtidos no sistema $4 \pi(\mathrm{PC}) \beta-\gamma$, que utiliza um detector proporcional em geometria $4 \pi$.

A simulação de Monte Carlo apresentou boa concordância com os dados experimentais, tanto para o ${ }^{60} \mathrm{Co}$ como para o ${ }^{133} \mathrm{Ba}$, indicando que esta metodologia é importante para a avaliação da atividade da fonte.

Os resultados da simulação de Monte Carlo para a nova geometria ainda não estão consolidados e, por esta razão, não foram usados para comparar com os dados experimentais. Entretanto, como a geometria do detector $4 \pi(\mathrm{PS})$ permaneceu a mesma do sistema original, que possui simetria cilíndrica, o uso do programa PENCYL produziu bons resultados, mesmo aplicando seus resultados com a nova geometria. 
$\mathrm{O}$ fato do detector de $\mathrm{NaI}(\mathrm{Tl})$ ter mudado para uma posição lateral, não acarretou alterações significativas na curva de extrapolação, para obter a atividade. Entretanto, sugere-se que, no futuro, seja feita uma análise mais adequada, aplicando-se a modelagem com o programa PENDOSES, que foi iniciada no presente trabalho.

As medidas efetuadas para o ${ }^{182}$ Ta são preliminares e ainda não estão consolidadas, portanto sugere-se que, no futuro, sejam feitas medidas mais detalhadas para possibilitar dados conclusivos.

As medidas de resolução para o detector $4 \pi(\mathrm{PS})$ foram efetuadas para que, no futuro, seja introduzido o efeito de resolução em energia para o cintilador plástico, no código desenvolvido por Takeda ${ }^{[30]}$.

O espaço existente no interior do cintilador plástico, destinado à introdução da fonte radioativa, reduz a eficiência para a detecção de elétrons, em razão da atenuação no ar. Sugere-se, como trabalho futuro, que novas configurações de suportes de fontes deverão ser elaboradas, com o objetivo de eliminar este espaço e, desse modo, obter eficiências de detecção de elétrons maiores.

Uma parte deste trabalho foi apresentada no ISRP-10 $\left(10^{\text {th }}\right.$ International Symposium on Radiation Physics 17-22 September, 2006, Coimbra, Portugal) e tendo sido publicada na revista Nuclear Instruments and Methods in Physics Research $\mathrm{A}^{[51]}$.

Outra parte deste trabalho foi apresentada no ICRM'2007 (International Committee for Radionuclide Metrology $-16^{\text {th }}$ International Conference on Radionuclide Metrology and its Applications, South Africa), e aceita para publicação na revista Applied Radiation and Isotopes ${ }^{[52]}$. 


\section{APÊNDICE A - Uso do PENELOPE para geometrias cilíndricas - programa PENCYL}

$\mathrm{O}$ arquivo abaixo se refere à descrição da geometria proposta por Baccarelli ${ }^{[29]}$, descrita na Figura 4-14, que foi utilizada na simulação por Monte Carlo pelo programa PENELOPE $^{[31]}$.

A geometria proposta por Baccarelli ${ }^{[29]}$, permitiu a aplicação do programa principal PENCYL ${ }^{[31]}$ que é utilizado para geometrias com simetria cilíndrica.

\begin{tabular}{|c|c|c|c|c|}
\hline \multicolumn{5}{|c|}{$\begin{array}{l}\text { TITLE Aida } \\
\text { GSTART Geom }\end{array}$} \\
\hline LAYER & & -12.80 & -12.50 & \\
\hline CYLIND & 10 & 0.00 & 9.50 & [CILINDRO DE AR] \\
\hline CYLIND & 4 & 9.50 & 20.00 & [mesa de ferro suporte] \\
\hline LAYER & & -12.50 & -0.30 & \\
\hline CYLIND & 5 & 2.34 & 2.54 & [anel de pyrex da foto] \\
\hline CYLIND & 3 & 2.54 & 2.64 & [capa de aluminio da foto] \\
\hline CYLIND & 10 & 2.64 & 3.70 & {$\left[\begin{array}{lll}\text { CILINDRO } & \text { DE } & A R\end{array}\right]$} \\
\hline CYLIND & 4 & 3.70 & 3.80 & [CILIDRO DE FERRO SUPORTE] \\
\hline CYLIND & 10 & 3.80 & 9.50 & [CILINDRO DE AR] \\
\hline CYLIND & 7 & 9.50 & 19.50 & [BLINDAGEM DE CHUMBO] \\
\hline LAYER & & -0.30 & -0.20 & \\
\hline CYLIND & 5 & 2.34 & 2.54 & [anel de pyrex da foto] \\
\hline CYLIND & 3 & 2.54 & 2.64 & [capa de aluminio da fot \\
\hline CYLIND & 10 & 2.64 & 3.70 & {$\left[\begin{array}{lll}\text { CILINDRO } & \text { DE } & A R\end{array}\right]$} \\
\hline CYLIND & 4 & 3.70 & 3.80 & [CILIDRO DE FERRO SUPORTE] \\
\hline CYLIND & 10 & 3.80 & 9.50 & [CILINDRO DE AR] \\
\hline CYLIND & 7 & 9.50 & 19.50 & [BLINDAGEM DE CHUMBO \\
\hline LAYER & & -0.20 & 0.00 & \\
\hline CYLIND & 5 & 0.00 & 2.54 & [tampa de pyrex da foto] \\
\hline CYLIND & 3 & 2.54 & 2.64 & [capa de aluminio da foto] \\
\hline CYLIND & 10 & 2.64 & 3.70 & {$\left[\begin{array}{lll}C I L I N D R O & D E & A R\end{array}\right]$} \\
\hline CYLIND & 4 & 3.70 & 3.80 & [CILIDRO DE FERRO SUPORTE] \\
\hline CYLIND & 10 & 3.80 & 9.50 & [CILINDRO DE AR] \\
\hline CYLIND & 7 & 9.50 & 19.50 & [BLINDAGEM DE CHUMBO] \\
\hline LAYER & & 0.00 & 0.10 & \\
\hline CYLIND & 1 & $0.0 \odot$ & 2.00 & [base inferior do cintil \\
\hline CYLIND & 10 & 2.00 & 3.70 & {$\left[\begin{array}{lll}\text { CILINDRO } & \text { DE } & A R\end{array}\right]$} \\
\hline CYLIND & 4 & 3.70 & 3.80 & [CILIDRO DE FERRO SUPORT] \\
\hline CYLIND & 10 & 3.80 & 9.50 & [CILINDRO DE AR] \\
\hline CYLIND & 7 & 9.50 & 19.50 & [BLINDAGEM DE CHUMBO] \\
\hline LAYER & & 0.10 & 0.30 & \\
\hline CYLIND & 1 & 0.00 & 2.00 & o cintilador 1 \\
\hline CYLIND & 2 & 2.00 & 2.10 & [cil.teflon que envolve c \\
\hline CYLIND & 10 & 2.10 & 3.70 & {$\left[\begin{array}{lll}\text { CILINDRO } & \mathrm{DE} & \mathrm{AR}\end{array}\right]$} \\
\hline CYLIND & 4 & 3.70 & 3.80 & [CILIDRO DE FERRC \\
\hline CYLIND & 10 & 3.80 & 9.50 & [CILINDRO DE AR] \\
\hline CYLIND & 7 & 9.50 & 19.50 & [BLINDAGEM DE CHUMBO] \\
\hline LAYER & & 0.30 & 0.442 & \\
\hline CYLIND & 10 & 0.00 & 1.00 & [CILINDRO D \\
\hline
\end{tabular}




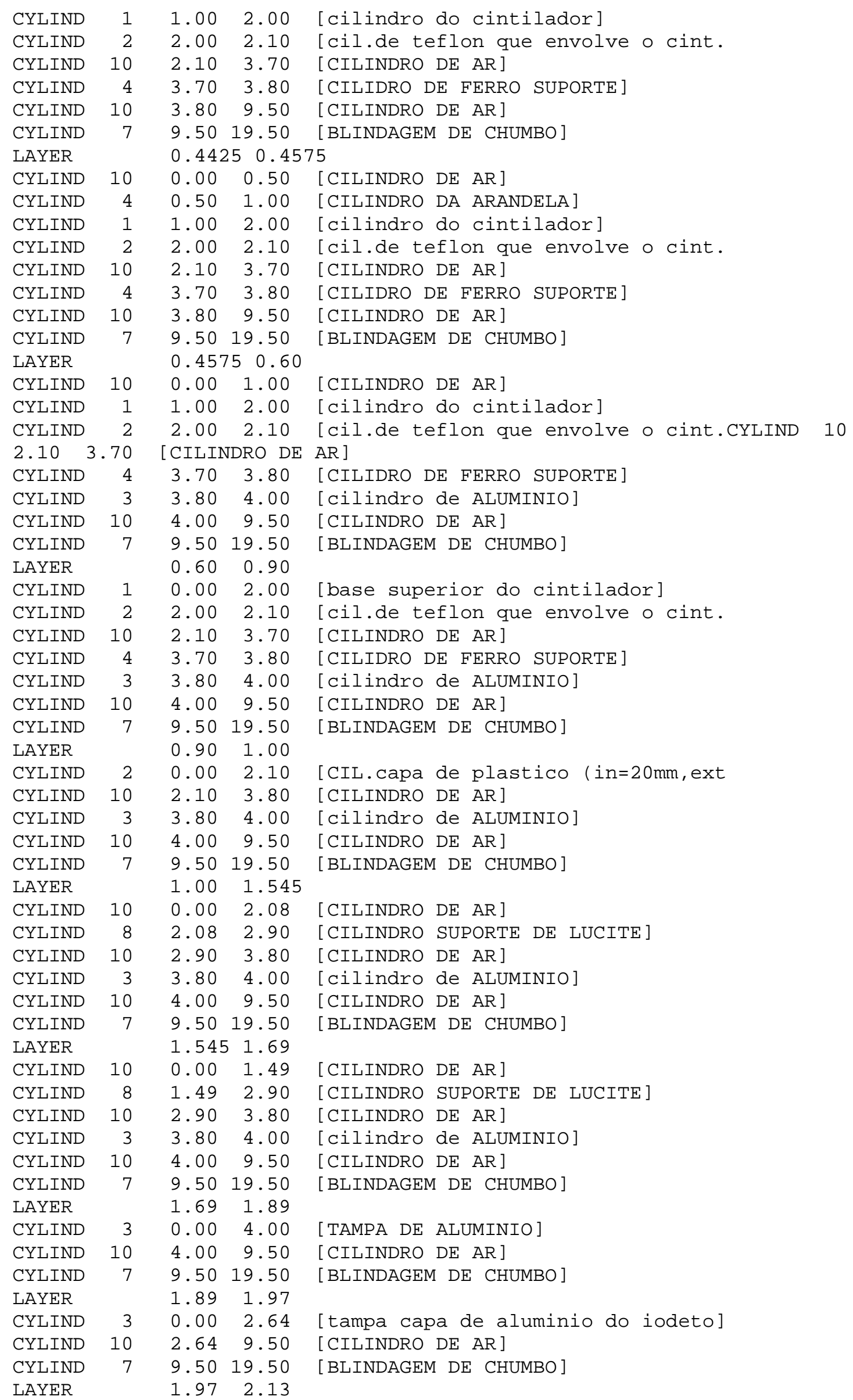




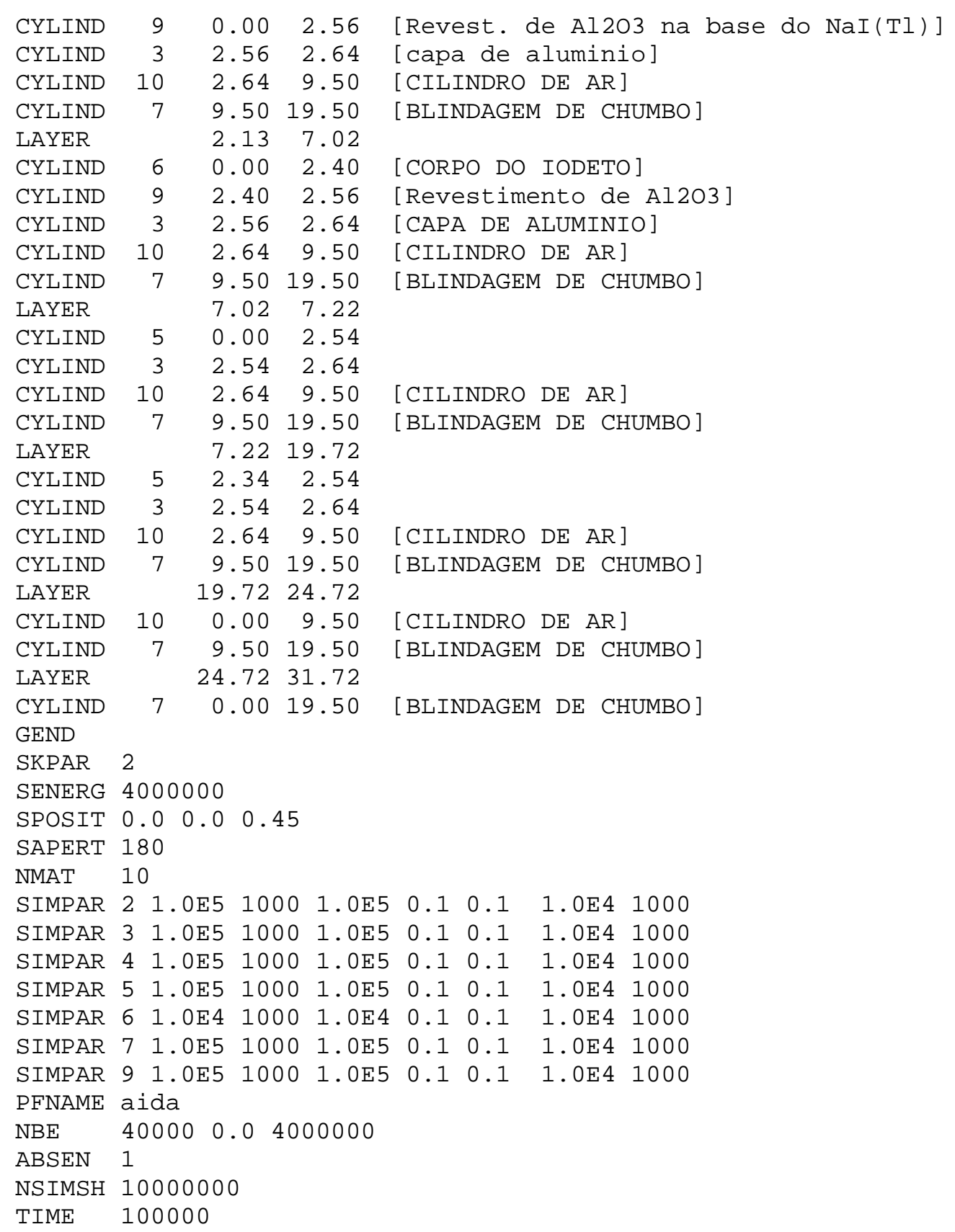




\section{APÊNDICE B - Uso do PENELOPE para geometrias complexas - programa PENDOSES}

O arquivo abaixo, z4.geo, refere-se a descrição da geometria proposta por este trabalho, descrita na Figura 3-5, que foi utilizada na simulação por Monte Carlo pelo programa PENELOPE ${ }^{[31]}$.

Para a geometria proposta neste trabalho, tornou-se necessária a utilização do programa principal PENDOSES ${ }^{[31]}$, que é aplicável a geometrias espaciais complexas. $\mathrm{Na}$ descrição da geometria foram definidos todos os planos, superfícies e módulos conforme o definido no arranjo experimental. Por ser o arquivo muito extenso (526 linhas) é apresentada aqui apenas alguns fragmentos da descrição contida nele.

$\mathrm{O}$ arquivo y001.in refere-se a entrada dos parâmetros de execução do programa PENDOSES ${ }^{[31]}$.

z4.geo

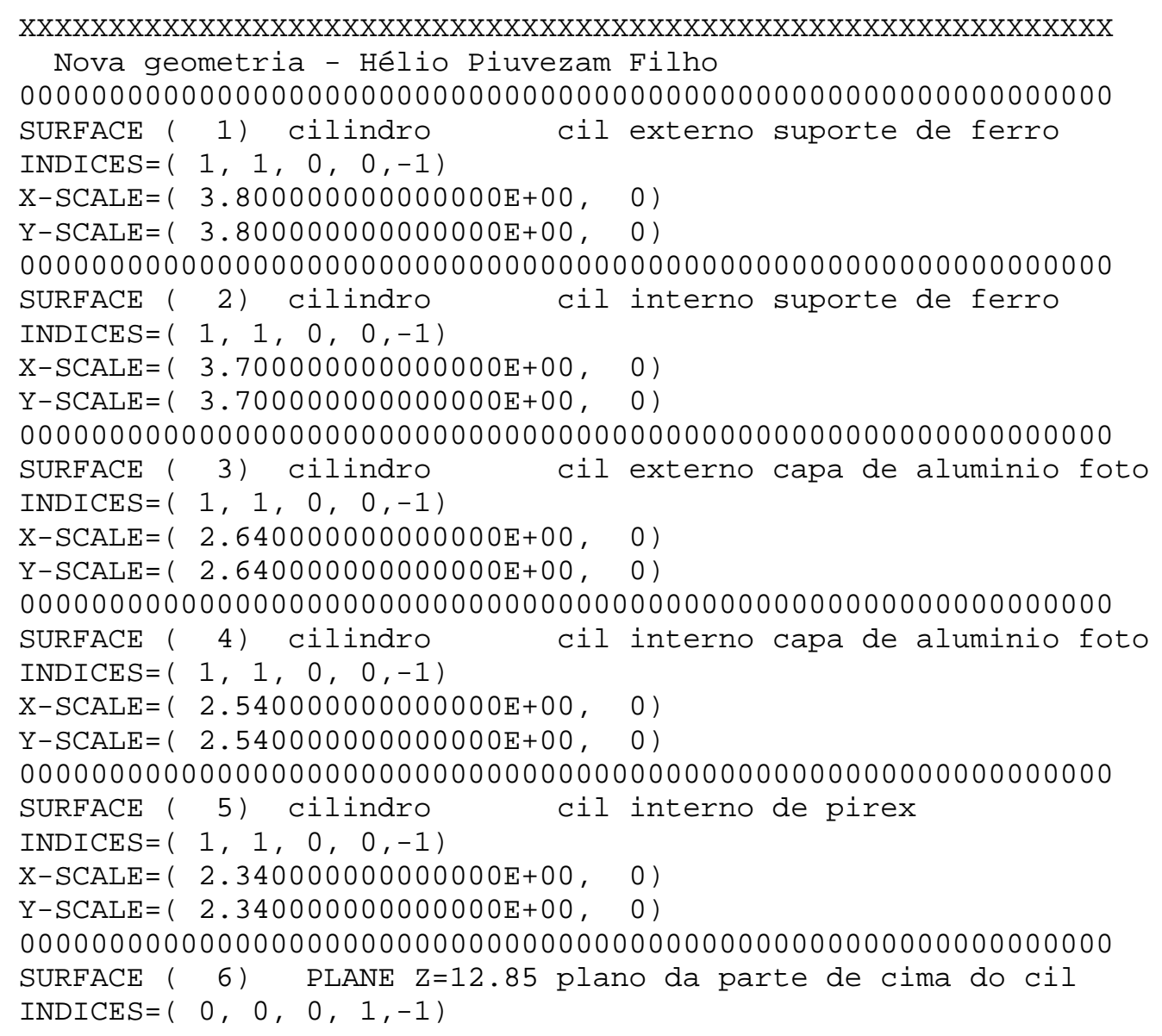


$Z-S C A L E=(1.285000000000000 E+01, \quad 0)$ 00000000000000000000000000000000000000000000000000000000000000000000 SURFACE ( 7) PLANE $Z=0.65$ plano da parte de baixo do cil INDICES $=(\Theta, \Theta, \Theta, 1,-1)$

$Z-S C A L E=(0.650000000000000 E+00, \quad 0)$ 0000000000000000000000000000000000000000000000000000000000000000 BODY ( 1) suporte de ferro MATERIAL ( 4$)$

SURFACE ( 6), SIDE POINTER $=(-1)$ aponta de cima para baixo SURFACE ( 7), SIDE POINTER $=(1)$ aponta de baixo para cima SURFACE ( 1$)$, SIDE POINTER $=(-1)$ escolhida parte de dentro SURFACE ( 2), SIDE POINTER $=(1)$ escolhida parte de fora 0000000000000000000000000000000000000000000000000000000000000000 BODY ( 2) cilindro de ar MATERIAL ( 10$)$

SURFACE $(6)$, SIDE POINTER $=(-1)$ aponta de cima para baixo SURFACE ( 7), SIDE POINTER $=(1)$ aponta de baixo para cima SURFACE ( 2), SIDE POINTER $=(-1)$ escolhida parte de dentro SURFACE ( 3), SIDE POINTER=( 1 ) escolhida parte de fora

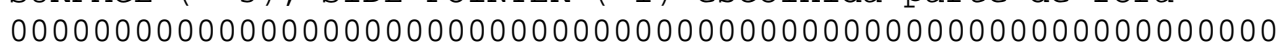

๑00000000000000000000000000000000000000000000000000000000000000000000 BODY ( 41) cilindro de chumbo

MATERIAL ( 7)

SURFACE ( 21), SIDE POINTER $=(-1)$ aponta da direita para esquerda SURFACE ( 23), SIDE POINTER=( 1 ) aponta da esquerda para direita SURFACE ( 24), SIDE POINTER $=(-1)$ escolhida parte de dentro SURFACE ( 25), SIDE POINTER $=(1)$ escolhida parte de fora 000000000000000000000000000000000000000000000000000000000000000 BODY ( 42) capa de aluminio no corpo do iodeto $\operatorname{MATERIAL}(3)$

SURFACE ( 21), SIDE POINTER $=(-1)$ aponta da direita para esquerda SURFACE ( 23), SIDE POINTER=( 1 ) aponta da esquerda para direita SURFACE ( 25), SIDE POINTER $=(-1)$ escolhida parte de dentro SURFACE ( 26), SIDE POINTER $=(1)$ escolhida parte de for 00000000000000000000000000000000000000000000000000000000000000000000 BODY ( 43$)$ corpo do iodeto $\operatorname{MATERIAL}(6)$

SURFACE ( 21), SIDE POINTER $=(-1)$ aponta da direita para esquerda SURFACE ( 22), SIDE POINTER=( 1 ) aponta da esquerda para direita SURFACE ( 26), SIDE POINTER $=(-1)$ escolhida parte de dentro

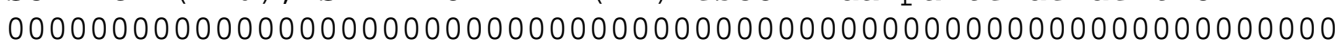
SURFACE ( 27 ) PLANO $\mathrm{y}=10.19$

INDICES $=(\Theta, \Theta, \odot, \Theta, \Theta)$ $\mathrm{AY}=(1.0000000000000000 \mathrm{E}+00,0)$ $A \Theta=(-1.019000000000000 \mathrm{E}+01, \quad 0)$ 0000000000000000000000000000000000000000000000000000000000000000000 SURFACE ( 28) PLANO $Y=12.50$ INDICES $=(\Theta, \Theta, \Theta, \Theta, \quad \odot)$ $A Y=(1.000000000000000 \mathrm{E}+00, \quad \odot)$ $A 0=(-2.26900000000000000 \mathrm{E}+01, \quad 0)$

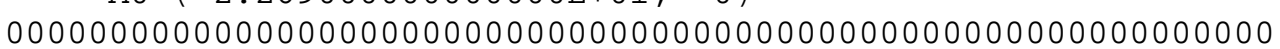
SURFACE ( 29 ) cilindro de PIREX DA FOTO DO IODETO INDICES $=(1,0,1,0,-1)$ $X-S C A L E=(2.40000000000000000 \mathrm{E}+00, \quad 0)$ $Z$-SCALE $=(2.40000000000000000 \mathrm{E}+\odot \odot, \quad \odot)$ 0000000000000000000000000000000000000000000000000000000000000000000000 BODY ( 44) cilindro de chumbo 
MATERIAL $(7)$

SURFACE ( 28$),$ SIDE POINTER=(-1) aponta da direita para esquerda

SURFACE ( 21), SIDE POINTER=( 1 ) aponta da esquerda para direita

SURFACE ( 24), SIDE POINTER $=(-1)$ escolhida parte de dentro

SURFACE ( 25), SIDE POINTER $=(1)$ escolhida parte de fora

๑०००००00000000000000000000000000000000000000000000000000000000

BODY ( 45) capa de aluminio no corpo do iodeto

MATERIAL ( 3)

SURFACE ( 28), SIDE POINTER $=(-1)$ aponta da direita para esquerda

SURFACE ( 21), SIDE POINTER=( 1 ) aponta da esquerda para direita

SURFACE ( 25), SIDE POINTER $=(-1)$ escolhida parte de dentro

SURFACE ( 26), SIDE POINTER $=(1)$ escolhida parte de for

00000000000000000000000000000000000000000000000000000000000000

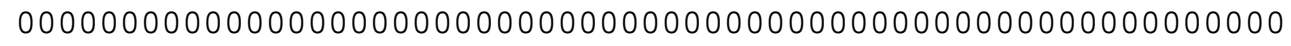 \\ BODY ( 47) CORPO DA FOTO DO iodeto \\ MATERIAL $(5)$ \\ SURFACE ( 28), SIDE POINTER $=(-1)$ aponta da direita para esquerda \\ SURFACE ( 27), SIDE POINTER=( 1 ) aponta da esquerda para direita \\ SURFACE ( 26), SIDE POINTER $=(-1)$ escolhida parte de dentro \\ SURFACE ( 29), SIDE POINTER $=(1)$ escolhida parte de FORA \\ 00000000000000000000000000000000000000000000000000000000000000000000 \\ BODY ( 48) cilindro de ar dentro da FOTO DO iodeto \\ MATERIAL ( ) \\ SURFACE ( 28), SIDE POINTER $=(-1)$ aponta da direita para esquerda \\ SURFACE ( 27$)$, SIDE POINTER=( 1 ) aponta da esquerda para direita \\ SURFACE ( 29), SIDE POINTER $=(-1)$ escolhida parte de dentro \\ 0000000000000000000000000000000000000000000000000000000000000 \\ SURFACE ( 30$)$ esfera contendo tudo \\ INDICES $=(1,1,1,0,-1)$ \\ $X-S C A L E=\left(\begin{array}{ll}3.0000000000000000 E+01, & 0\end{array}\right)$ \\ $Y-S C A L E=(3.000000000000000 E+01, \quad 0)$ \\ $Z-S C A L E=(\quad 3.00000000000000000 E+01,0)$

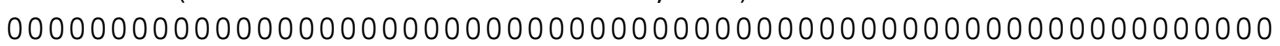 \\ MODULE ( 49$)$ \\ MATERIAL ( 10$)$ \\ SURFACE $(30)$, SIDE POINTER $=(-1)$ escolhida parte de dentro \\ BODY ( 1$)$ \\ BODY ( 2) \\ $\cdots$ \\ $\begin{array}{ll}\text { BODY } & (47) \\ \text { BODY } & (48)\end{array}$ \\ 1111111111111111111111111111111111111111111111111111111111111 \\ OMEGA $=(90.00000000000000 \mathrm{E}+01, \quad 0)$ DEG \\ THETA $=(\quad 0.00000000000000 \mathrm{E}+01,0)$ DEG \\ $\mathrm{PHI}=(-90.0000000000000000 \mathrm{E}+01, \quad 0)$ DEG \\ $\mathrm{X}$-SHIFT $=(+0.000000000000000 \mathrm{E}+01, \quad 0)$ \\ $\mathrm{Y}-\mathrm{SHIFT}=(+0.00000000000000000 \mathrm{E}+01, \quad 0)$ \\ $Z$-SHIFT $=(+0.000000000000000 \mathrm{E}+01, \quad 0)$

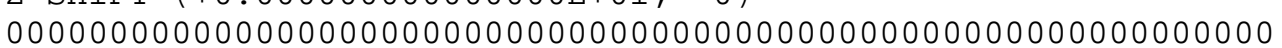 \\ END $\quad 0000000000000000000000000000000000000000000000000000000000000$
}


y001.in

TITLE Resposta do Arranjo Hélio/Aida

KPAR 1 [Primary particles: 1=electron, 2=photon, 3=positron] EQ 1.173238E6 [Initial energy, in eV]

SPOSIT $\odot \odot \odot \quad$ [Source position: $X \odot, Y \Theta, Z \odot$ in $\mathrm{cm}$ ]

SDIREC $\odot \odot$

SAPERT 360

[Beam direction: THETA, PHI in deg]

NMAT 10

[Beam aperture, ALPHA in deg]

$\begin{array}{lllll} & \end{array}$

DSMAX 1. $1.0 \mathrm{E} 10$

[Maximum step length, in $\mathrm{cm}$ ]

SIMPAR 1.0E5 1.0E3 1.0E5 0.100 .10 1.0E4 1.0E3 [EABSs, C1, C2, WCC, Wcr]

DSMAX 1.0E10 [Maximum step length, in $\mathrm{cm}$ ]

SIMPAR 1.0E5 1.0E3 1.0E5 0.100 .10 1.0E4 1.0E3 [EABSs, C1, C2, WcC,Wcr]

DSMAX 1.0E10 [Maximum step length, in $\mathrm{cm}$ ]

SIMPAR 1.0E5 1.0E3 1.0E5 0.100 .10 1.0E4 1.0E3 [EABSs, C1, C2, WcC, Wcr]

DSMAX 1.0E10 [Maximum step length, in $\mathrm{cm}$ ]

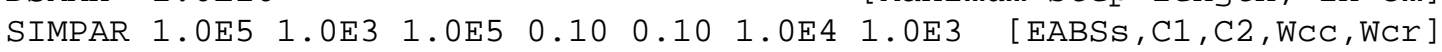

DSMAX 1.0E10 [Maximum step length, in $\mathrm{cm}$ ]

SIMPAR 1.0E5 1.0E3 1.0E5 0.100 .10 1.0E4 1.0E3 [EABSs, C1, C2, WcC, Wcr]

DSMAX 1.0E10 [Maximum step length, in $\mathrm{cm}$ ]

SIMPAR 1.0E5 1.0E3 1.0E5 0.100 .10 1.0E4 1.0E3 [EABSs, C1, C2, WcC, Wcr]

DSMAX 1.0E10 [Maximum step length, in $\mathrm{cm}$ ]

SIMPAR 1.0E5 1.0E3 1.0E5 0.100 .10 1.0E4 1.0E3 [EABSs, C1, C2, WcC,Wcr]

DSMAX 1.0E10 [Maximum step length, in $\mathrm{cm}$ ]

SIMPAR 1.0E5 1.0E3 1.0E5 0.100 .10 1.0E4 1.0E3 [EABSs, C1, C2, WcC, Wcr]

DSMAX 1.0E10 [Maximum step length, in $\mathrm{cm}$ ]

SIMPAR 1.0E5 1.0E3 1.0E5 0.100 .10 1.0E4 1.0E3 [EABSs, C1, C2, WcC,Wcr]

DSMAX $1.0 \mathrm{E} 10$

PFNAME aida

GFNAME Z4.geo

[Maximum step length, in $\mathrm{cm}$ ]

NSIMSH 1000000

TIME 1000000

RSEED 1234554321

[Material file name, 18 characters]

[Geometry file name, 18 characters]

[Desired number of showers, $\max =2 * * 31-1$ ]

[Allotted simulation time, in sec]

[Random number generator seeds] 


\section{REFERÊNCIAS BIBLIOGRÁFICAS}

[1] BIPM, Bureau International des Poids et Mesures. http://www.bipm.org, acesso em 04/06/2007.

[2] INMETRO, Instituto Nacional de Metrologia, Normalização e Qualidade Industrial. http://www.inmetro.gov.br - acesso em 04/06/2007.

[3] IRD, Instituto de Radioproteção e Dosimetria. http://www.ird.gov.br - acesso em 04/06/2007.

[4] BAERG, A. P., Measurement of radioactivity disintegration rate by the coincidence method. Metrologia, 2 (1), p: 23-32, 1966.

[5] BAERG, A. P., Absolute measurement of radioactivity. Metrologia, $\underline{3}$ (4), p: 105-108, 1967.

[6] BAERG, A. P., The efficiency extrapolation method in coincidence counting. Nuclear Instruments and Methods. 112, p: 143-150, 1973.

[7] CAMPION, P. J., The standardization of radioisotopes by beta-gamma coincidence method using high efficiency detectors. Int. J. Appl. Radiat. Iso., $\underline{4}, \mathrm{p}:$ 232-248, 1959.

[8] GANDY, A., Mesure absolute de l'activité des radionucléides par la méthode des coincidences beta-gamma à l'aide de détecteurs de grand efficacité Étude des coincidences instrumentales. Int. Journ. Appl. Radiat. Isot. $\underline{11}$, p: $75,1961$.

[9] GANDY, A., Mesure absolute de l'activité des radionucléides par la méthode des coincidences beta-gamma à l'aide de détecteurs de grand efficacité Corretions de temps morts. Int. Journ. Appi. Radiat. Isot. 13, p: 501, 1962.

[10] HOUTHERMANS, H., MIGUEL, M. 4 $\pi \beta-\gamma$ coincidence counting for the calibration of nuclides with complex decay schemes. Int. J. Appl. Radiat. Isot. 13 p: 137-142, 1962.

[11] KAWADA, Y., Extended applications and improvement of the $4 \pi \beta-\gamma$ coincidence method in the standardization of radionuclides. Res. of ETL. Japan, ETL-730, 1972.

[12] MOURA, L. P., Método de Coincidência Generalizado para a Medida Absoluta da Atividade de Radionuclídeos - Aplicação da Determinação do Coeficiente de Conversão Interna da Transição de $279 \mathrm{keV}$ do ${ }^{203} \mathrm{Tl}$. Tese de Doutorado apresentada à Universidade de Campinas, 1969. 
[13] TAYLOR, J. G. V., The total internal conversion coefficient of the $279 \mathrm{keV}$ transition following the decay of ${ }^{203} \mathrm{Hg}$ as measured by a new coincidence method. Canad. Journ. Phys., $\underline{40}$ (4) p: 383, 1962.

[14] HILARIO, K. A. F., Desenvolvimento de métodos de medida de atividade empregando sistemas de coincidência para radionuclídeos que desintegram pela Dupla Emissão Beta Menos - Beta Mais/Captura Eletrônica - aplicação na padronização do ${ }^{192} \mathrm{Ir},{ }^{152} \mathrm{Eu}$ e ${ }^{186}$ Re., Tese de Doutorado, IPEN, 2002

[15] MOREIRA, D. S., Padronização dos radionuclídeos multi-emissores gama ${ }^{166 m} \mathrm{Ho}$ e ${ }^{72} \mathrm{Ga}$ e determinação de suas intensidades gama por decaimento, Tese de Doutorado, IPEN, 2005.

[16] RATEL, G., MICHOTTE, C., BIPM comparison BIPM.RI(II)-K1.Co-60 of the activity measurement of the radionuclide ${ }^{60} \mathrm{Co}$. BIPM Final Report-Co-60 2003/02/28, fevereiro, 2003.

[17] van WYNGAARDT, W. M., SIMPSON, B.R.S., Absolute activity measurement of the electron-capture-based radionuclides ${ }^{139} \mathrm{Ce},{ }^{125} \mathrm{I},{ }^{192} \mathrm{Ir}$ and ${ }^{65} \mathrm{Zn}$ by liquid scintillation coincidence counting. ICRM 2005, Proceedings of the $15^{\text {th }}$ International Metrology and its Applications, 5-9 September 2005, Oxford, UK, p: 1454

[18] LNHB, Laboratoire National Henri Becquerel, CIEMAT/NIST Method, http://www.nucleide.org/ICRM_LSC_WG/icrmciematnist.htm - acesso em 04/06/2007.

[19] SIMPSON, B.R.S., van WYNGAARDT, W. M., Activity measurements of the high-energy pure $\beta$-emitters ${ }^{89} \mathrm{Sr}$ and ${ }^{90} \mathrm{Y}$ by the TDCR efficiency calculation technique. ICRM 2005, Proceedings of the $15^{\text {th }}$ International Metrology and its Applications, 5-9 September 2005, Oxford, UK, p: 1481

[20] KAWADA, Y., OHTUKA, M.,WANG,O.W, HINO,Y., Absolute radioactivity measurements by the use of a $\mathbf{4} \boldsymbol{\pi} \boldsymbol{\beta}-\mathbf{4} \boldsymbol{\pi} \boldsymbol{\gamma}$ detector configuration $\mathrm{Appl}$. Radiat. Isot. 60, 2-4, p: 357, 2004.

[21] RATEL, G., International comparison of activity measurement of a solution of ${ }^{109}$ Cd. CCEMRI(II)/87-7, maio 1987.

[22] RATEL, G., Activity measurement of a ${ }^{75}$ Se solution in the frame of an international comparison (june 1992). CCEMRI(II)/93-14, maio 1993.

[23] RATEL, G., International comparison of activity measurements of a solution of ${ }^{125}$ I. CCEMRI(II)/89-2, abril 1989.

[24] KOSKINAS, M. F., SILVA, E.A., YAMAZAKI, I. M., DIAS, M. S., Standardization of ${ }^{241}$ Am solution, Appl. Radiat. Isot. 64, p: 1238-1241, 2006. 
[25] KOSKINAS, M. F., PIRES, C.A., YAMAZAKI, I. M., SILVA, E.A., DIAS, M. S., Standardization of ${ }^{55} \mathrm{Fe}$ by tracing method. $16^{\text {th }}$ International Conference on Radionuclide Metrology and its Applications, Programme and Abstracts book, ICRM 2007, September 3-7, 2007, Cape Town, South Africa, p: 023.

[26] RYTZ, A., International comparison of activity measurements of a solution of ${ }^{133}$ Ba. Rapport BIPM - 85/11, nov. 1985.

[27] PUGLIESI, R. Sistema de Coincidência para a Medida Absoluta de Atividade de Radionuclideos Empregando Cintilador Líquido. Dissertação de mestrado, IPEN, 1978

[28] KOSKINAS, M.F. Desenvolvimento de um Sistema de Coincidência para Medida Absoluta de Atividade de Radionuclideos Empregando Detectores de Barreira de Superfície. Tese de Doutorado, IPEN, 1988.

[29] BACCARElli A. M., Sistema Primário por Coincidências $4 \pi \beta-\gamma$ Para a Padronização de Radionuclídeos Empregando Cintiladores Plásticos, Tese de Doutorado, IPEN, 2003.

[30] TAKedA, M. N., Aplicação do Método de Monte Carlo no Estudo da Atividade Obtida em Sistema de Coincidências $4 \pi \beta-\gamma$ para Radionuclídeos com ESQUEMA de Desintegração Complexos. Tese de Doutorado, IPEN, 2006.

[31] SALVAT S., FERANDEZ-VAREA J. M., ACOSTA E., SEMPAU J. PENELOPE - A Code for Monte Carlo Simulation of Electron and Photon Transport. NEA, 2001.

[32] FIRESTONE, R. B., SHIRLEY, V.S., Table of Isotopes, $8^{\text {th }}$ ed. New York, 1996.

[33] HELMER, R.G. and SCHONFELD, E., BNM - Table de Radionucléides, Commissariat à L'Énergie Atomique, 2004.

[34] EVAnS, R. D.; DAVISSON, C. M.; The Atomic Nucleus. New York, McGrawHill, 1955.

[35] MARMiER, P., SHELdON, E., Physics of Nuclei and Particles, Academic Press, 1969.

[36] KNOLL, G. F., Radiation detection and measurement. 3'th Edition. John Willey \& Sons, Inc., 1999.

[37] PRICE, W.J., Nuclear Radiation Detection, McGraw-Hill, New York, 1958.

[38] BROWN, F.B., KAHLER, A.C., MCKINNEY, G.W., MOSTELLER, R.D., WHITE, M.G., MCNP5+Data+MCNPX Workshop. Workshop presentation at the 2007 ANS Mathematics \& Computation Division Topical Meeting (M\&C+SNA-2007), Monterey, CA, April 15, 2007. 
[39] AGOSTINELLI S., et all._GEANT4 - a simulation toolkit. Nucl. Instrum. Meth. Phys. Res. A: 506, 3, p. 250,2003

[40] EGS, EGS computer code system - a general purpose package for the Monte Carlo simulation of the coupled transport of electrons and photons. http://rcwww.kek.jp/research/egs/index.html. - acesso em 04/06/2007.

[41] FLUKA, FLUKA - fully integrated particle physics MonteCarlo simulation package. www.fluka.org. - acesso em 04/06/2007.

[42] VArgas, M.J., GUERRA, A.L., Application of PENELOPE code to the efficiency calibration of coaxial germanium detectors. ICRM 2005, Proceedings of the $15^{\text {th }}$ International Metrology and its Applications, 5-9 September 2005, Oxford, UK, p:1319

[43] RaZdolescu, A.C., CASSetTe, P., SAHAGiA, M., Measurement of ${ }^{\mathbf{5 5}} \mathbf{F e}$ solution activity by LSC-TDCR method. $16^{\text {th }}$ International Conference on Radionuclide Metrology and its Applications, Programme and Abstracts book, ICRM 2007, September 3-7, 2007, Cape Town, South Africa, p:28

[44] JAUBERT, F., Standardization of a ${ }^{\mathbf{1 8 6}}$ Re Sodium Perphenate radiochemical solution using the TDCR method in the liquid scintillation counting. $16^{\text {th }}$ International Conference on Radionuclide Metrology and its Applications, Programme and Abstracts book, ICRM 2007, September 3-7, 2007, Cape Town, South Africa, p:77.

[45] BÉ, M.-M., CHISTÉ, V., DULIEU, C., BROWNE, E., CHECHEV, V., KUZMENKO, N., HELMER, R., NICHOLS, A., SCHÖNFELD, E., DERSCH, R. Table of Radionucleides, BIPM-5, 2004.

[46] HAMADA, M. M., MESQUITA, C. H., Preparação de detectores plásticos cintiladores e caracterização de parâmetros físico-químicos. In $2^{\circ}$. Congresso Geral de Energia Nuclear de 24 a 29 de abril de 1988, Rio de Janeiro, Brasil.

[47] NUCLEAR ENTERPRISES, Scintillator catalogue, San Carlos, CA, 1967.

[48] CAMPION, P. J., Procedures for accurately diluting and. dispensing radioactive solutions, Monographie BIPM-1, Bureau International des Poids et Mesures, 1975.

[49] DIAS, M. S., Programa computacional CONTAC - Comunicação Pessoal, 2003.

[50] COX, D. R. and ISHAM, V., A bivariate point process connected with electronic counters. Proceedings of the Royal Society of London, A, 356, p. 149-160, 1977. 
[51] DIAS, M. S., PIUVEZAM-FILHO, H., BACCARELLI, A. M., TAKEDA, M. N. and KOSKINAS, M. F., Monte Carlo Simulation of $\beta-\gamma$ Coincidence System Using Plastic Scintillators in $\mathbf{4} \pi$ Geometry, Nucl. Instrum. Meth. Phys. Res. A, 580, p: 380-383, 2007.

[52] DIAS, M. S., PIUVEZAM-FILHO, H., KOSKINAS, M. F., Optimization of a Coincidence System Using Plastic Scintillators in $\mathbf{4} \pi$ Geometry, aceito para publicação na revista Applied Radiation and Isotopes. 